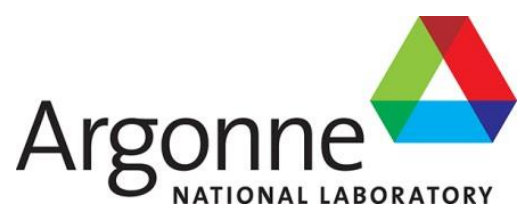

ANL-SMR-8

\title{
Design Report for the $1 / 2$ Scale Air-Cooled RCCS Tests in the Natural convection Shutdown heat removal Test Facility (NSTF)
}

Nuclear Engineering Division 


\begin{abstract}
About Argonne National Laboratory
Argonne is a U.S. Department of Energy laboratory managed by UChicago Argonne, LLC

under contract DE-AC02-06CH11357. The Laboratory's main facility is outside Chicago, at 9700 South Cass Avenue, Argonne, Illinois 60439. For information about Argonne

and its pioneering science and technology programs, see www.anl.gov.
\end{abstract}

\title{
DOCUMENT AVAILABILITY
}

Online Access: U.S. Department of Energy (DOE) reports produced after 1991 and a growing number of pre-1991 documents are available free via DOE's SciTech Connect (http://www.osti.gov/scitech/)

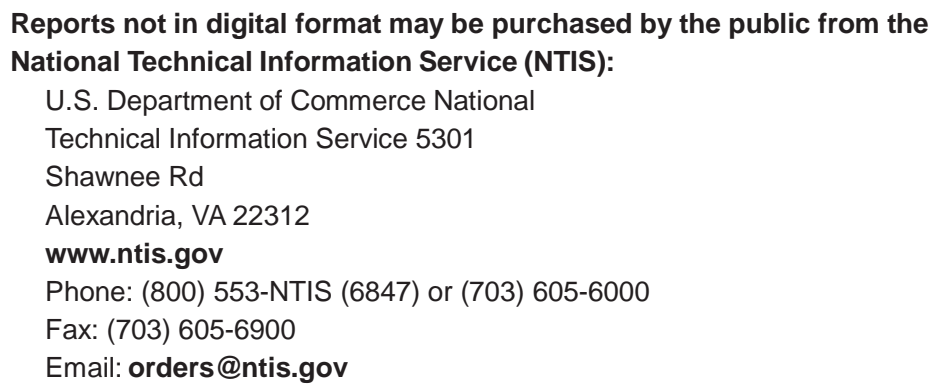

Reports not in digital format are available to DOE and DOE contractors from the Office of Scientific and Technical Information (OSTI):

U.S. Department of Energy

Office of Scientific and Technical Information

P.O. Box 62

Oak Ridge, TN 37831-0062

www.osti.gov

Phone: (865) 576-8401

Fax: (865) 576-5728

Email: reports@osti.gov

\section{Disclaimer}

This report was prepared as an account of work sponsored by an agency of the United States Government. Neither the United States Government nor any agency thereof, nor UChicago Argonne, LLC, nor any of their employees or officers, makes any warranty, express or implied, or assumes any legal liability or responsibility for the accuracy, completeness, or usefulness of any information, apparatus, product, or process disclosed, or represents that its use would not infringe privately owned rights. Reference herein to any specific commercial product, process, or service by trade name, trademark, manufacturer, or otherwise, does not necessarily constitute or imply its endorsement, recommendation, or favoring by the United States Government or any agency thereof. The views and opinions of document authors expressed herein do not necessarily state or reflect those of the United States Government or any agency thereof, Argonne National Laboratory, or UChicago Argonne, LLC. 


\section{Design Report for the $1 / 2$ Scale Air-Cooled RCCS Tests in the Natural convection Shutdown heat removal Test Facility (NSTF)}

prepared by

D. D. Lisowski, M. T. Farmer, S. Lomperski, D. J. Kilsdonk, N. Bremer, and R. W. Aeschlimann Nuclear Engineering Division, Argonne National Laboratory

June 2014 
This page was intentionally left blank. 


\section{Executive Summary}

The Natural convection Shutdown heat removal Test Facility (NSTF) is a large scale thermal hydraulics test facility that has been built at Argonne National Laboratory (ANL). The facility was constructed in order to carry out highly instrumented experiments that can be used to validate the performance of passive safety systems for advanced reactor designs. The facility has principally been designed for testing of Reactor Cavity Cooling System (RCCS) concepts that rely on natural convection cooling for either air or water-based systems.

Standing 25-m in height, the facility is able to supply up to $220 \mathrm{~kW}$ at $21 \mathrm{~kW} / \mathrm{m}^{2}$ to accurately simulate the heat fluxes at the walls of a reactor pressure vessel. A suite of nearly 400 data acquisition channels, including a sophisticated fiber optic system for high density temperature measurements, guides test operations and provides data to support scaling analysis and modeling efforts. Measurements of system mass flow rate, air and surface temperatures, heat flux, humidity, and pressure differentials, among others; are part of this total generated data set.

The following report provides an introduction to the top level-objectives of the program related to passively safe decay heat removal, a detailed description of the engineering specifications, design features, and dimensions of the test facility at Argonne. Specifications of the sensors and their placement on the test facility will be provided, along with a complete channel listing of the data acquisition system. 
This page was intentionally left blank. 


\section{Contents}

Executive Summary

1 Program Objectives $\quad 1$

1.1 Program Scope . . . . . . . . . . . . . . . . . . . . . . . . . . . 2

1.2 Experiment Requirements . . . . . . . . . . . . . . . . . . 3

1.3 Full Scale Design Basis . . . . . . . . . . . . . . . . . . . . . . . . 4

2 Facility Overview $\quad 7$

2.1 Primary Components . . . . . . . . . . . . . . . . . . 9

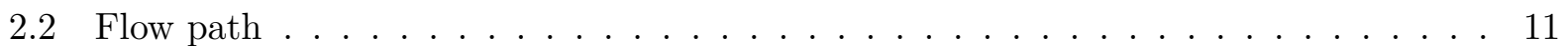

3 Test Assembly Description $\quad 13$

3.1 Base Support and Cavity Framework . . . . . . . . . . . . . . . . . . . 13

3.2 Flow path ducting . . . . . . . . . . . . . . . . . . . 15

3.2 .1 Inlet downcomer . . . . . . . . . . . . . . . . . . . . 15

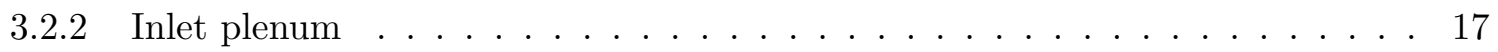

3.2 .3 Riser ducts . . . . . . . . . . . . . . . . . . . . 19

3.2 .4 Outlet Plenum . . . . . . . . . . . . . . . . . . . . 22

3.3 Heated cavity . . . . . . . . . . . . . . . . . . . . . 25

3.3.1 Unheated Paneling . . . . . . . . . . . . . . . . . . . . 25

3.3 .2 Heated Wall . . . . . . . . . . . . . . . . . . . . 26

3.3.3 Primary Heated Plate . . . . . . . . . . . . . . . . . 27

3.3 .4 Heater Subpanels . . . . . . . . . . . . . . . . . 30

3.3 .5 Ceramic Heaters . . . . . . . . . . . . . . . . . . . . 32

3.3.6 Heated Wall Insulation Panels . . . . . . . . . . . . . . . . . . . . 32

3.4 Chimney stacks . . . . . . . . . . . . . . . . . . . . . . 34

3.4.1 Vertical and Horizontal Exhaust Configurations . . . . . . . . . . . . . . 35

3.4.2 Forced Flow Benchmark . . . . . . . . . . . . . . . . . . . . . 37

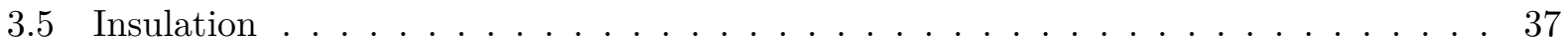

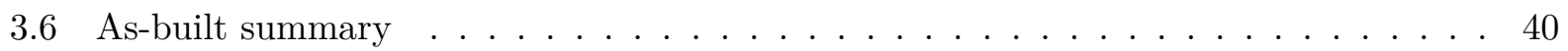

4 Experiment Control $\quad 41$

4.1 Data Acquisition . . . . . . . . . . . . . . . . . . . . . 42

4.2 Heater Power Control . . . . . . . . . . . . . . . . . . . 43

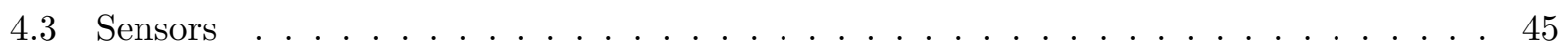

4.3.1 Wall Thermocouples . . . . . . . . . . . . . . . . . 45 
4.3 .2 Heat Flux Sensors ． . . . . . . . . . . . . . . . . . . 58

4.3 .3 Meteorological . . . . . . . . . . . . . . . 62

4.3.4 Differential Pressure . . . . . . . . . . . . . . . . . 64

4.3.5 Inlet Flow and Humidity . . . . . . . . . . . . . . . . 66

4.3 .6 Gas Temperature . . . . . . . . . . . . . . . . . 67 67

4.3 .7 Luna Fiber Optic Temperature . . . . . . . . . . . . . . . 70

$\begin{array}{lll}5 & \text { Test Operations } & 75\end{array}$

$\begin{array}{ll}\text { References } & 77\end{array}$

$\begin{array}{ll}\text { Appendix A: Emissivity records } & 79\end{array}$

$\begin{array}{ll}\text { Appendix B: cDAQ channel list } & 81\end{array}$ 


\section{List of Figures}

1 GA-MHTGR concept, single module shown $\ldots \ldots \ldots \ldots$

2 Solid model rendering of NSTF facility, inclusive of building, support, and personnel

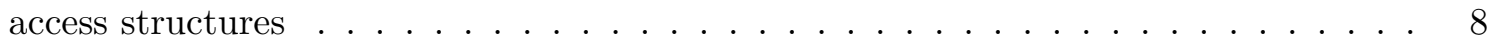

3 Primary segments of the NSTF. A. inlet downcomer, B. inlet plenum, C. heated cavity, D. riser tubes, E. outlet plenum, F. chimney . . . . . . . . . . . . . . 10

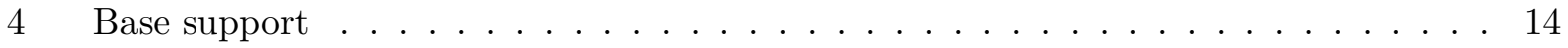

5 Lower skeleton framework . . . . . . . . . . . . . . . . . . . . . . 14

6 Inlet downcomer (front view) and equivalent segment lengths . . . . . . . . . . 15

$7 \quad$ Flow conditioner . . . . . . . . . . . . . . . . . . 16

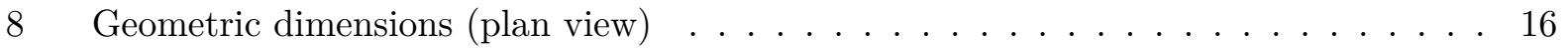

9 Inlet plenum. Duct stub shown connects to inlet downcomer, rectangular slotted holes connect to riser ducts. Interior volume measures 44" tall, 51.75 width (parallel to riser slots), and 59.75" depth, of which only $31.75 "$ is available for the working gas due to the present of the false back wall. . . . . . . . . . . . . . 18

10 Cross section of riser ducts (dimensional drawing above, picture below) . . . . . 20

11 Top plate which bears the weight of the twelve riser ducts . . . . . . . . . . . 21

12 View into the outlet plenum from opened east wall. False west wall visible behind

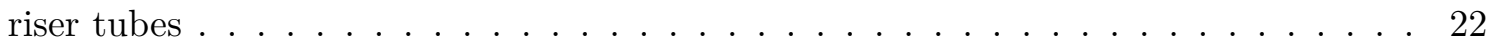

13 Exploded view of north/south panels on outlet plenum . . . . . . . . . . . 23

14 Cross section (east/west) of outlet plenum and surrounding insulation panels . . . . 24

15 Plan view of NSTF heated cavity and test section. Heater surface is shown in red, riser ducts in blue. Hatched perimeter denotes insulated areas. . . . . . . . . . . . 26

16 Lower heated plate prior to installation. Eye hooks were temporarily installed for lifting, thermocouples visible . . . . . . . . . . . . . . . 28

17 Dimensions and mounting hole specifications of primary heated plate (top shown) . 29

18 Heated wall, heater subpanel assembly . . . . . . . . . . . . . . . . 30

19 AutoCAD drawing of heater subpanel with ceramic heaters outlined . . . . . . . . . 31

20 Electrical detail of Main and Guard heating zones _ . . . . . . . . . . . . . . 33

21 Variable component locations on chimney ducting. Five butterfly valves and dual forced blowers . . . . . . . . . . . . . . . . . 34

22 Flow paths for chimney ducting (single path shown for clarity). Baseline 'Vertical' in blue, alternative 'horizontal' in purple . . . . . . . . . . . . . . . . 36

23 Flow vs frequency for dual fan loft blowers . . . . . . . . . . . . . . . . 37 
24 Cross section of heated cavity outlining areas of insulation. Viewed from a north facing perspective . . . . . . . . . . . . . . . 39

25 Primary areas of flexibility, dimensions shown for 'as-built' configuration . . . . . . 40

26 Plan view of Building 308 and NSTF test operations . . . . . . . . . . . . 41

27 Communications overview . . . . . . . . . . . . . . . . . 42

28 Eurotherm power and Mini electrical wiring . . . . . . . . . . . . . . . . 44

29 Heated plate thermocouple mounting method . . . . . . . . . . . . . . . 46

30 iTi model BHT, $300{ }^{\circ} \mathrm{C}$ Polyimide HFT . . . . . . . . . . . . . . . . 58

31 Position of weather station of Bldg. 308 roof top . . . . . . . . . . . . . . 63

32 Picture of weather station of Bldg. 308 roof top . . . . . . . . . . . . . . 63

33 Chimney differential pressure tap location . . . . . . . . . . . . . 65

34 Riser differential pressure taps (all risers except $2,4,8,10$ ) . . . . . . . . 65

35 Placement of inlet and outlet instruments for riser . . . . . . . . . . . . 67

36 Typical rake junction locations, placed along upper plenum top panel and extending

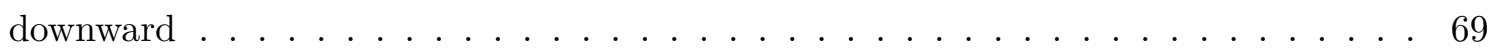

37 Luna fiber setup, setup near base mount and fed from inlet plenum . . . . . . . . . 71

38 Method of Luna fiber optic cables securement to capillary support tubes . . . . . . . 72

39 Details of Luna fiber optic cables in NSTF, dimensional locations . . . . . . . . . 73 


\section{List of Tables}

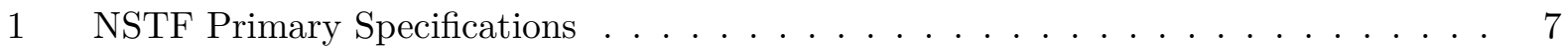

$2 \quad$ Ducting segment types and equiv. lengths for horizontal and vertical flow paths . . . 35

3 Material and thermal specifications for NSTF insulation . . . . . . . . . . . 38

4 Summary of National Instruments data aquisition devices . . . . . . . . . . . . . 43

$5 \quad$ NSTF Instrumentation Summary . . . . . . . . . . . . . . . . . . . . 45

6 Summary of heat flux sensors on risers. Procured from iTi Inc., model BHT . . . . . 59

$7 \quad$ Device specifications for Davis VantageVue weather station . . . . . . . . . . . . 62

8 Differential pressure device specifications . . . . . . . . . . . . . . . . . . . . 64

9 Inlet plenum humidity probe specifications . . . . . . . . . . . . 66

10 Inlet mass flow meter specifications . . . . . . . . . . . . . . . . . . 66

11 Specifications of Luna ODiSi A-10 . . . . . . . . . . . . . . 70

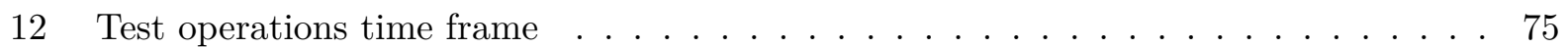

13 Measured emissivity values for NSTF north \& south walls . . . . . . . . . . . . 79

14 Specific measurement locations and emissivity readings . . . . . . . . . . . . . . 80 
This page was intentionally left blank. 


\section{Chapter 1}

\section{Program Objectives}

The overlying philosophy for this research program is to provide data that can support development and verification of passively safe decay heat removal systems for advanced nuclear power plants. The top level test objectives are ultimately to verify that the following operational requirements can be met by a given design:

1. Maintain the vessel wall at safe limits during normal operation and accident conditions, which in turn must ultimately ensure safe peak core fuel temperatures (i.e. retain a solid form) across all design basis scenarios.

2. Maintain the reactor cavity concrete and support structures at safe limits during normal operation and accident conditions to prevent concrete materials degradation and possible failure.

The effort at Argonne National Laboratory (ANL) is centered on an experimental facility for data generation, which is driven by an underlying scaling analysis and supported by computational modeling. The facility, coined the Natural convection Shutdown heat removal Test Facility (NSTF) has been specifically designed to examine the prototype Reactor Cavity Cooling System (RCCS) designs.

Given the potential cross cutting ability of the RCCS to function within multiple designs, a key experiment objective is to generate high quality, traceable, and qualified data that can be used to establish a performance window within which the RCCS is successfully able to operate. 


\subsection{Program Scope}

The objectives of the experiments in the NSTF and other supporting RCCS projects (e.g. universities) are to obtain experimental data which can be utilized to:

1. Validate codes which can be used in licensing and are therefore focused on accidents and the safety response of the RCCS.

2. Optimize the RCCS design for a 60 year lifetime by focusing on different configurations and parameters.

Each objective may suggest different instrumentation and measurement uncertainty requirements. In addition, each objective may result in diverse requirements on the experiment boundary conditions and ranges for the controlled parameters. The first objective, validation data, is required for two classes of thermal-fluid and safety codes

1. Integrated Systems codes such as RELAP5: the measurement requirements will be similar to those for legacy LWR experiments. However due to the higher material temperature limits required by this generation of high temperature gas-cooled reactors, this will demand finer resolution in the resulting data sets and thus may require a more robust preparation of the input deck.

2. Computational Fluid Dynamics (CFD) codes such as STAR-CMM+ and FLUENT: this class of codes demands higher resolution data relative to the integrated system codes to support advanced model development and to resolve modeling uncertainties.

The scaling methodology that was documented in a previous report (i.e. ANL-GenIV079), [1], provides the background and similarity relationships that were derived to ensure preservation of key thermal hydraulic behavior during the tests. This scaling basis determines the structuring of the entire group of experiments, and also provides the technical basis for extrapolating the test results to plant conditions. The top level-objectives can then be met within the constraints of the system design functional requirements. This approach 
ultimately produces a comprehensive matrix of separate effects tests, as well as component characterization and facility qualification tests. These results are then used to define the scope of confirmatory integral effect tests.

\subsection{Experiment Requirements}

The scaling basis, the top level code and modeling validation objectives, and the thermo-fluid phenomena important to the design and licensing basis produce the test facility functional design requirements. Thus, the required tests may be summarized as follows based on function and type:

- Confirmation of scaling laws: An early set of experiments will be required to confirm that the scaling basis is appropriate and that the assumptions/approximations made in the derivations of the scaling laws are acceptable within the uncertainties of the experiments. Specifically, the mass flow and temperature rise as predicted by the similarity relations will be compared against those determined empirically.

- RCCS design performance: Natural circulation start-up, parallel channel interaction and stratification effects, non-uniform spatial heating, and ultimate heat removal envelope. The procedure of these tests will be dictated by the experiment setup because they do not need to mimic the exact time and power history of a full scale design.

- GA-MHTGR accident scenarios: Heat removal at normal operating conditions, heat removal under accident conditions, and heat removal with partial/full system failure. These tests will be performed at true time scales for valid extrapolation to a full scale scenario, specifically the time history of the decay heat curve inputted as boundary conditions for the experimental operation.

The test section materials and the remainder of the facility should be of a similar material to the actual plant system in terms of emissivity and thermal properties. One specific example is the use of carbon steel for the riser ducts. Stainless steel is typically preferred 
in this type of experiment for its superior corrosion resistance but will be omitted to better simulate the actual plant system.

The thermo-fluid conditions in the test section, test cavity, and the rest of the facility should be a scaled replica of the actual plant system in terms of initial conditions and boundary conditions. The facility instrumentation should address the top-level objective of providing validation data for both integrated system level and CFD codes, as well as characterizing the thermal performance of the RCCS.

\subsection{Full Scale Design Basis}

The NSTF is a large-scale thermal hydraulics test facility built to examine the performance of passive decay heat removal systems for advanced plant concepts. A full scale design was selected based upon the General Atomics (GA) Modular High Temperature Gas cooled Reactor (MHTGR), a gas-cooled reactor using helium as the primary coolant with prismatic fuel elements in a hexagonal core [2]. The full plant design would comprise four reactors with two steam turbine generators providing a net power output of $540 \mathrm{MW}_{e}$ [3]. This RCCS concept was selected primarily due to the availability and relatively mature nature of the engineering design. However, the fundamental idea relies simply on a heat flux or temperature boundary condition from the RPV wall and thus may be suitable for crosscutting technologies.

Based upon this selected full scale design, the NSTF represents a $1 / 2$ axial and $20^{\circ}$ sector slice scaled model. These are the result of design selection criteria that maintained full radial dimensions, an axial height reduced by half and twelve riser ducts out of the full 227 . 


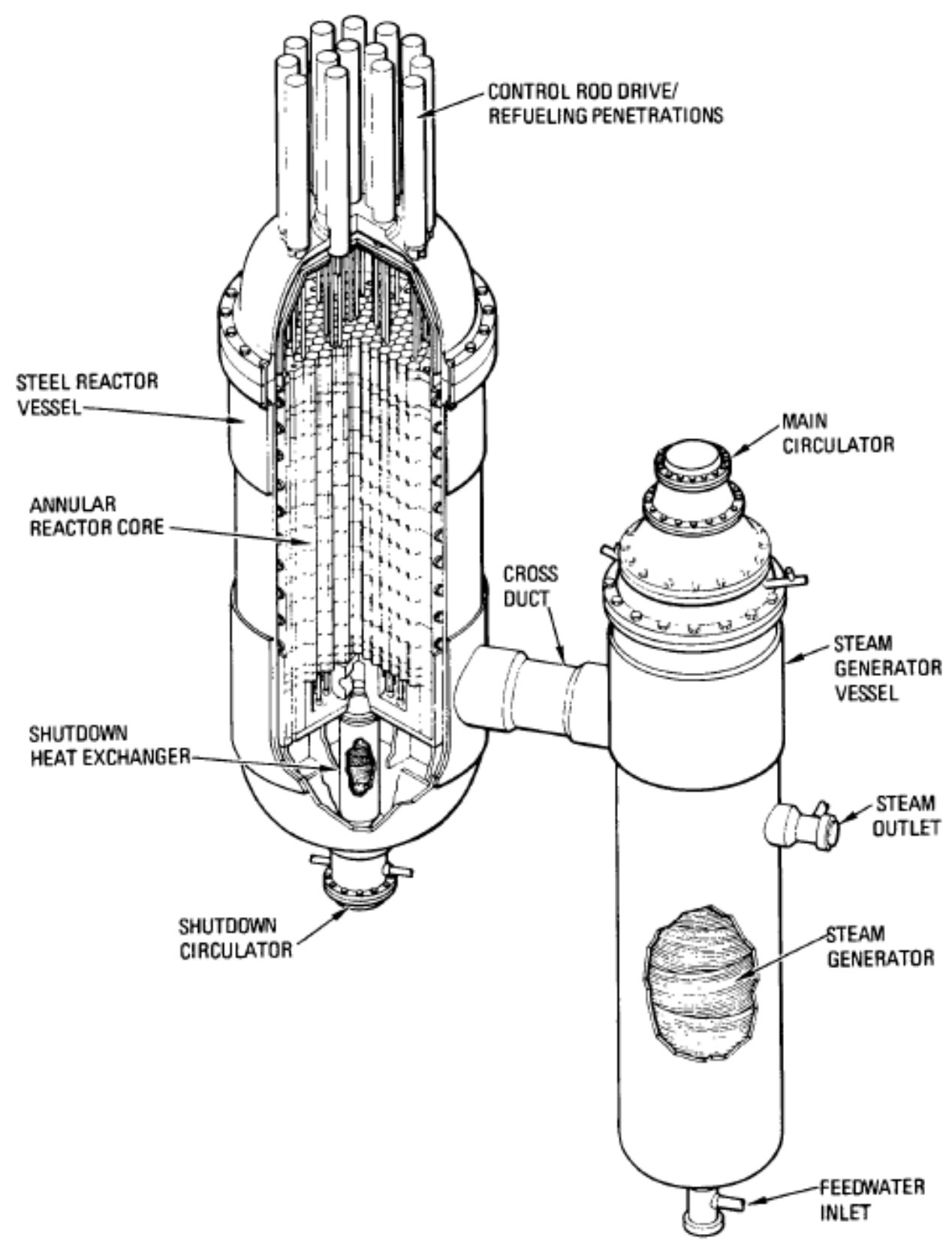

Figure 1: GA-MHTGR concept, single module shown 
This page was intentionally left blank. 


\section{Chapter 2}

\section{Facility Overview}

The overall facility height for air-based testing is 25.5-m, and water-based testing can be accommodated with a thermal centers separation distance up to 15-m. Although the facility is principally designed for natural convection testing, forced convection experiments can also be accommodated to guide experimental practices such as instrument calibration and isothermal flow testing. A summary of the primary specifications for the facility and a rendering of the as-built design are provided in Table 1, and Figure 2, respectively.

Table 1: NSTF Primary Specifications

\begin{tabular}{|l|l|}
\hline General & $\begin{array}{l}\text { Natural convection air-flow thermal hydraulic test facility. } \\
\text { Water-based testing can be accommodated with thermal centers } \\
\text { separation distance up to } 15 \mathrm{~m}\end{array}$ \\
\hline Overall facility height & 83.8 -ft $(25.5$-m) \\
\hline Flow operating modes & Natural or forced convection \\
\hline Heated section flow area & $\begin{array}{l}\text { Rectangular, } 52 \text {-in }(132-\mathrm{cm}) \text { wide cavity with adjustable cavity } \\
\text { depth of } 18 \text { to } 59 \text {-in }(45 \text { to } 150 \text {-cm) }\end{array}$ \\
\hline Heated section length & 270 -in $(6.86$-m) overall height \\
\hline Heating distribution & One side heated; other three sides are adiabatic \\
\hline Heated operating modes & $\begin{array}{l}\text { Constant heat flux or temperature }\left(677^{\circ} \mathrm{C} \text { maximum), or }\right. \\
\text { arbitrary combination of } 1 \text { \& } 2\end{array}$ \\
\hline Total input power & $220 \mathrm{~kW}$ at $21.6 \mathrm{~kW} / \mathrm{m}^{2}$ \\
\hline Spatial control resolution & $\begin{array}{l}\text { Ten } 26 \text {-in }(67-\mathrm{cm}) \text { axial segments, } 4 \text { azimuthal control zones at } \\
\text { each axial elevation (two central zones plus two guard heater } \\
\text { zones) }\end{array}$ \\
\hline Chimney design & $\begin{array}{l}\text { Two } 59 \text {-ft }(18-\mathrm{m}) \text { high, } 24 \text {-in }(60 \text {-cm) diameter circular ducts that } \\
\text { allow different flow path configurations }\end{array}$ \\
\hline
\end{tabular}




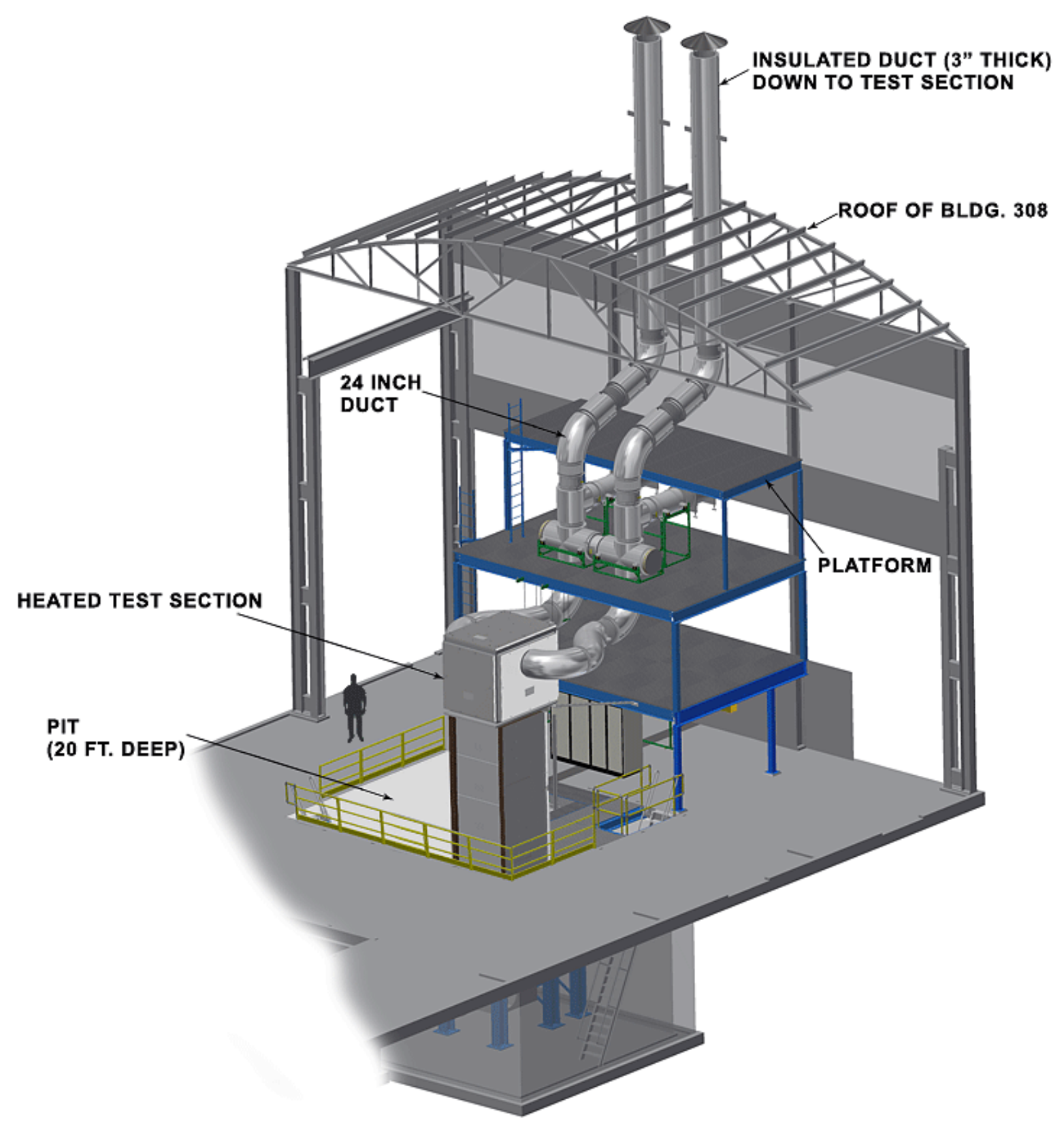

Figure 2: Solid model rendering of NSTF facility, inclusive of building, support, and personnel access structures 


\subsection{Primary Components}

The NSTF consist of six major components, Figure 3, of which both plenums (inlet, outlet), heated cavity, and riser ducts have been designed to accurately replicate the full plant design concept. The remaining segments have been designed to minimize distortions and provide a best-attempt surrogate design for maintaining full design thermal hydraulic flow patterns while catering to the physical constraints of the Argonne laboratory space.

The chimney ducts were designed based off two primary criteria: preserve the swirling behavior (originating in the outlet plenum) while following the natural contour of the laboratory space. The first criterion, detailed in previous reports [4], stems from a computational effort that modeled the full scale RCCS system. It was found that as the hot air exits the riser ducts, it forms a circular motion within the outlet plenum and continuing into the chimney ducts. Thus designers proposed various chimney designs for the scaled NSTF and submitted these to the computational project. A series of iterations led to the final design, which ultimately preserved this swirling behavior and catered to the building contour.

The inlet downcomer was designed largely to serve as the most practical and feasible implementation for an experimental facility. The full scale RCCS design features eight concentric chimney ducts, where the hot air is exhausted within a core or central duct and the cool air is drawn on the ductwork surrounding this hot core. Within the containment, the air supply flows down a series of ducts that are integral to the concrete walls, separated by 2" of insulation behind the heater risers. This seemingly elaborate design of inlet system introduces only the ability to transfer part of the heat from the hot exhaust into the cool supply. Official reports by General Atomics [2] indicate a riser inlet temperature of $22{ }^{\circ} \mathrm{C}$, thus the pre-heating effects were assumed to be negligible. To examine the programs $2^{\text {nd }}$ objective (the cavity wall temperature limits), a thermal resistance will be included along with the experimental data to better extrapolate the results to the full scale design. 


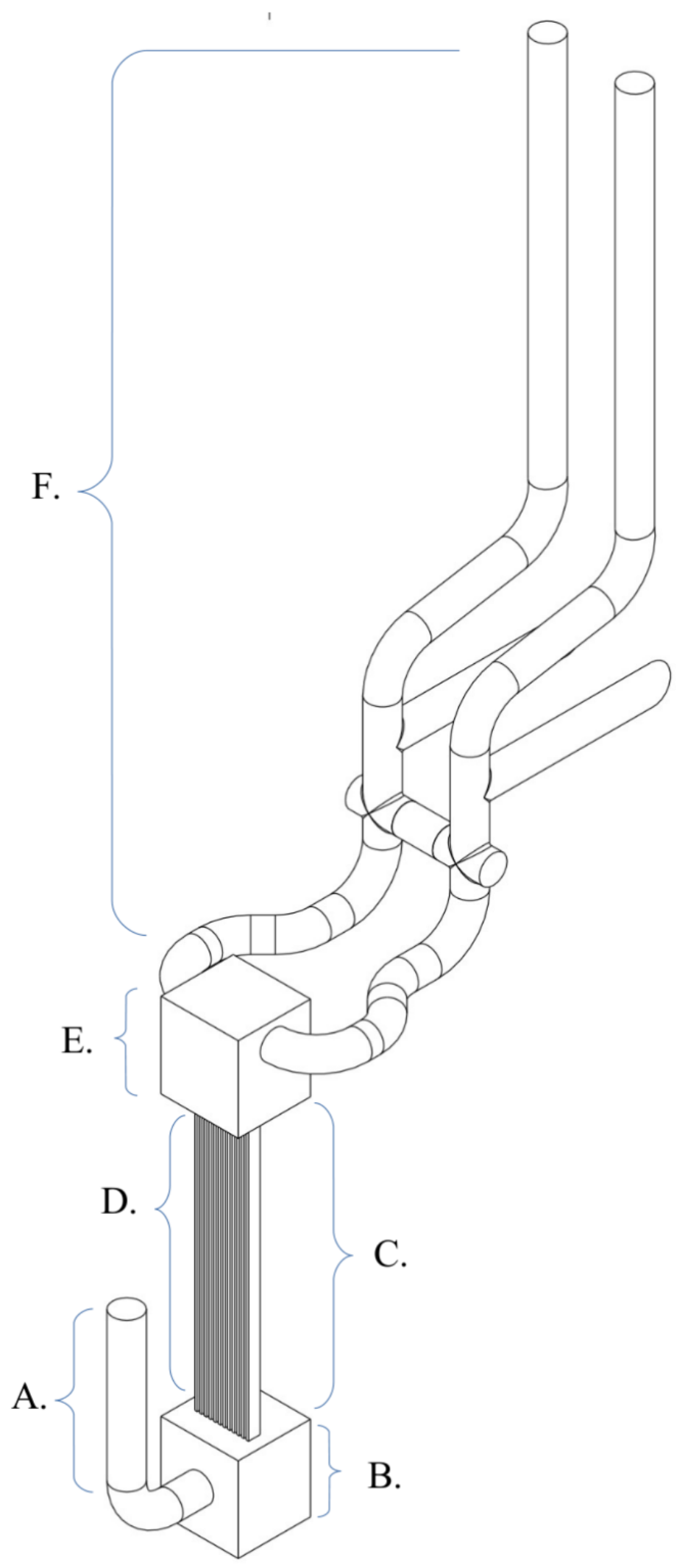

Figure 3: Primary segments of the NSTF. A. inlet downcomer, B. inlet plenum, C. heated cavity, D. riser tubes, E. outlet plenum, F. chimney 


\subsection{Flow path}

The flow path through the NSTF begins at the down comer inlet, where an initial flow conditioner straightens the velocity profile before plunging horizontally into the inlet plenum. The opening to the riser ducts is located at the top wall of this plenum, which causes the air volume split and distributing itself among the twelve channels. Once residing in the riser ducts, radiative and convective thermal flux heat the exterior walls which conduct through to the interior and ultimately into the air volumes by convection. This pattern continues along the full $7 \mathrm{~m}$ length of the risers, where the incoming air volumes gain thermal energy and rise in temperature. This influences results in the natural circulation phenomena, which prescribes a change in density with change in temperatures. As the air heats and it's density is lowered, gravitational forces cause it to rise along the ducts, leaving behind a reduced pressure that draws more air in and augments this cycle. By the time the air volumes have reached the top of the riser ducts, they have risen nearly 80 - 100 degrees in temperature and have created a strong force for natural circulation flow. The air exits from the twelve riser ducts at a nominal $4-6 \mathrm{~m} / \mathrm{s}$ and penetrates into the outlet plenum. The large momentum of the incoming air creates a jet that continues to rise within the plenum. With a horizontal offset of the ducts nearest the west plenum wall, and an abrupt a change in flow direction due to the ceiling, the flow begins a swirling pattern within the plenum. The swirling continues for a discrete time frame, traveling several cycles while mixing with the exhaust from the other eleven ducts. Eventually, the air volumes combined and find their way through dual chimney openings along the north and south walls. The combined air volumes split, each traveling up their respective chimney ducts before finally exhausting to the atmosphere. 
This page was intentionally left blank. 


\section{Chapter 3}

\section{Test Assembly Description}

The following sections detail the engineering specifications, design features, and dimensions of the test facility at Argonne. Details of mechanical systems will be presented first, followed by ducting components, heated cavity, and finally a stand alone section on the various insulating materials used. References will be made to specific engineering drawing numbers, which are included in-line with the text.

\subsection{Base Support and Cavity Framework}

The structural base assembly that supports the primary test assembly components was manufactured from W12x65 I-beam sections and weighs approximately 30,000 lbs. Base supports, six in total, extend to the concrete floor and are secured by four 1.25 " bolts. The total height of the assembly is 6' tall, Figure 4 .

Resting on top of the base support is a U-channel framework that serves as the exoskeleton for supporting the heavy steel assemblies that make up the heated cavity, Figure 5. Built in two sections; each is constructed around six ASTM A36, MC12x45 channels that join onto 1" steel plates to makeup the skeleton framework. 

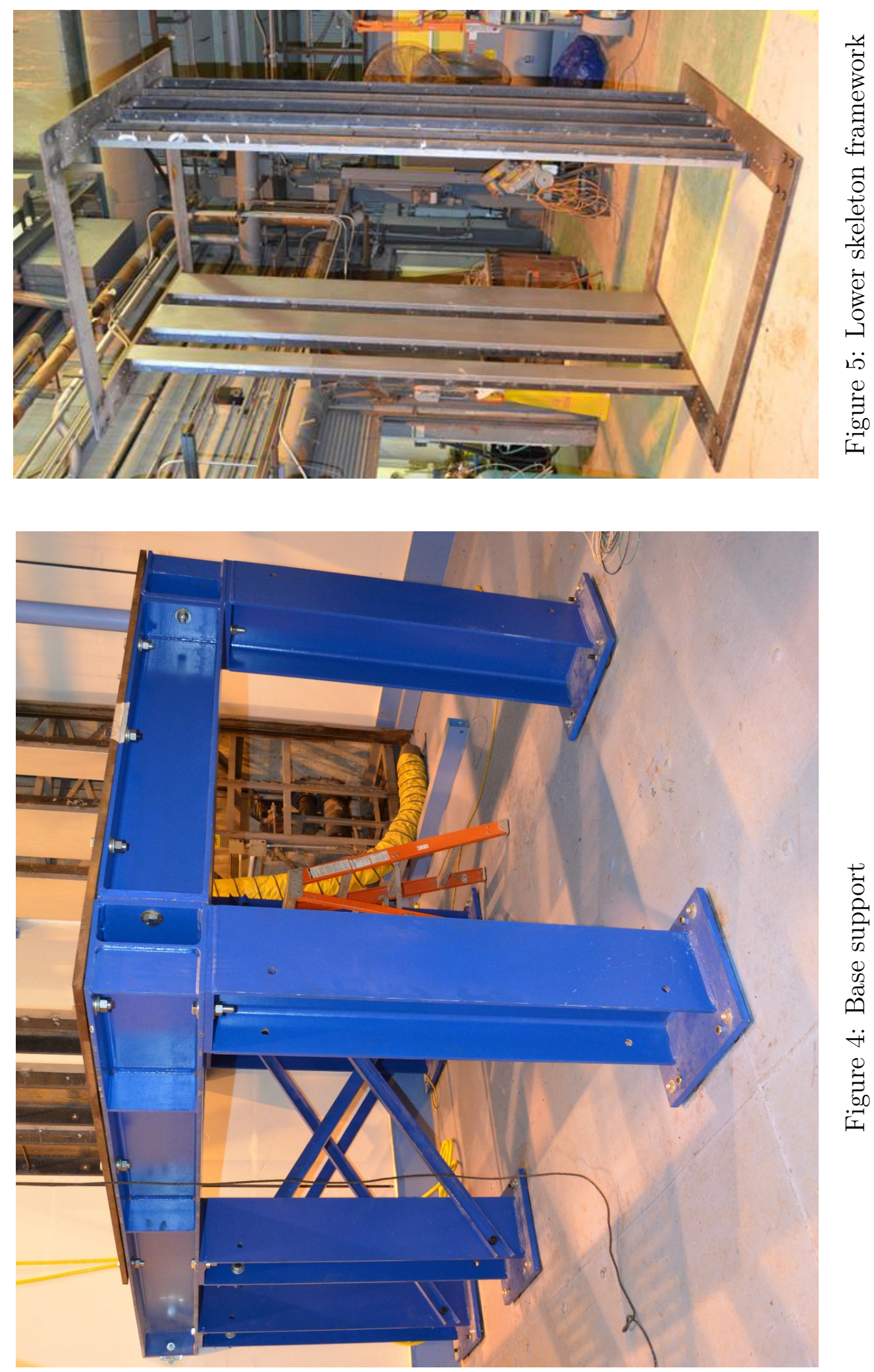

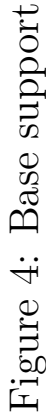




\subsection{Flow path ducting}

\subsubsection{Inlet downcomer}

The air supply to the NSTF enters through an inlet downcomer, an uninsulated 24" diameter duct that provides a means to stabilize and measure the incoming flow, Figure 6 The inlet downcomer begins with a vertical straight length, $90^{\circ}$ elbow, and finally horizontal straight, which combined span an equivalent length (distance along centerline of ducting segments) of $184.5 "$.

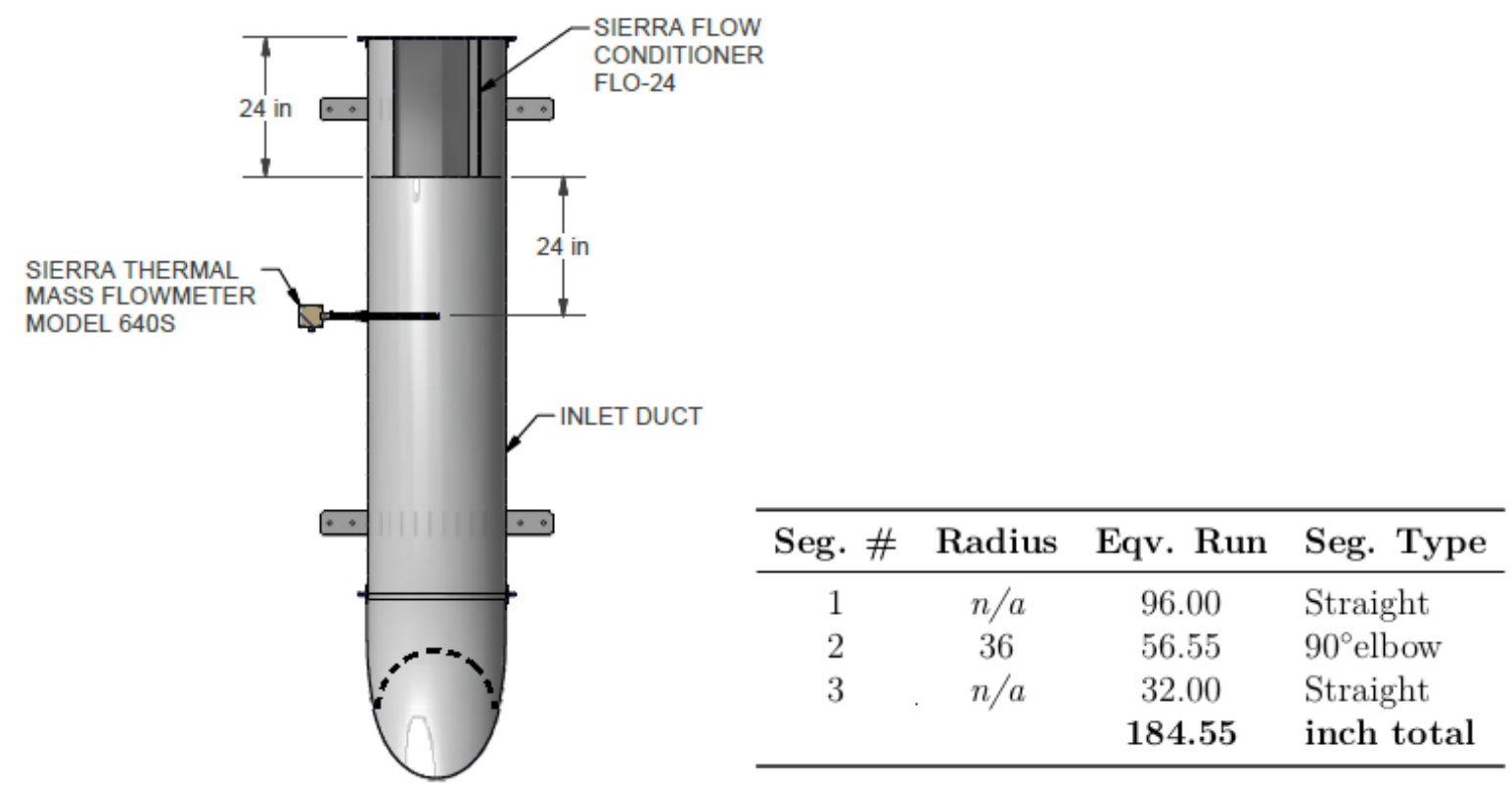

Figure 6: Inlet downcomer (front view) and equivalent segment lengths

We have positioned a Sierra flow conditioner, Figures 7 - 8, which sits at the top edge of the duct and extends 24" deep as a means to establish a fully developed inlet flow profile. Along with the entrance and exit lengths, these design choices stem from a experimental requirement to accurately measure the inlet flow conditions. 

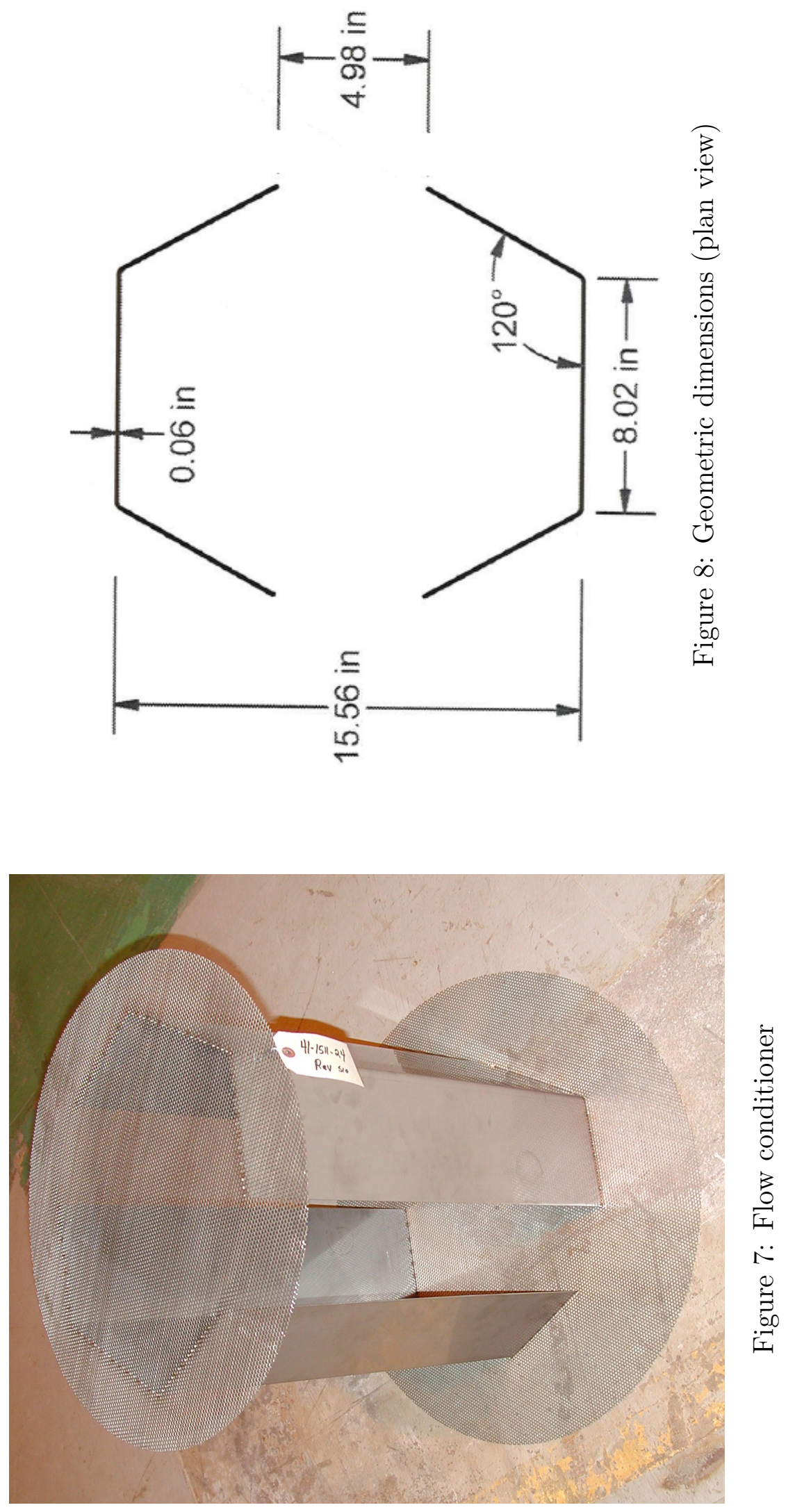


\subsubsection{Inlet plenum}

The inlet plenum is a large volume that provides an essentially zero pressure boundary condition for the incoming air from the downcomer to distribute among the twelve riser channels, Figure 9 . The assembly is constructed from $1 / 8$ " thick aluminum, alloy 3003 . The total available volume of the inlet plenum is $78 \mathrm{ft}^{3}\left(2.21 \mathrm{~m}^{3}\right)$; however a divider plate reduces the available area for air flow to $41.7 \mathrm{ft}^{3}\left(1.18 \mathrm{~m}^{3}\right)$. The unused back cavity is insulated and available for access should maintenance be required.

The configuration of the inlet plenum mates the downcomer ducting to the center of the west plenum wall. The centerline of each of the three inlet ports measures 16" from the bottom, and all are centered along their respective widths (33" for the north and south ports, 52 " for the primary west port).

To facilitate instrument placement for measurement of the inlet flow conditions into twelve riser tubes, the ducts extend 7" below the ceiling of the inlet plenum. The inlet plenum ceiling contains twelve slots for this purpose, and the slotted joint is sealed against air leakage by a Kevlar wrap. The purpose of this slotted design is to allow unconstrained movement due to thermal expansion, as a fixed support would induce significant stress onto the steel riser ducts. At the expected steady-state operating temperatures during experimental operations, the riser ducts may expand upwards of 1-cm. 


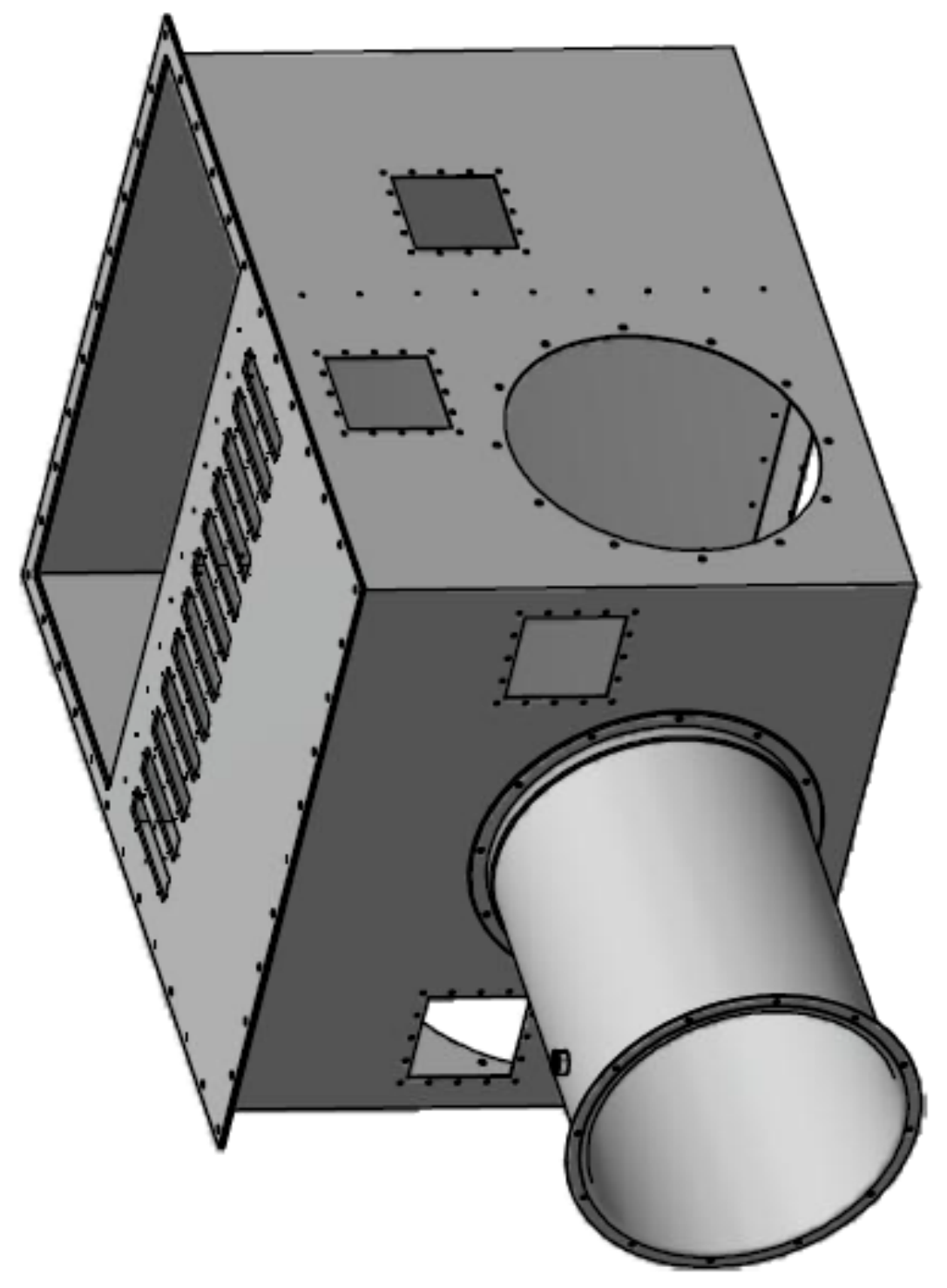

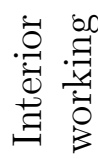

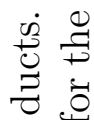

离

$\circ$ 궁

$\stackrel{\pi}{0}$

.

응 오

कै

공 궁

要

สี

常

总言

$\stackrel{0}{=}$

$=$ is

造

릴

ह

ช

导

○.

on

包

기응

○

$\Rightarrow \widetilde{\Omega}^{3} \beta$

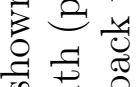

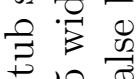

药罂西

过次

击牥

$\dot{1}+$

寻吉

들 है

䓠泀焉

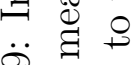

बं

㬅言意 


\subsubsection{Riser ducts}

The NSTF houses twelve (x12) riser ducts as the primary flow area test section, and are constructed from welded structural rectangular steel tubing, ASTM A 500 Gr. B The cross-section dimensions are duplicate of the full scale GA-MHTGR design, and measure 10"x2"x0.188"W, at an approximate weight of $385 \mathrm{lbs} /$ riser, Figure 10. The length of each duct measures 295"; however, only 272" resides within the heated cavity due to the 7" extension below into the inlet plenum and 16" above into the outlet plenum.

The combined weight of the twelve tubes totals 4,620 lbs and required creative mounting methods to omit the need for rigging the full assembly. Each riser tube features a 3/8" plate that has been welded 16" below the top lip as a means to support the individual tubes. The installation process required hoisting above the outlet plenum, and dropping each duct through a slotted support plate into the heated cavity. The plate, manufactured from 1" thick ASTM A 36 steel and weighing approximately 1,820 lbs, bears the full load of the ducts and is secured to the exterior support skeleton, Figure 11. 

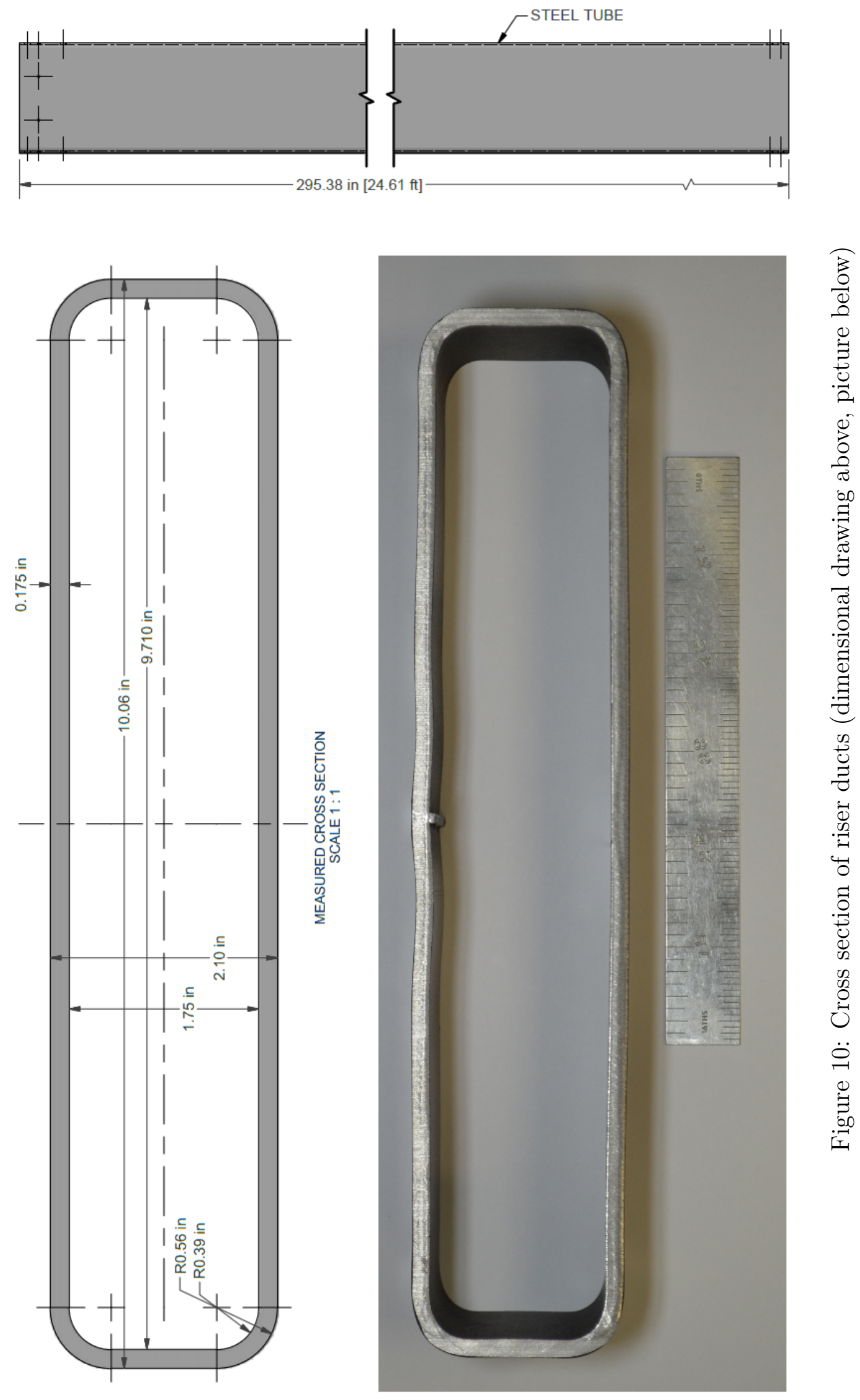


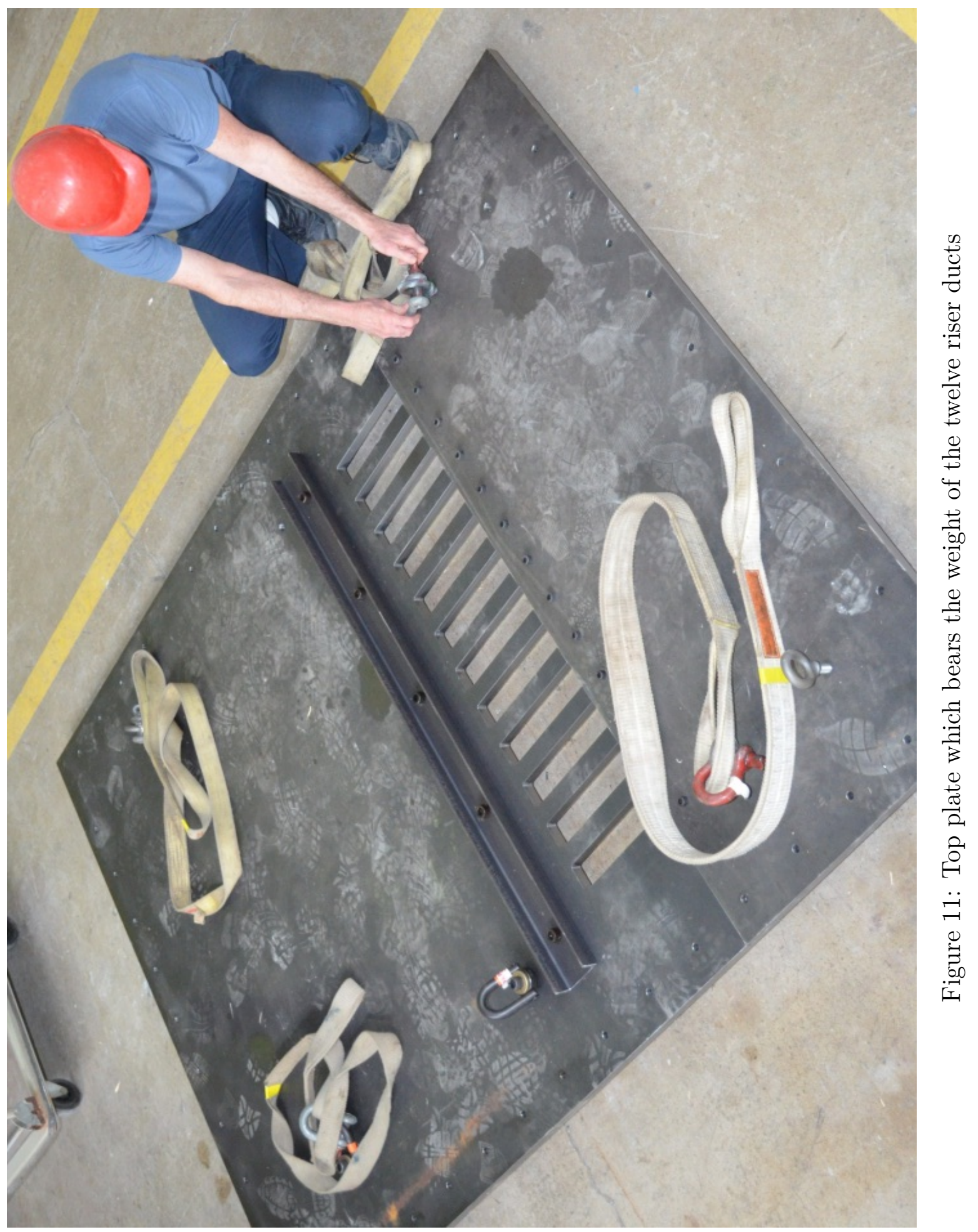




\subsubsection{Outlet Plenum}

Flow through the individual riser ducts rejoins in the upper plenum being riser up and into the dual symmetric chimneys, Figure 12. The riser tubes protrude 16 " past the floor of the outlet, which primarily allows for access to instrumentation ports, and also reduces the effort when installing a false-floor, since the riser tubes can be kept in their position without reconfiguration.

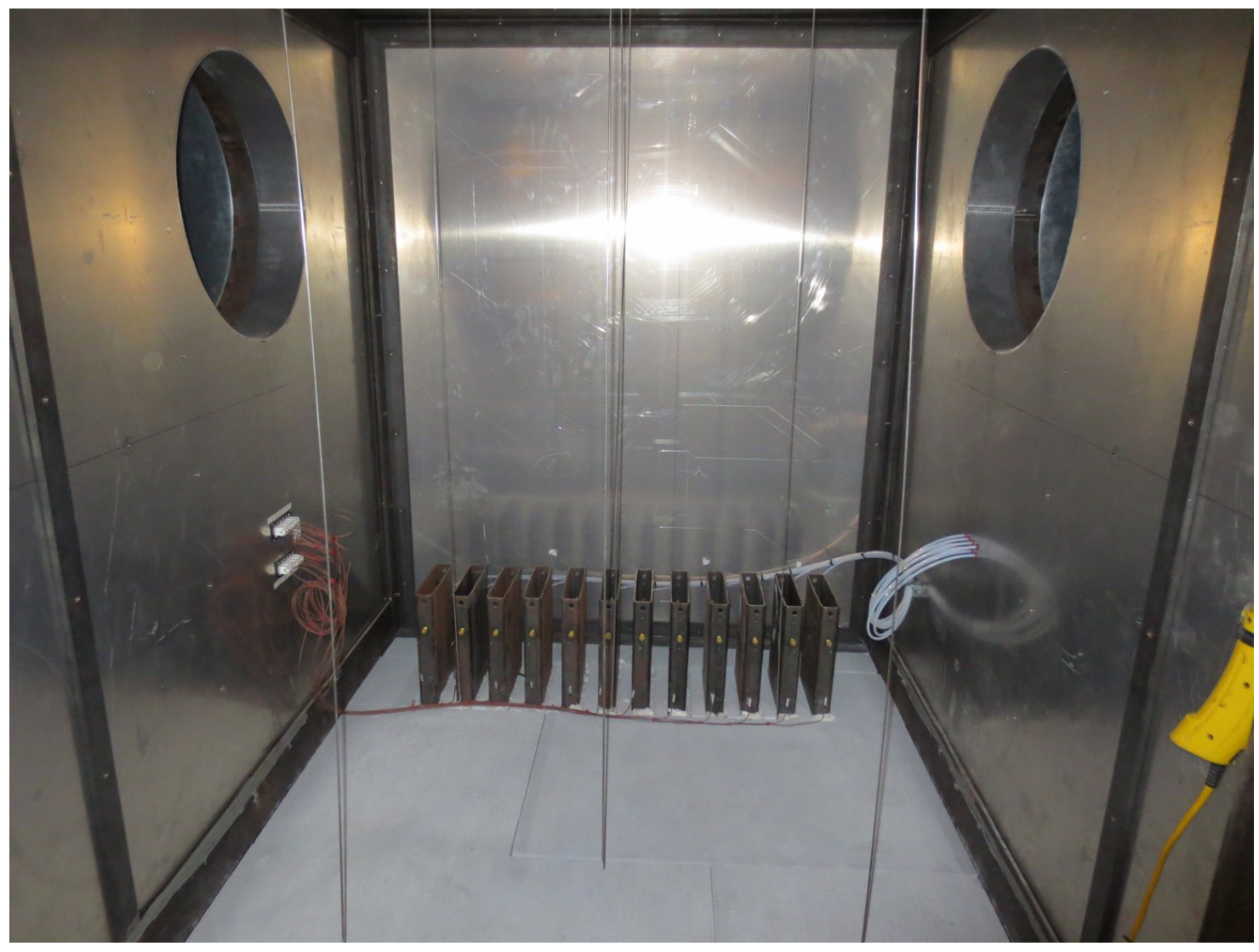

Figure 12: View into the outlet plenum from opened east wall. False west wall visible behind riser tubes

The plenum interior measures 74" tall, 87" east/west, and 64" north/south. The plenum features adjustable false-floors and walls as a means to adjust the inside volume. The asbuilt design consists a false wall on the western side, reducing width (west - east) from 87" to 74 ". The interior volume measures $203.8-\mathrm{ft}^{3}\left(5.77-\mathrm{m}^{3}\right)$, which is reduced by the false west 
wall from the total available volume of $240-\mathrm{ft}^{3}\left(6.79-\mathrm{m}^{3}\right)$. The 24 " diameter ports, which serve as the entrance into the chimney ductwork on the north and south pacing walls, are positioned at the plenum centerline (east-west) and elevated 56.5" from the plenum floor, or 40.5" above the top surface of the riser tube end. From the centerline of the riser tubes and chimney ports, the east-west offset measures 16.5"

The exterior paneling on the outlet plenum consists of five similarly designed sub-assemblies, which are constructed in the same fashion as the heated cavity west wall panels: a steel angle (L3x2x1/4") framework that contains 6" of insulation, and is protected on both inside and outside facing walls by $1 / 8$ " thick aluminum sheets. Each panel weighs approximately 800 lbs., and has mounting provisions for hoisting and lifting operations. An exploded view of the north and south panels is shown below in Figure 13, and an east-west cross section of the entire outlet plenum and paneling in Figure 14.

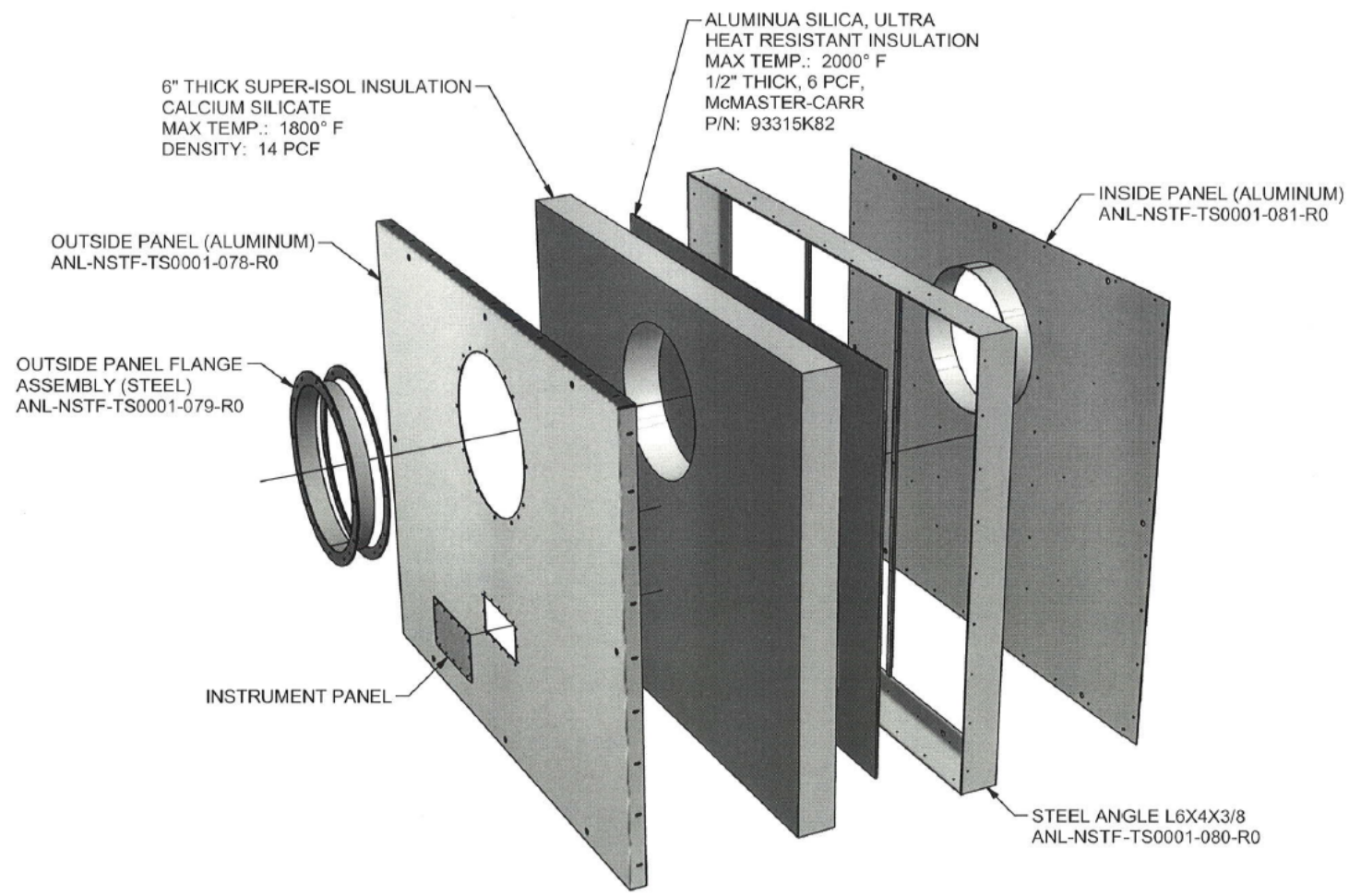

Figure 13: Exploded view of north/south panels on outlet plenum 


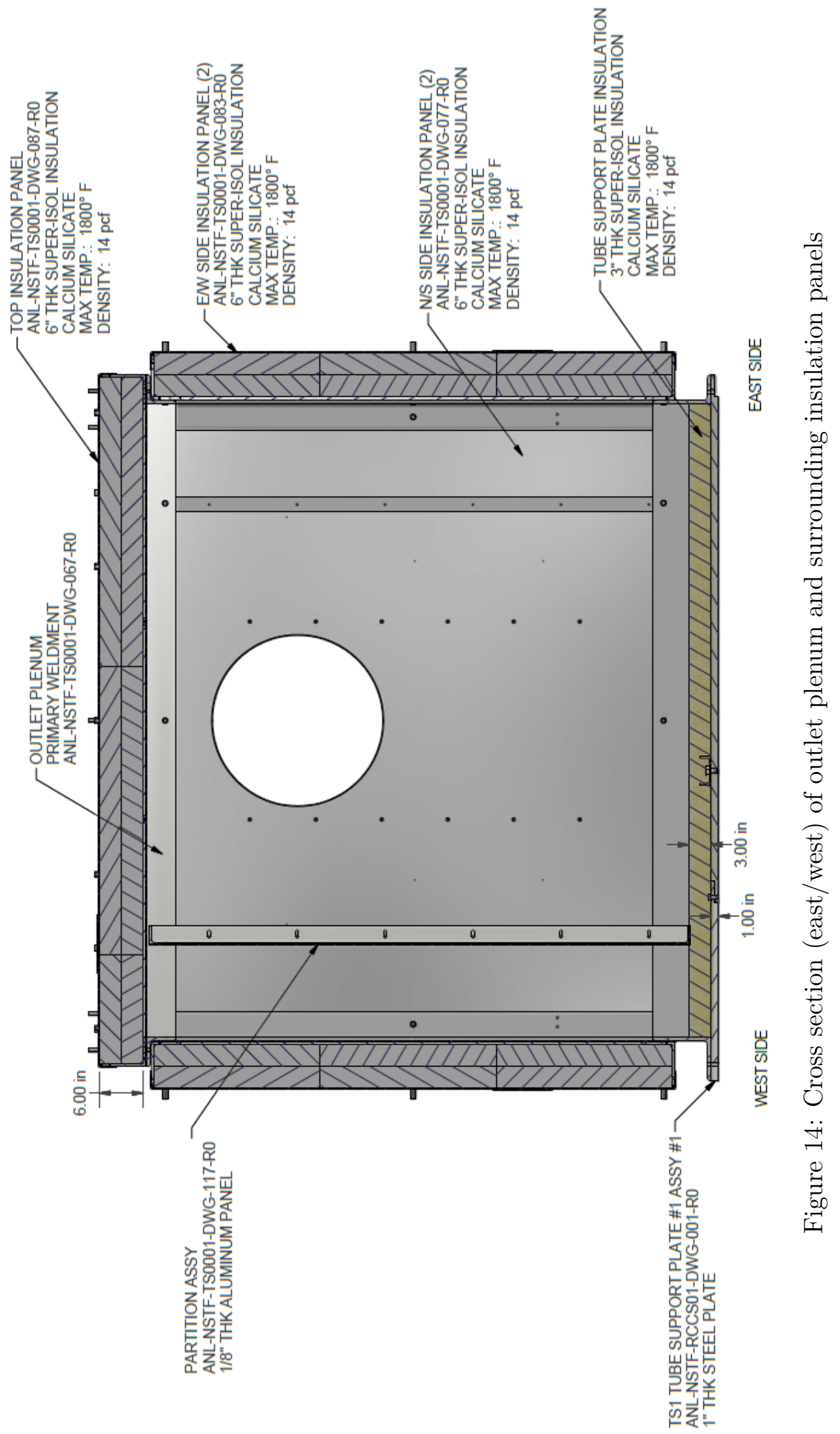




\subsection{Heated cavity}

The primary test section of the NSTF is an insulated enclosure that provides a means of heat transfer from the radiant heater source (simulated reactor vessel) to the twelve riser ducts, and is built around the U-channel skeleton framework. One side of the cavity is heated (mocking up the exterior of the reactor vessel), while the other three sides are adiabatic. This heated enclosure has an overall height of $22 \mathrm{ft}(6.7 \mathrm{~m})$, in a 52" (132 cm) wide cavity with an adjustable cavity depth that can range from 17.7" to 59" (45-150 cm) in increments of $1 "(2.5 \mathrm{~cm})$, Figure 15. The spacing between the front facing surfaces of the riser tubes and heated plate used for the first round of test operations measures 27.82" (706.55 mm), and the area for heat transfer off the primary heated plate measures $109.6 \mathrm{ft}^{2}\left(10.18 \mathrm{~m}^{2}\right)$. Details of the insulation materials will be given in later sections.

\subsubsection{Unheated Paneling}

The insulated panels on the north and south walls are placed on hinges that facilitate removal and access without needing to perform a major disassembly. Twenty-four panel assemblies are required to cover the full area of the north and south walls. Each panel measures 67 "x21", and is constructed from 6" of insulation (facing inward), and protected by 16 gauge aluminum, alloy 3000, on the outward surface. The hinges secure to $1 / 2 "-13$ steel spacing studs placed across the width of each U-channel, and when fully installed allow for complete enclosure and isolation of the heated interior from the ambient surroundings. The four panels on the west wall are constructed from a steel angle (L3x2x1/4") framework that contains 6" of insulation, and is protected on both inside and outside facing walls by $1 / 8$ " aluminum. Each panel weighs approximately 267 lbs., and has mounting provisions for hoisting and lifting operations. 


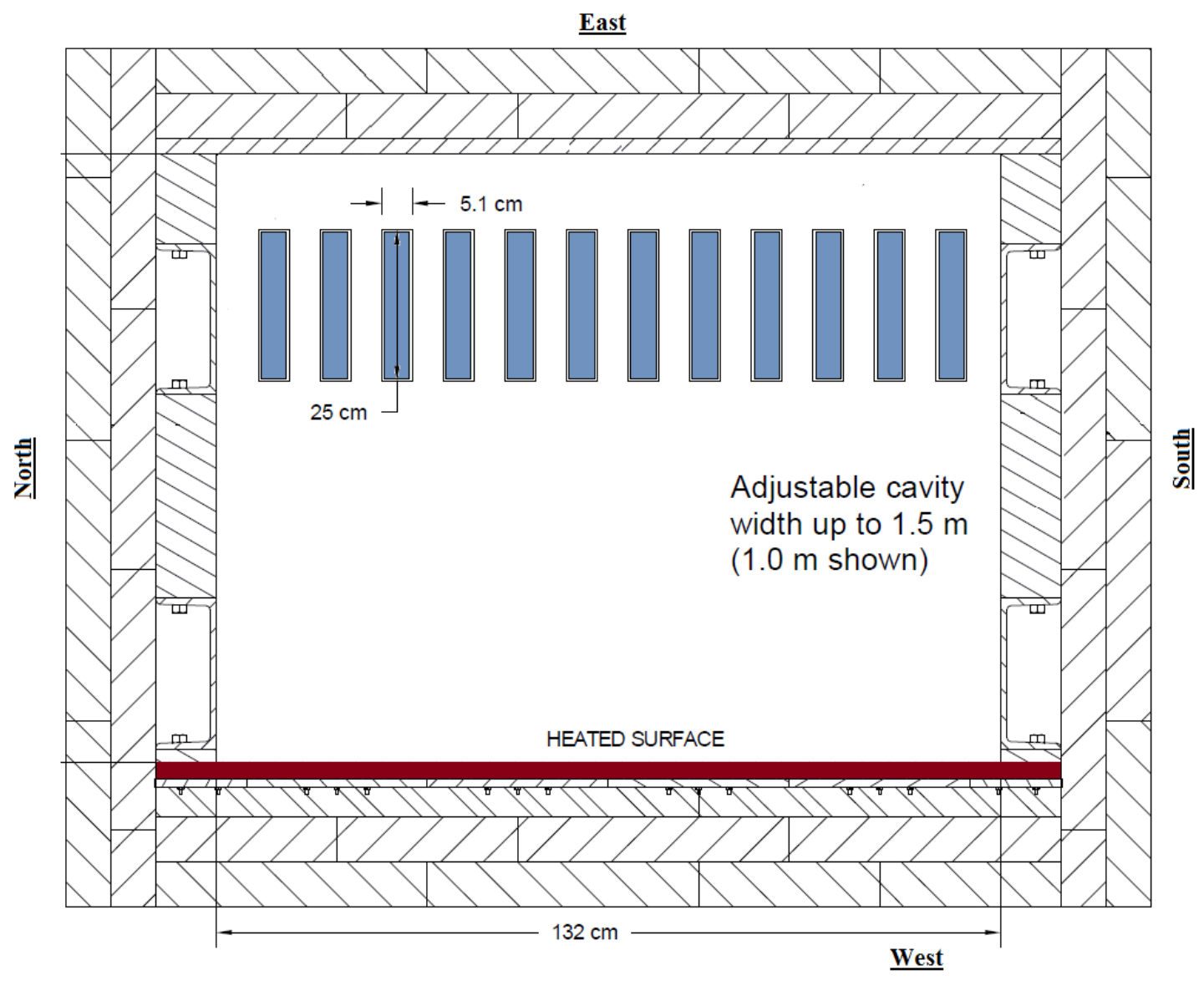

Figure 15: Plan view of NSTF heated cavity and test section. Heater surface is shown in red, riser ducts in blue. Hatched perimeter denotes insulated areas.

\subsubsection{Heated Wall}

The heated east wall comprises a nine layer composite to provide the necessary structurally support for the massive steel plate, provide an efficient means for heat transfer, and also insulate the system from parasitic heat losses. These nine layers were constructed and installed as three separate sub-assemblies: two vertical primary plates, four rows of heater sub-panels, and four rows of outside insulation panels. An air gap separates the 1st and 2nd, and a thin buffer layer of insulation separate the 2nd and 3rd. 


\subsubsection{Primary Heated Plate}

To accurately represent the heat flux condition off the walls of a prototypic RPV, the primary heat source in the NSTF (electrically powered radiant heaters, detailed in later sections) are placed behind a 1" steel plate as a means to smooth any sharp temperature gradients from the hot coils while also providing the necessary emissivity for radiation heat transfer to the riser tubes. Figure 16 shows the lower plate in preparation for installation, including temporary eye bolts needed to hoist the 2,230 lb plate onto the skeleton framework.

This plate is fabricated from SAE 1020 low carbon steel which has stated ladle composition limits given as $0.18 \% / 0.23 \% \mathrm{C}, 0.30 \% / 0.60 \% \mathrm{Mn}, 0.040 \% \mathrm{P}_{\max }, 0.50 \% \mathrm{~S}_{\max }$, and $\mathrm{Fe}$ being the remaining constituent. The surface condition of the back plate is mill scale oxidized so that its emissivity was initially in the 0.7 to 0.9 range. This emissivity was measured prior to test operations and is detailed in Appendix A. The same plates were used from the early PRISM/RVACS work [5], a project at ANL which investigated a similar concept for passive decay heat removal. Early reports have mentioned that the researchers hand selected these plates based on uniformity and surface condition which had a thin surface scale that was an electrically nonconducting oxide with a dull dark-purple coloration. Furthermore, they add that surface deformation by grinding for welding and thermocouple spot welding was kept at a minimum. The primary heated plate has enlarged mounting holes to allow for thermal expansion in all directions. The plate is hung to skeleton support structure, separated by 2" spacers and insulation, so that the heater plate subassembly is allowed to expand horizontally and vertically. Figure 17 shows dimensions and mounting points for the lower plate. 


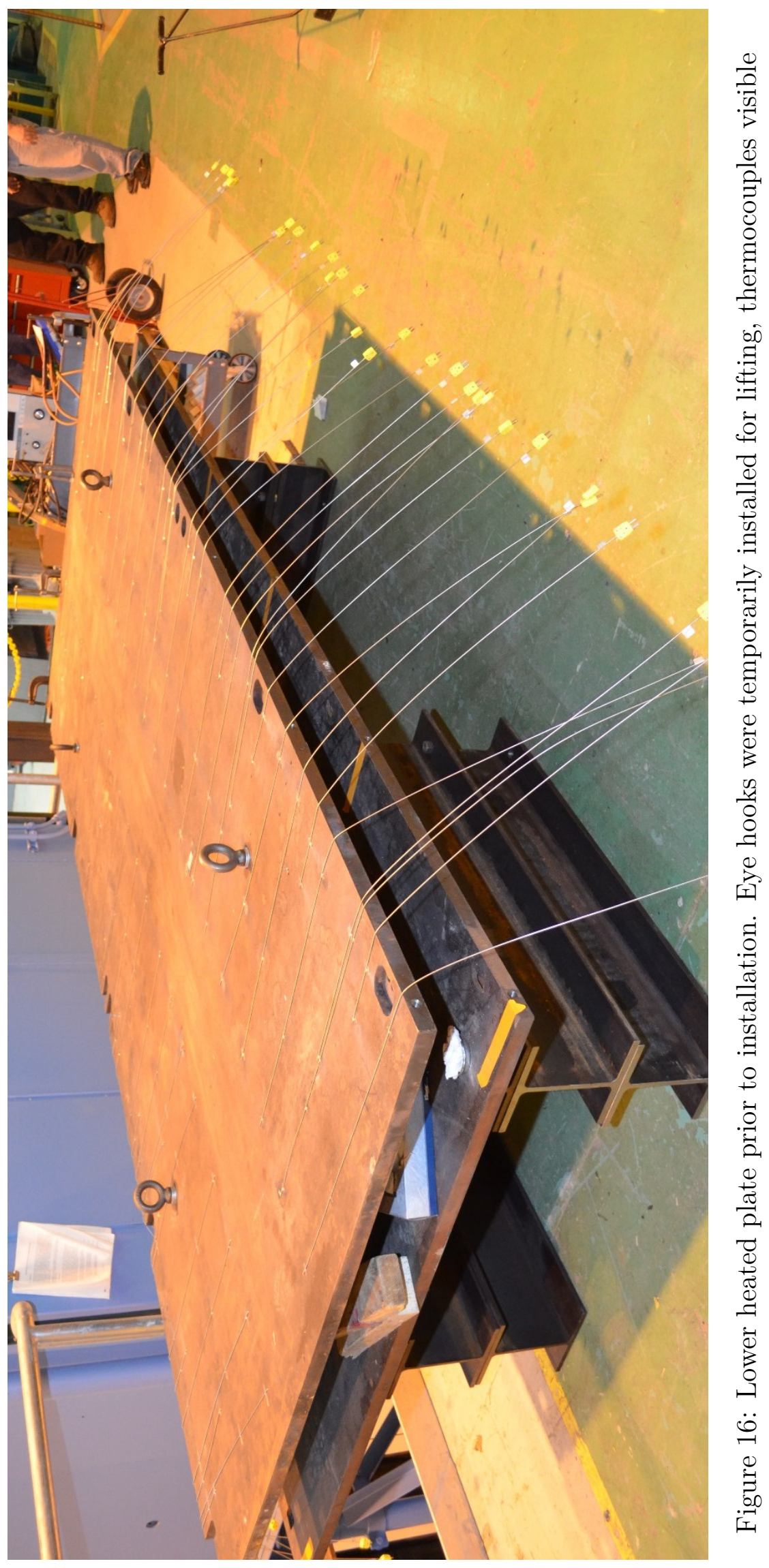




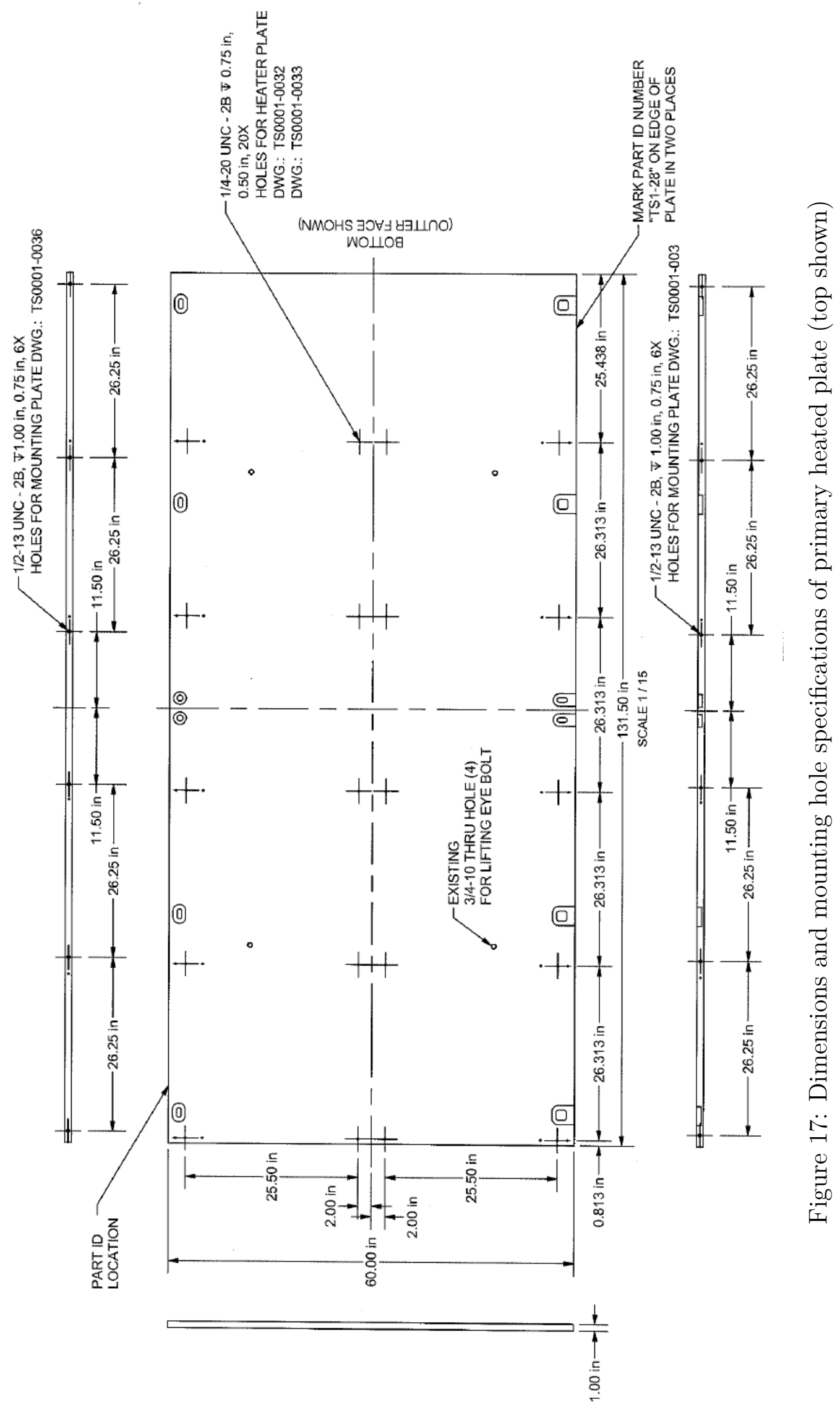




\subsubsection{Heater Subpanels}

The heater sub-panels, ten in total, serve as the primary area for power control, heat transfer, and insulation for the 220 ceramic heater plates. The mounting system, Figure 19, positions the radiant coils of the heaters away from the test section as a means to provide uniformity in the heat flux across the plate. This setup also minimized the risk of electrically shorting out the heater coils against any neighboring conductive materials.

The stainless steel sheets were sandblasted and then heat treated to $1900^{\circ} \mathrm{F}$ to relieve internal and surface stresses. The sandblasting process was performed to enhance the surface emissivity of the sheets from about 0.25 to about 0.90 uniformly over both sides of the sheets, significantly improving heat transfer and temperature uniformity, and thereby reduce the chance of warping the stainless steel sheet. The ceramic heaters (detailed in the following section) are fastened to the steel sheet with 10-32 size studs that are welded to the steel sheets. Each heater subassembly contains twenty ceramic plate electric heater elements (6in x 12-in). The 16 central heater elements are one heater zone, and the four edge heater elements compose the second heater zone on the 2-ft x 5-ft heater plate subassembly.
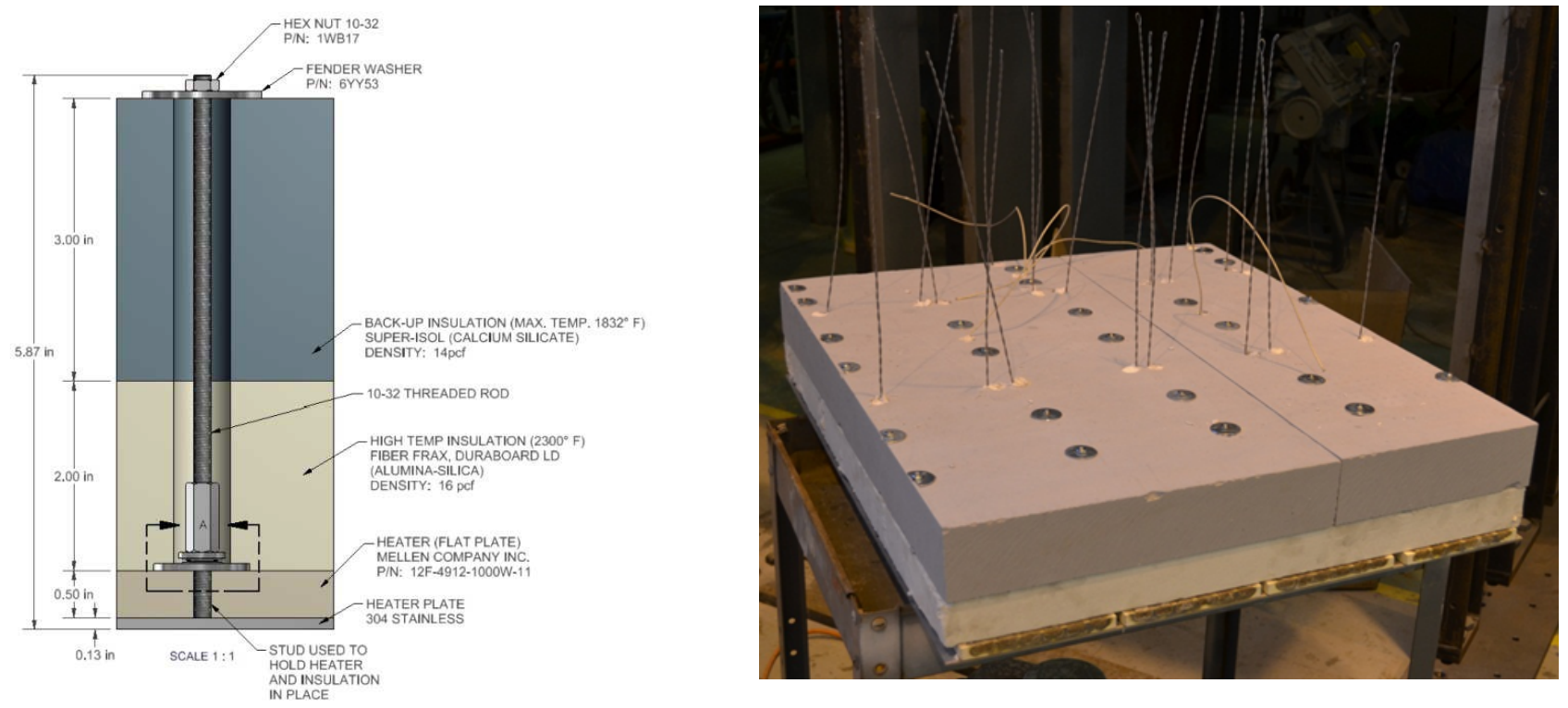

Figure 18: Heated wall, heater subpanel assembly 


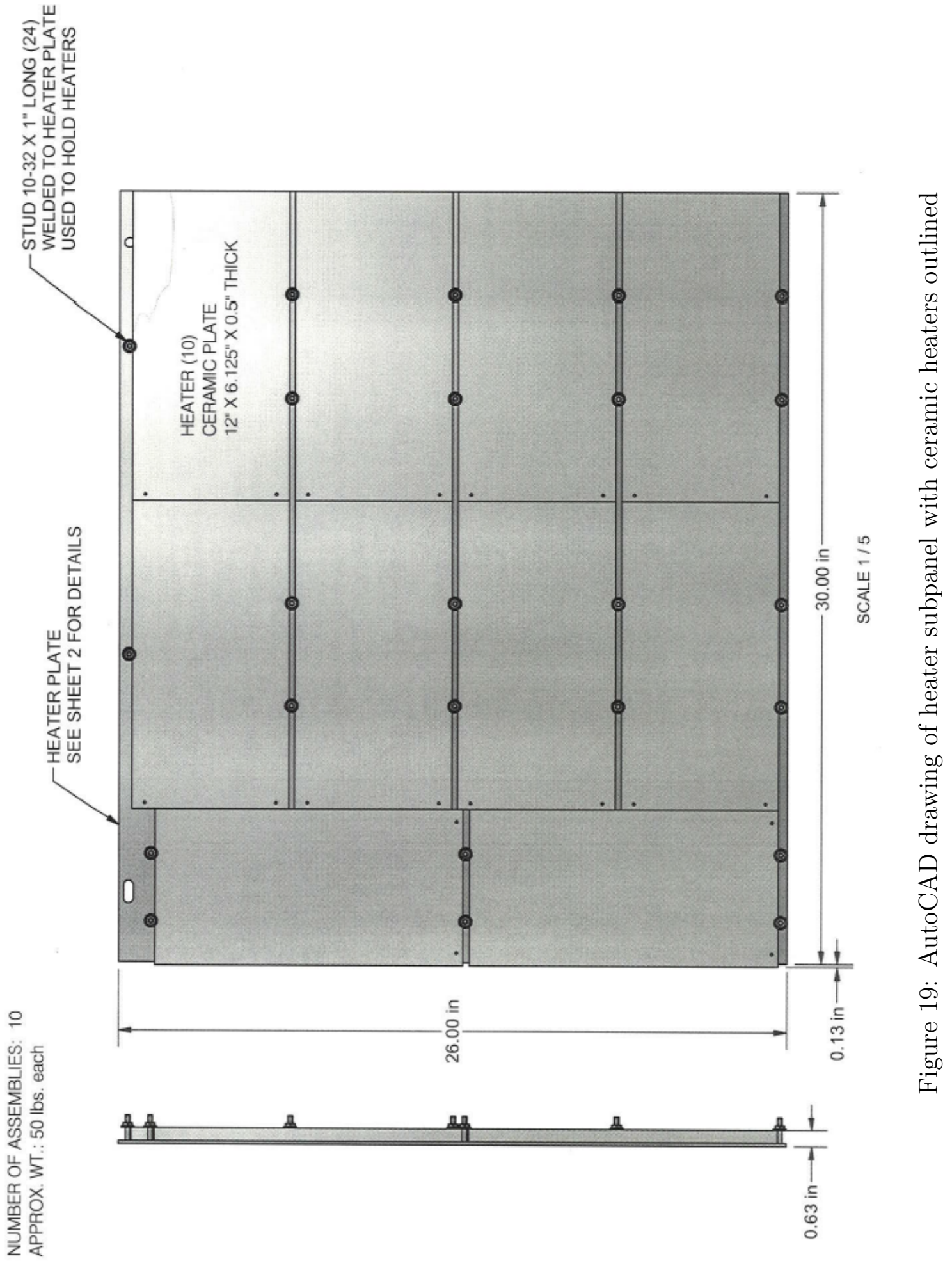




\subsubsection{Ceramic Heaters}

The heat source within the NSTF comprises an array of radiant heaters powered by 480 and 240 VAC. 200 individual ceramic heaters, each measuring 6"x12"x0.5", are capable of supplying up to $1,100 \mathrm{~W}$ each, totaling a maximum available power of $220 \mathrm{~kW}$. These 200 individual plates are grouped into 40 control zones, 20 designated as the "main" and 20 as the "guard" zones. Each "main" consists of 8 ceramic heater plates, while each "guard" consists of 2 ceramic heater plates, Figure 20. The parallel series connections of each Main and Guard result in 120VAC across any individual heater element.

These 40 control zones produce a power distribution that provides $80 \%$ of the total from the Main and the remaining 20\% from the Guard zones. For the purposes of test operations, power is primarily supplied to the Main zones while the Guards are adjusted to maintain a uniform temperature distribution across the heated plate, minimizing thermal gradients and reducing stresses.

\subsubsection{Heated Wall Insulation Panels}

The outside insulation panels on the heated wall, installed in four vertical rows, are constructed from framed assembly that is similar to the opposing cold wall insulation panels. A sheet metal framework houses two stacks of of 3 " insulation (6" in total), and is protected on the exterior surface by $1 / 8$ " aluminum sheet metal panel. Each panel weighs approximately 270 lbs., and has mounting provisions for hoisting and lifting operations. 


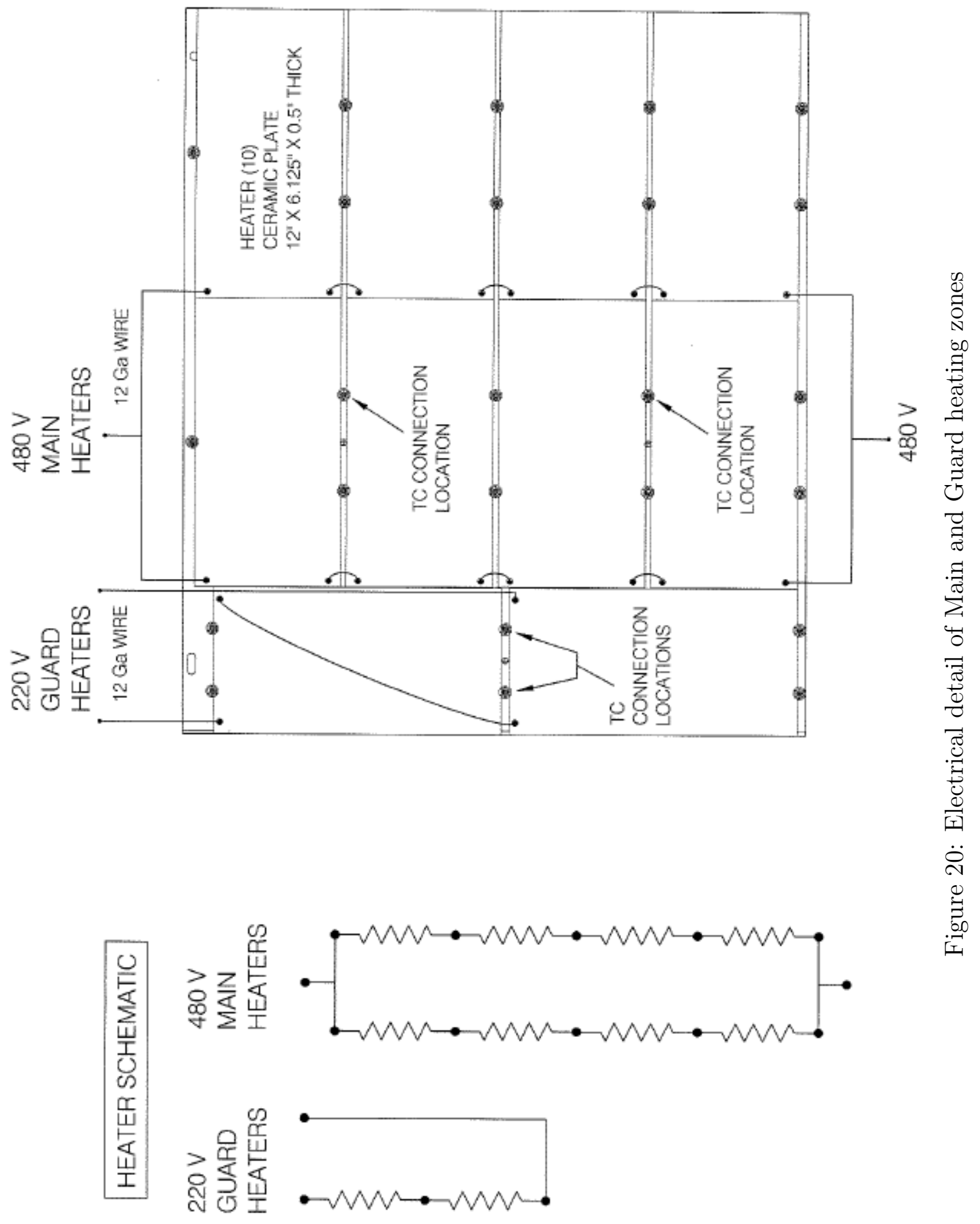




\subsection{Chimney stacks}

The chimney in the NSTF consists of dual ductwork assemblies that provide the necessary driving head and chimney effect to transport the heated gases to the outside environment. The ducts, constructed from 24" diameter, 14 gauge galvanized steel, and are wrapped in 3" of mineral wool followed by a 0.016 " protective aluminum jacket. The ductwork model was designed to preserve the thermal hydraulic flow patterns observed in full scale simulations while also catering to the physical requirements of the building space. Thus, the end product is an intricate flow path that includes multiple elbows of varying degrees, vertical, horizontal, and sloped duct runs. A design priority was placed on flexibility in forming alternative networks for varying flow path configurations. Included are 5 butterfly valves (loafers) and two forced fan loft blowers for isothermal testing, Figure 21.

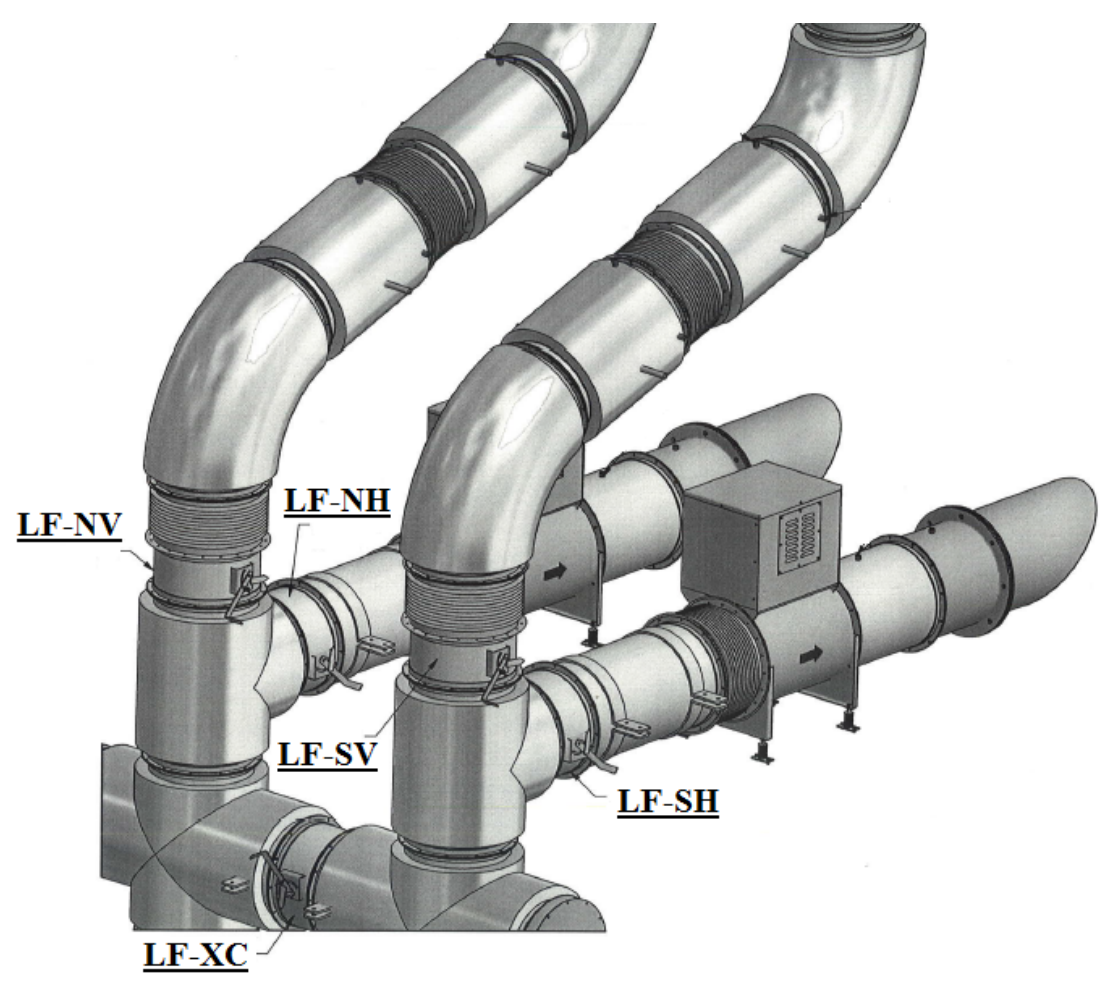

Figure 21: Variable component locations on chimney ducting. Five butterfly valves and dual forced blowers 


\subsubsection{Vertical and Horizontal Exhaust Configurations}

The standard or baseline configuration for the chimney duct work removes the heated gas via both north and south segments along the full elevation of the network piping, ultimately exiting from the vertical stacks extending through the building's roof. The alternative configuration, which is used during isothermal benchmarks or at a reduced atmospheric discharge, closes the vertical stack dampers and vents air through the building's east wall. Either flow path runs through several network segments, comprising of elbows, straight lengths, bellows, damper valves, etc..

The equivalent flow paths, as measured from the exit of the outlet plenum, measures 826.13" for the vertical and 470.37" for the horizontal configurations. A detailed breakdown of the various network segments for both configurations is provided in Table 2, and visual provided in Figure 22.

Table 2: Ducting segment types and equiv. lengths for horizontal and vertical flow paths

\begin{tabular}{cccl}
\hline Seg. \# & Radius & Eqv. Run & \multicolumn{1}{c}{ Seg. Type } \\
\hline 1 & $36 ”$ in & $56.55 "$ & $90^{\circ}$ elbow \\
2 & 36 in & 28.27 & $45^{\circ}$ elbow \\
3 & $n / a$ & 22.00 & Straight \\
4 & 36 & 28.27 & $45^{\circ}$ elbow \\
5 & $n / a$ & 13.75 & Bellows \\
6 & 36 & 56.55 & $90^{\circ}$ elbow \\
7 & $n / a$ & 13.75 & Bellows \\
8 & $n / a$ & 42.00 & 4-way \\
9 & $n / a$ & 40.00 & Tee (straight thru.) \\
10 & $n / a$ & 12.00 & Valve \\
11 & $n / a$ & 13.75 & Bellows \\
12 & 36 & 44.61 & $90^{\circ}$ elbow \\
13 & $n / a$ & 36.13 & Straight \\
14 & $n / a$ & 13.75 & Bellows \\
15 & $n / a$ & 36.13 & Straight \\
16 & 36 & 44.61 & $90^{\circ}$ elbow \\
17 & $n / a$ & 324.00 & Straight \\
& & $\mathbf{8 2 6 . 1 3}$ & inch total \\
\hline
\end{tabular}

\begin{tabular}{cccl}
\hline Seg. \# & Radius & Eqv. Run & \multicolumn{1}{c}{ Seg. Type } \\
\hline 1 & $36 "$ & $56.55 "$ & $90^{\circ}$ elbow \\
2 & 36 & 28.27 & $45^{\circ}$ elbow \\
3 & $n / a$ & 22.00 & Straight \\
4 & 36 & 28.27 & $45^{\circ}$ elbow \\
5 & $n / a$ & 13.75 & Bellows \\
6 & 36 & 56.55 & $90^{\circ}$ elbow \\
7 & $n / a$ & 13.75 & Bellows \\
8 & $n / a$ & 42.00 & 4-way \\
9 & 20 & 31.42 & Tee (side port) \\
10 & $n / a$ & 12.00 & Valve \\
11 & $n / a$ & 43.00 & Straight \\
12 & $n / a$ & 13.75 & Bellows \\
13 & $n / a$ & 31.06 & Fan blower \\
14 & $n / a$ & 30.00 & Straight \\
15 & $n / a$ & 48.00 & Tappered straight \\
& & $\mathbf{4 7 0 . 3 7}$ & inch total \\
& & & \\
& & &
\end{tabular}



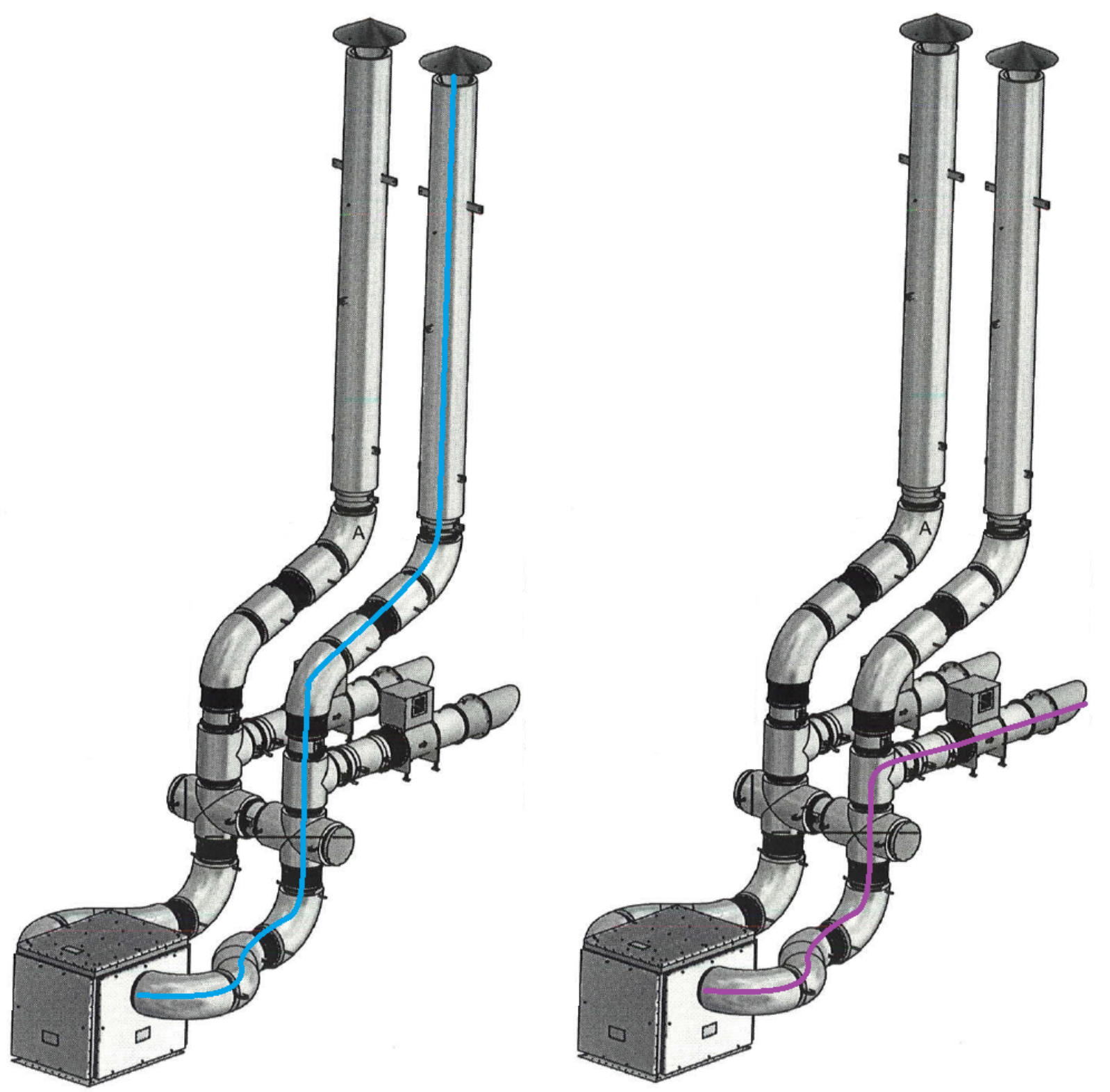

Figure 22: Flow paths for chimney ducting (single path shown for clarity). Baseline 'Vertical' in blue, alternative 'horizontal' in purple 


\subsubsection{Forced Flow Benchmark}

The fan loft blowers, model 24 AFB-H purchased from Air Products Equipment Co., are powered by 3-phase 460VAC power and controlled by a variable frequency drive (VFD) up to $1,725 \mathrm{RPM}$. They are able to withstand temperatures up to $500^{\circ} \mathrm{F}$, and thus suitable for active heating operation in the NSTF. The primary purpose of these blowers is to obtain isothermal flow to benchmark and verify the working state of instrumentation, and also to provide a safety mechanism in the event of an overheated temperature condition. A relation to the system flow rate and driven frequency of the twin fan loft blowers is provided in Figure 23.

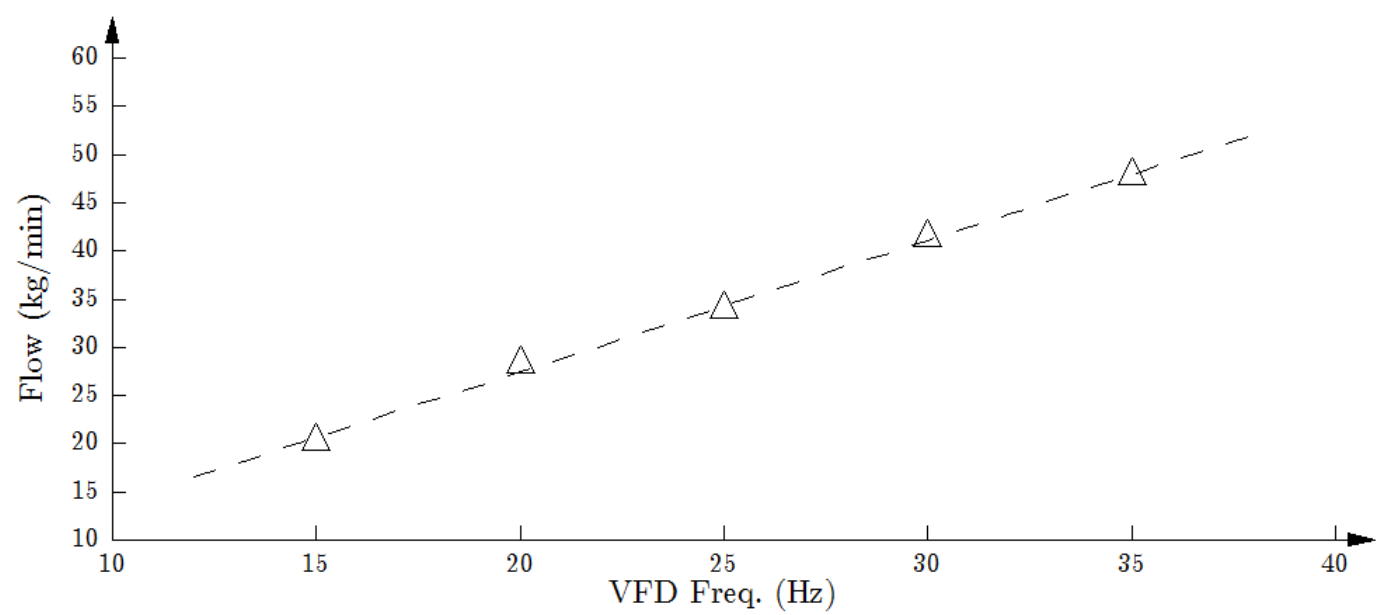

Figure 23: Flow vs frequency for dual fan loft blowers

\subsection{Insulation}

In an effort to reduce heat losses to the ambient surroundings, the NSTF is heavily insulated in primary control areas at or after the heat source. Non-insulated areas include the inlet downcomer, inlet plenum, and horizontal chimney ducts. SuperIsol ${ }^{\circledR}$ was used on all test section insulated panels and walls, Duraboard $\mathrm{LD}^{\circledR}$ was used as the backing for the ceramic heaters, Enerywrap $80^{\circledR}$ was used for the chimney ductwork, and Durablanket $\mathrm{S}^{\circledR}$ was used as filler and patchwork in smaller areas throughout. Thermal specifications and properties 
of the insulation materials used are provided in Table 3.

Table 3: Material and thermal specifications for NSTF insulation

\begin{tabular}{|c|c|c|c|c|c|c|}
\hline Name & Thickness & Max Temp & Density & \multicolumn{3}{|c|}{$\begin{array}{c}\text { Thermal Conductivity } \\
\left(\text { BTU-in } / \mathrm{hr}^{-} \mathrm{ft}^{2}-{ }^{\circ} \mathbf{F}\right)\end{array}$} \\
\hline Super Isol $^{\circledR}$ & $3 "$ & $1,800{ }^{\circ} \mathrm{F}$ & $16 \mathrm{pcf}$ & $\begin{array}{c}400{ }^{\circ} \mathrm{F} \\
0.416\end{array}$ & $\begin{array}{c}750{ }^{\circ} \mathrm{F} \\
0.554\end{array}$ & $\begin{array}{c}1100^{\circ} \mathrm{F} \\
0.693\end{array}$ \\
\hline Duraboard LD ${ }^{\circledR}$ & $2 "$ & $2,300^{\circ} \mathrm{F}$ & $16 \mathrm{pcf}$ & $\begin{array}{c}400{ }^{\circ} \mathrm{F} \\
0.55\end{array}$ & $\begin{array}{c}1000{ }^{\circ} \mathrm{F} \\
0.847\end{array}$ & $\begin{array}{c}1600{ }^{\circ} \mathrm{F} \\
1.339\end{array}$ \\
\hline Durablanket $\mathrm{S}^{\circledR}$ & $1 "$ & $2,150^{\circ} \mathrm{F}$ & 8 pcf & $\begin{array}{c}600{ }^{\circ} \mathrm{F} \\
0.56\end{array}$ & $\begin{array}{c}1000^{\circ} \mathrm{F} \\
0.977\end{array}$ & $\begin{array}{l}1600^{\circ} \mathrm{F} \\
2.003\end{array}$ \\
\hline Enerywrap $80^{\circledR}$ & $3 "$ & $1,200^{\circ} \mathrm{F}$ & 8 pcf & $\begin{array}{c}75^{\circ} \mathrm{F} \\
0.71\end{array}$ & $\begin{array}{c}200{ }^{\circ} \mathrm{F} \\
0.90\end{array}$ & $\begin{array}{c}300^{\circ} \mathrm{F} \\
1.08\end{array}$ \\
\hline
\end{tabular}

Figure 24 shows a north facing cross section of the heated cavity, which identifies the various types of insulation and thicknesses used to retain thermal energy within the enclosure. The north and south walls (not shown) are of similar construction to the west wall, and ultimately include the same 6" thickness of Duraboard LD ${ }^{\circledR}$ insulation. The east (heated) wall comprises a matrix of different materials, which was necessary to ensure compliance with the elevated temperatures found nearest the ceramic heaters. Insulation on the 24 " ductwork is included for all duct length with the exception of the inlet piping and horizontal fan loft forced blower segments. Nominally 24" inner diameter, a layer of 3" thick mineral wool insulation surrounds the bare ducts, which is further covered by a 0.016 " protective aluminum jacket. 


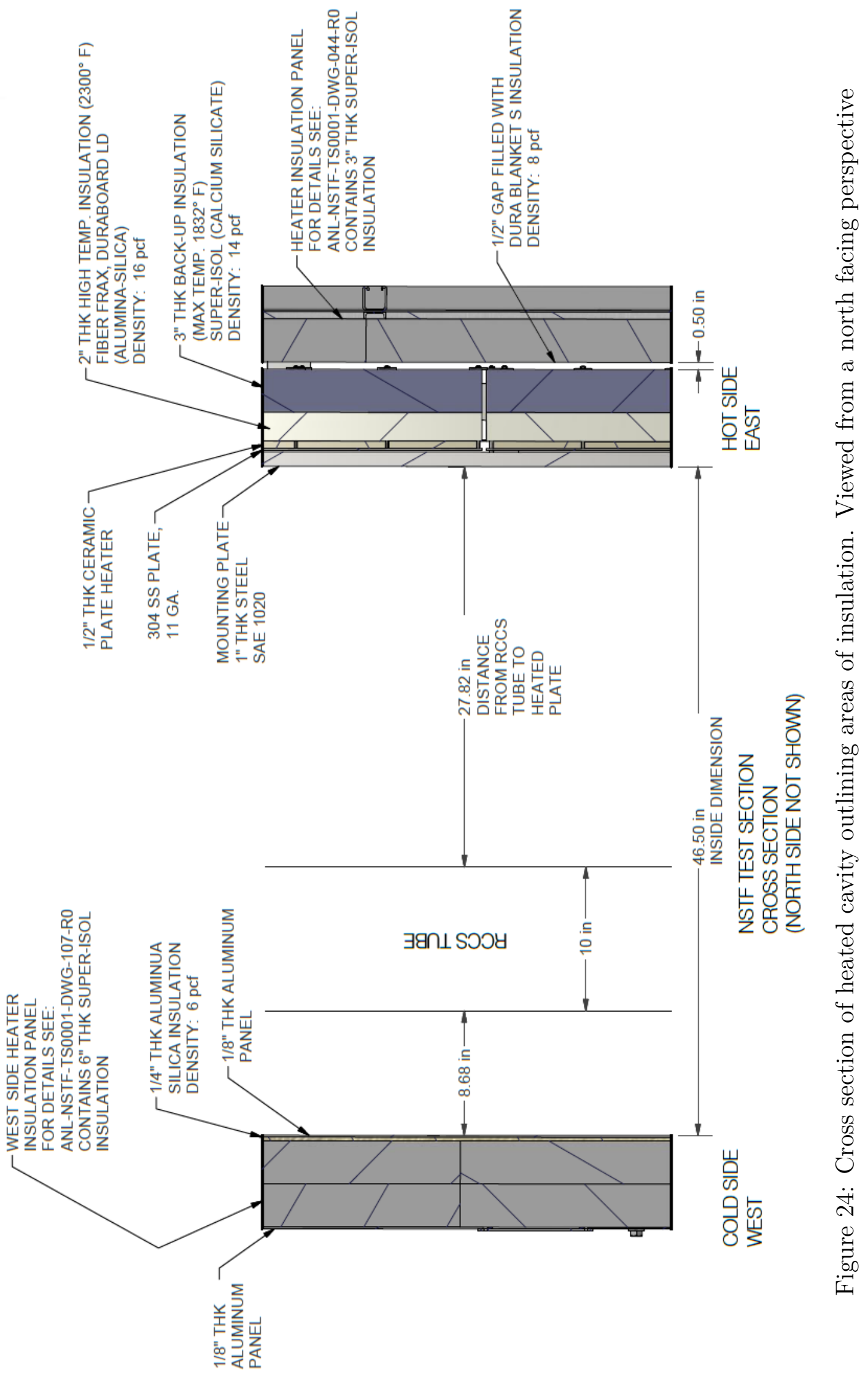




\subsection{As-built summary}

As described in sections above, the NSTF is a high-flexible experimental apparatus that can be re-configured to different testing states with minimal or reduced effort. The areas that have been designed specifically for reconfiguration include the heated wall to riser tube horizontal spacing, the extension of the riser ducts into the outlet plenum, and the presence of false walls on both the inlet and outlet plenum. These four areas are the primary variables that will be reconfigured in future test operations, but in their present state define the 'asbuilt' configuration of the NSTF, Figure 25.

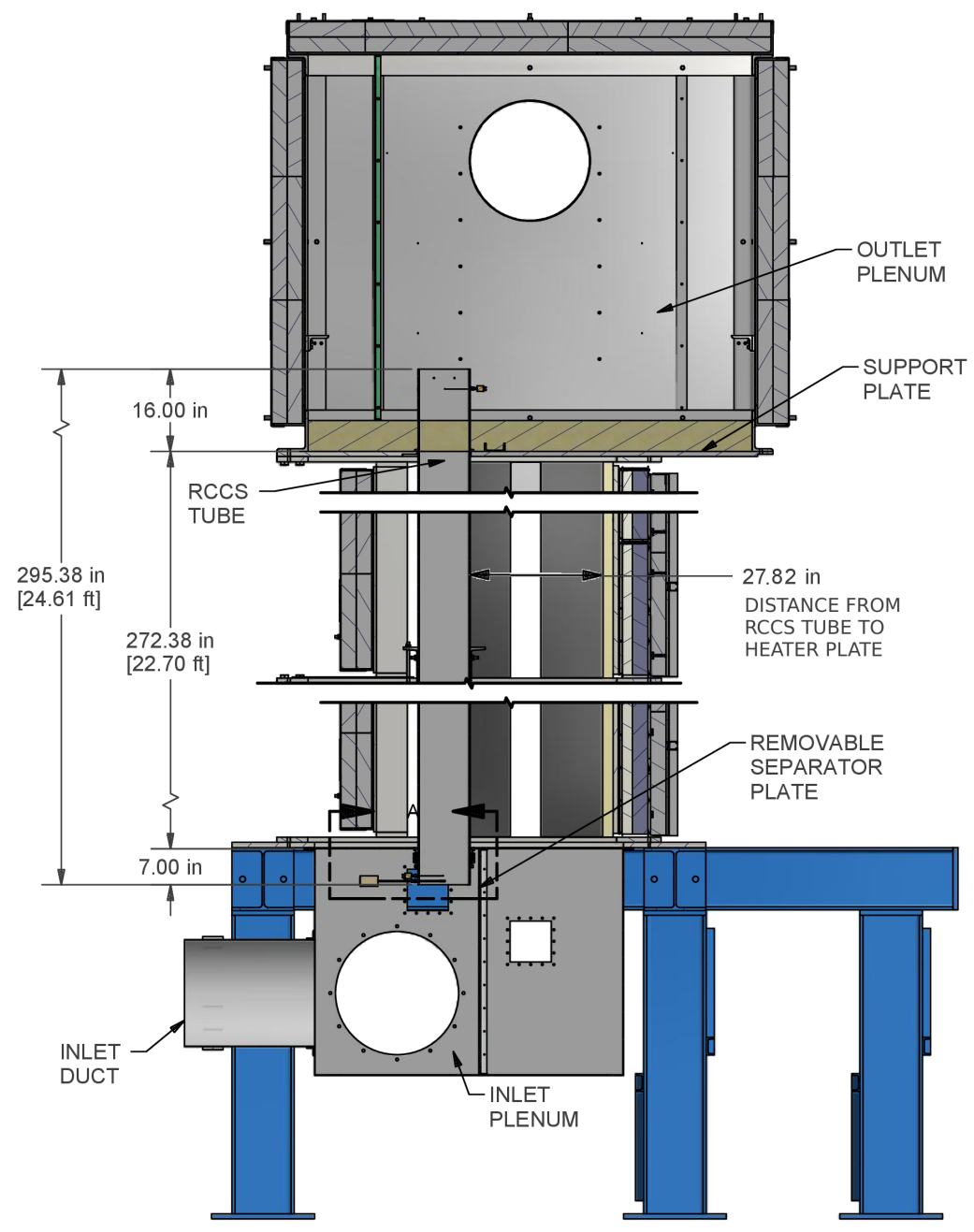

Figure 25: Primary areas of flexibility, dimensions shown for 'as-built' configuration 


\section{Chapter 4}

\section{Experiment Control}

The NSTF features a sophisticated suite of data acquisition and instrumentation for test operations in a dedicated control room, Figure 26. The data acquisition boards are placed at four points alongside the test section and routed to the central control station.

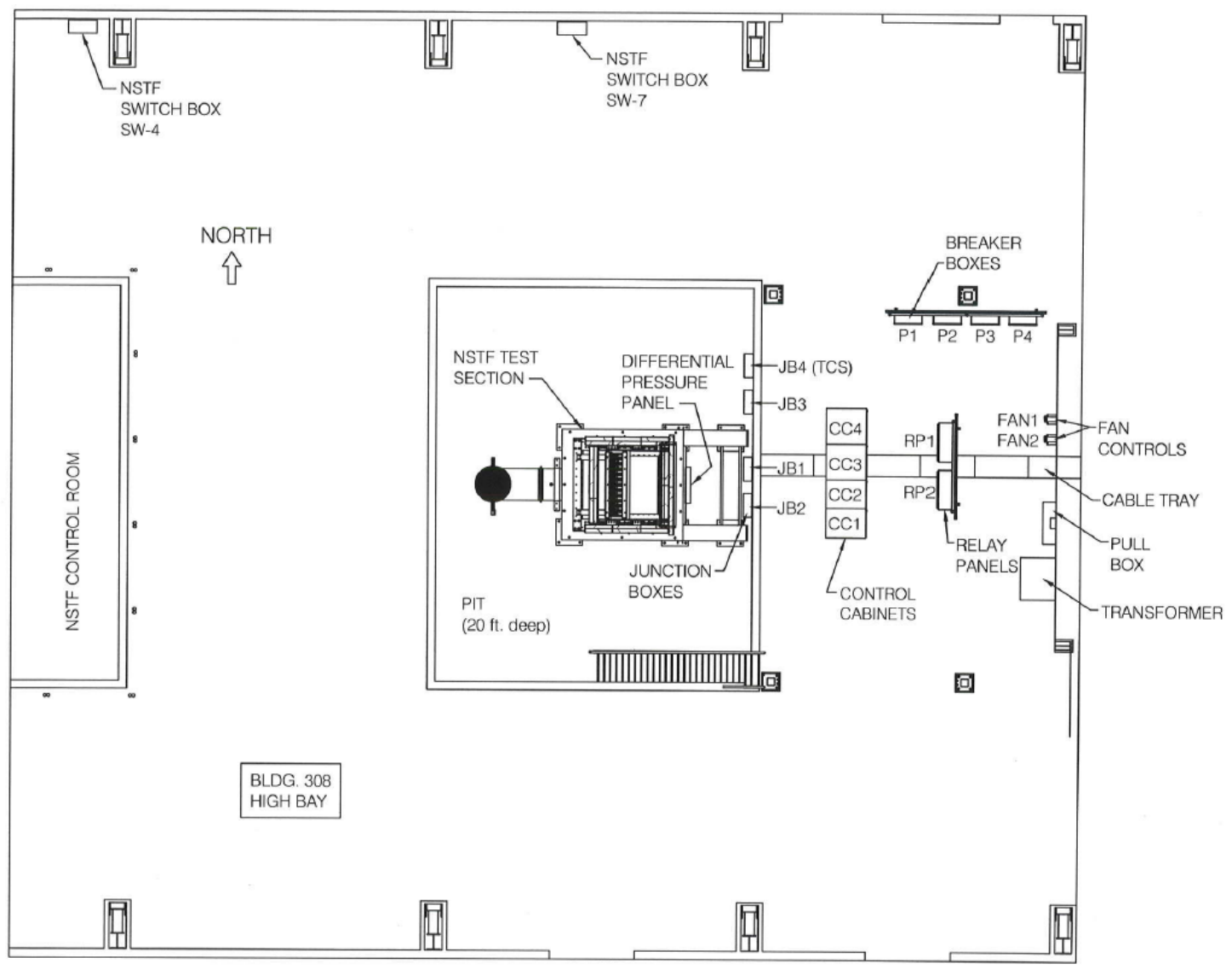

Figure 26: Plan view of Building 308 and NSTF test operations 


\subsection{Data Acquisition}

The data acquisition and control suite comprises several individual devices that have all been linked to the primary control computer via TCP/IP and a central switch, Figure 27. This network was created to facilitate data logging and ensure synchronization across disparate devices. The control software is LabVIEW 2012, which interacts with all devices except the LUNA fiber optic system. The computational demands of the fiber hardware require a dedicated system, although remote viewing, control, and data file access are still possible during test operations.

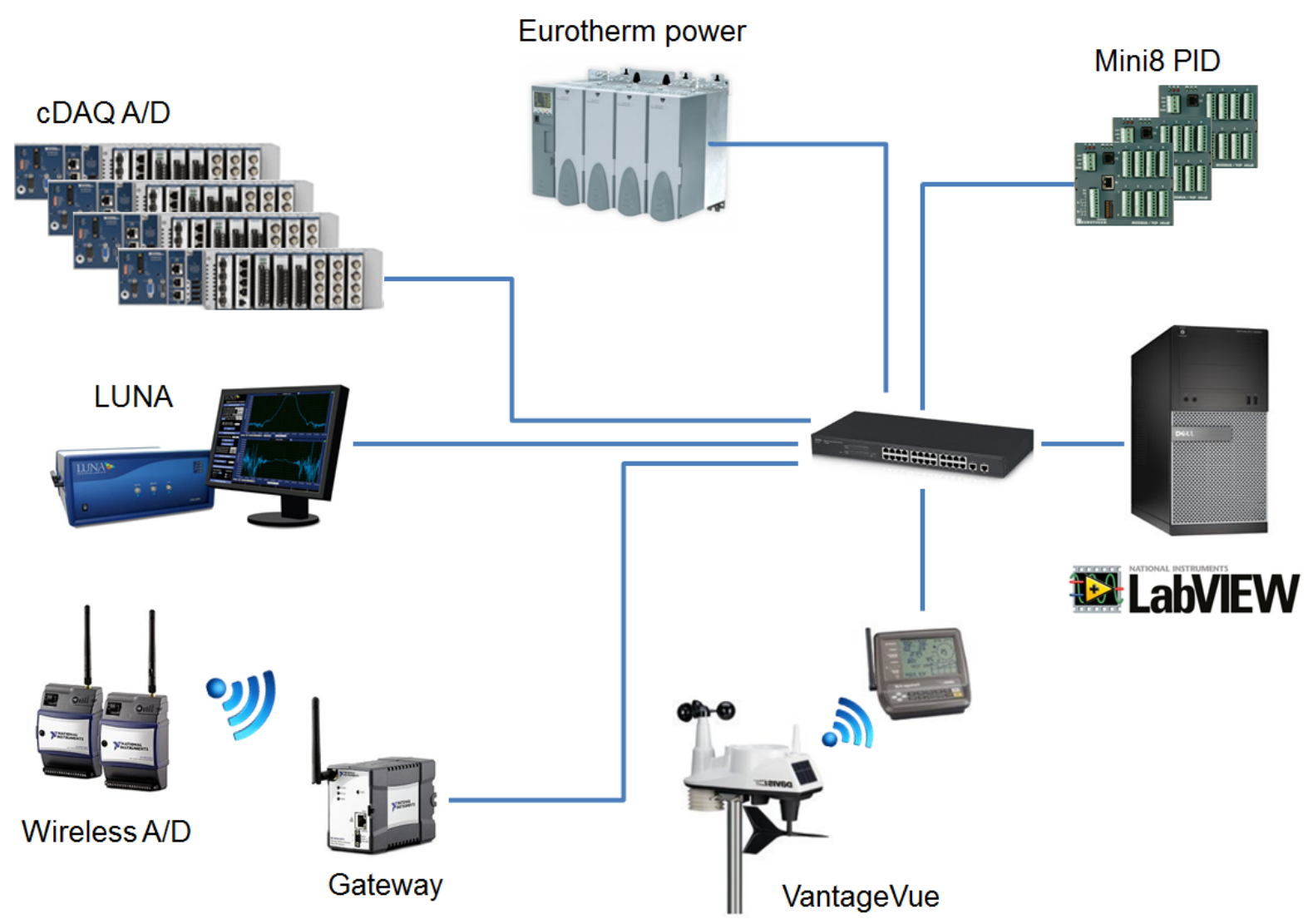

Figure 27: Communications overview

The core of the data acquisition system is four A/D converters housed in cDAQ chassis (cDAQ-9188 from National Instruments) which provide access to all the thermocouples, heat flux sensors, and analogue flow transmitters installed on the NSTF. Each cDAQ can 
be filled with up to eight cards for various analogue input/output requirements. The NSTF is currently fitted with twenty-six NI-9214 cards, each able to read sixteen high-resolution thermocouple input channels. Additionally, two NI-9205 cards provide sixteen -10-10VDC analogue input channels, and one NI-9265 provides four analogue output (4-20mA) for control of the chimney damper actuators. To measure temperature measurements along the chimney duct work, we have installed two wireless thermocouple transmitters, National Instruments model WSN-3212, which can monitor and relay a total of eight thermocouples back to a wireless receiver and read into the primary LabVIEW software. A summary of these National Instrument devices is provided in Table 4.

Table 4: Summary of National Instruments data aquisition devices

\begin{tabular}{cll}
\hline Qty. & \multicolumn{1}{c}{ Model } & \multicolumn{1}{c}{ Description } \\
\hline x4 & cDAQ-9188 & 8 slot cDAQ chassis \\
x26 & NI-9214 & 16-Channel Isothermal Thermocouple Input Module \\
x2 & NI-9205 & 32-Ch $\pm 200 \mathrm{mV}$ to $\pm 10 \mathrm{~V}, 16-B i t, 250 \mathrm{kS} / \mathrm{s}$ Analog Input Module \\
x2 & WSN-3212 & 4 Ch, 24-Bit, Programmable Thermocouple Input Node \\
x1 & NI-9265 & 4-Channel, 100 $\mathrm{kS} / \mathrm{s}, 16$-Bit, 0 to $20 \mathrm{~mA}$ Analog Output Module \\
\hline
\end{tabular}

\subsection{Heater Power Control}

The heated section can be operated in one of three different modes: i) constant heat flux $\left(21.6 \mathrm{~kW} / \mathrm{m}^{2}\right.$ maximum), ii) constant temperature $\left(677^{\circ} \mathrm{C}\right.$ maximum $)$, or iii) an arbitrary combination of these two modes. The 220 radiant heaters have been zoned into 40 control zones, 20 designated as the "main" and 20 as the "guard" zones, and produce a power distribution that provides $80 \%$ of the total from the Main and the remaining $20 \%$ from the Guard zones. The temperature and/or heat flux can be spatially controlled due to the fact that the heaters are zoned; the overall height is broken down into ten $67 \mathrm{~cm}$ long axial segments, while there are four azimuthal control zones at each axial elevation (two central zones plus two guard heater zones) yielding 40 control zones in total. 
The zones are powered by 40 Eurotherm EPower controllers, rated for $600 \mathrm{~V}$ at $50 \mathrm{~A}$. The units maintain target power within $+/-1 \%$ of full scale during any moderate variations in line voltage, load impedance, and ambient temperature. Controllers perform real time measurements of actual delivered power via internal measurements of supply voltage and current, which are both accurate to within $+/-1 \%$. These have been configured in 5 primary banks, each with 4 substations, and communicate directly with the central control station via the iTools control software. Each of the 40 Eurotherm controllers and accompanying heated zones is hard wired to a Mini8 temperature controller that is programmed to a prescribed temperature set point. Should the thermocouple at this zone reach the safety trip set points it will automatically trigger a signal to deactivate the related contactor and thus shut off all main power to the individual zone. A top-level wiring diagram of the heater power system and control is provided in Figure 28, and references to the full 40 zones and related naming conventions is provide in Appendix B.

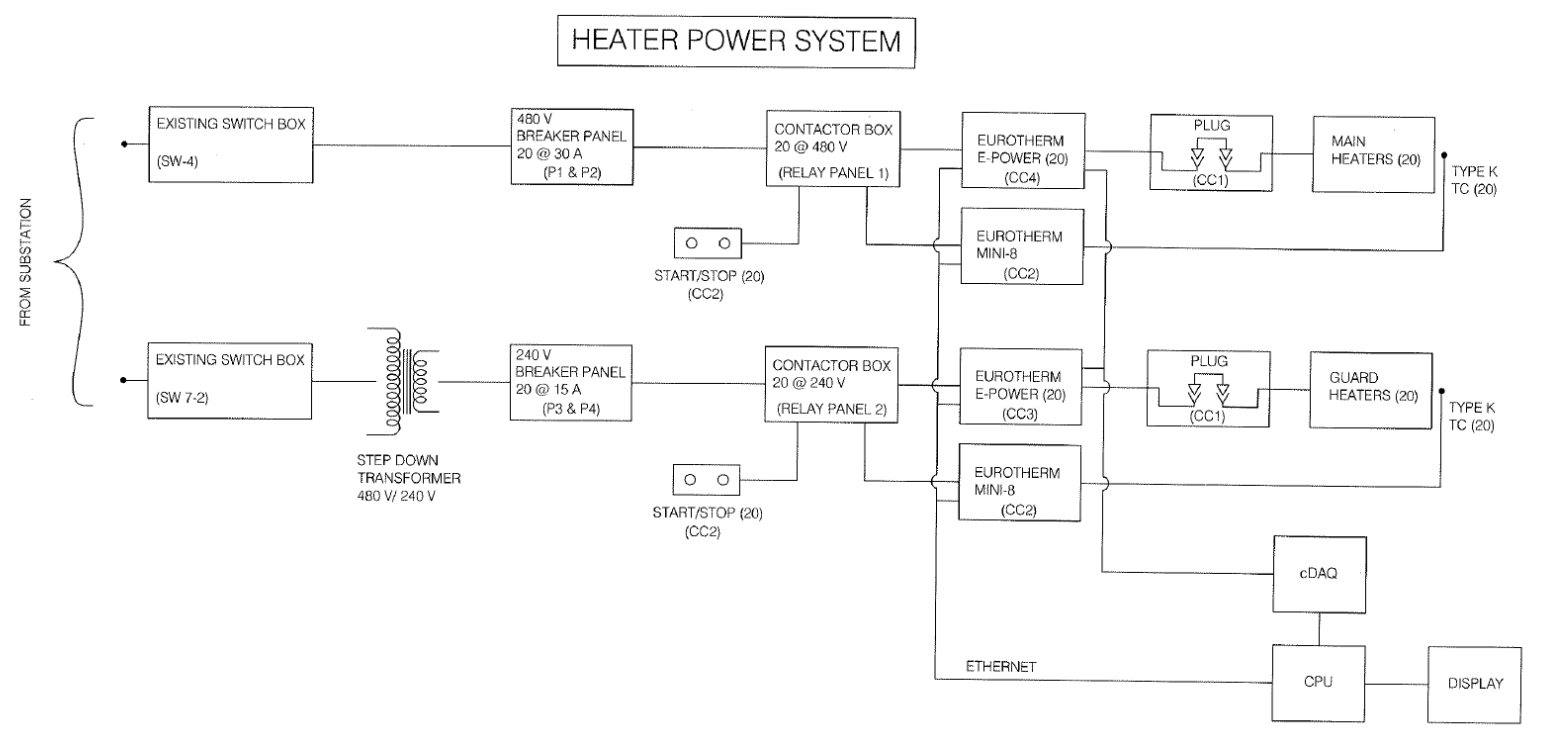

Figure 28: Eurotherm power and Mini electrical wiring

Actual power control for each of the Eurotherm zones is performed by the method of Phase Angle control, which varies the amount of each cycle which is applied to the load by switching the controller thermistor on part-way through the cycle. This method of power control is 
the preferred mode for true power control, and is receptive to online power verification by true RMS voltage and current measurements.

\subsection{Sensors}

Sensors positioned along the test assembly measure local surface temperatures, local and bulk air temperatures, air volumetric and mass flow rates, the total normal radiative and convective components of the total heat flux, the electric power input to the heaters, and the local and total or bulk heat flux. These data will be used to evaluate the heat removal performance for particular configurations and testing conditions. The primary measurement objective is to determine the local and bulk heat flux transport rates and associated heat transfer coefficients.

The following sections will supply detailed information about the instrumentation, which consists of thermocouples, differential pressure transducers, radiation and heat flux transducers, mass flow meters, and the wind monitor and humidity instrumentation. An overview summary is provided in Table 5 .

Table 5: NSTF Instrumentation Summary

\begin{tabular}{llccc}
\hline \multicolumn{1}{c}{ Measurement } & \multicolumn{1}{c}{ Location } & Quantity & Instrument & Range \\
\hline Mass flow rate & Inlet downcomer & x1 & Sierra 640S & $0-1 \mathrm{~kg} / \mathrm{s}$ \\
Pressure drop & Risers, chimneys & x10 & Dwyer 607 & $\pm 0.25 \mathrm{inH} 2 \mathrm{O}$ \\
Humidity & Inlet plenum & x1 & Dwyer RHP & $3-95 \% \mathrm{RH}$ \\
Heat flux & Riser wall & x16 & iTi BHT & $0-300 \mathrm{~kW} / \mathrm{m} 2$ \\
Meteorological & Building roof & x1 & Davis VantageVue & - \\
Temperature (TC) & throughout & x368 & Type-K & $-200-1,350{ }^{\circ} \mathrm{C}$ \\
Temperature (optic fiber) & Riser gas space, wall & x13 & LUNA & $20-200{ }^{\circ} \mathrm{C}$ \\
\hline
\end{tabular}

\subsubsection{Wall Thermocouples}

All NSTF thermocouples (a total of 368) are type- $\mathrm{K}$ with an accuracy of $+/-2.2^{\circ} \mathrm{C}$ or $0.75 \%$ of measured temperature. The vast majority of these sensors are located on the heated plates and surrounding insulated panels. Sensors are flush-mounted for accurate measurement of 
surface temperatures without disruption of the flow field.

Figure 29 shows the installation method used for the heated plate TCs. Sensor wires were passed through the plates from the opposite side of the 1-in thick steel plates through a 5/32-in. dia. hole that is countersunk $90^{\circ}$ to a $1 / 4$-in. opening. A high-temperature thermal cement is used to bond junctions to the plate. Note that the wires are not joined at the junction and so the electrical circuit is completed through the steel plate. This allows detachment of the wire from the plate to be detected as an open circuit, which is not the case if the wires are bonded together at the junction as in conventional configurations.

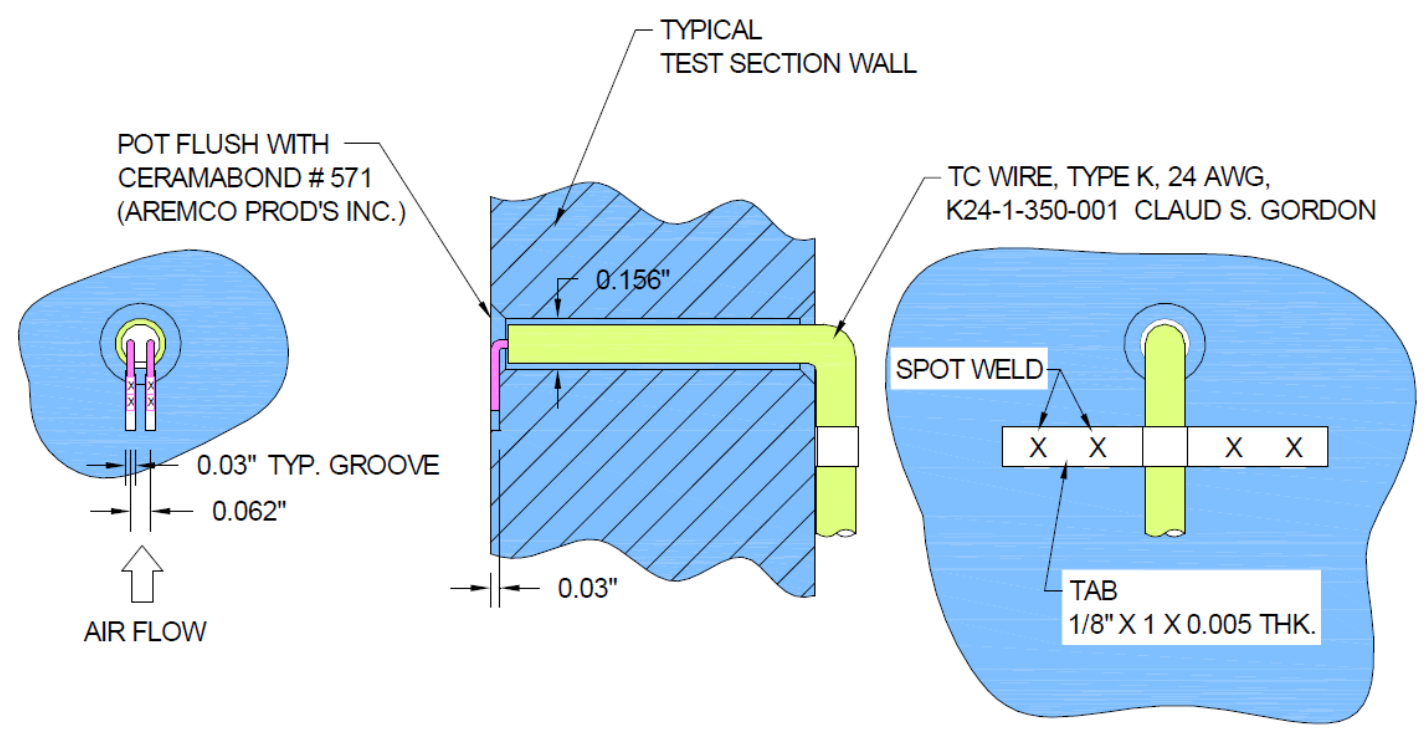

Figure 29: Heated plate thermocouple mounting method

The locations of the TC hole penetrations in the heated plates are provided on the following pages, along with those positioned on the opposing west wall, the adjacent northsouth walls, and outlet plenum panels (five in total, plenum floor omitted). 
Design Report for the $1 / 2$ Scale Air-Cooled RCCS Tests in the NSTF

June 2014

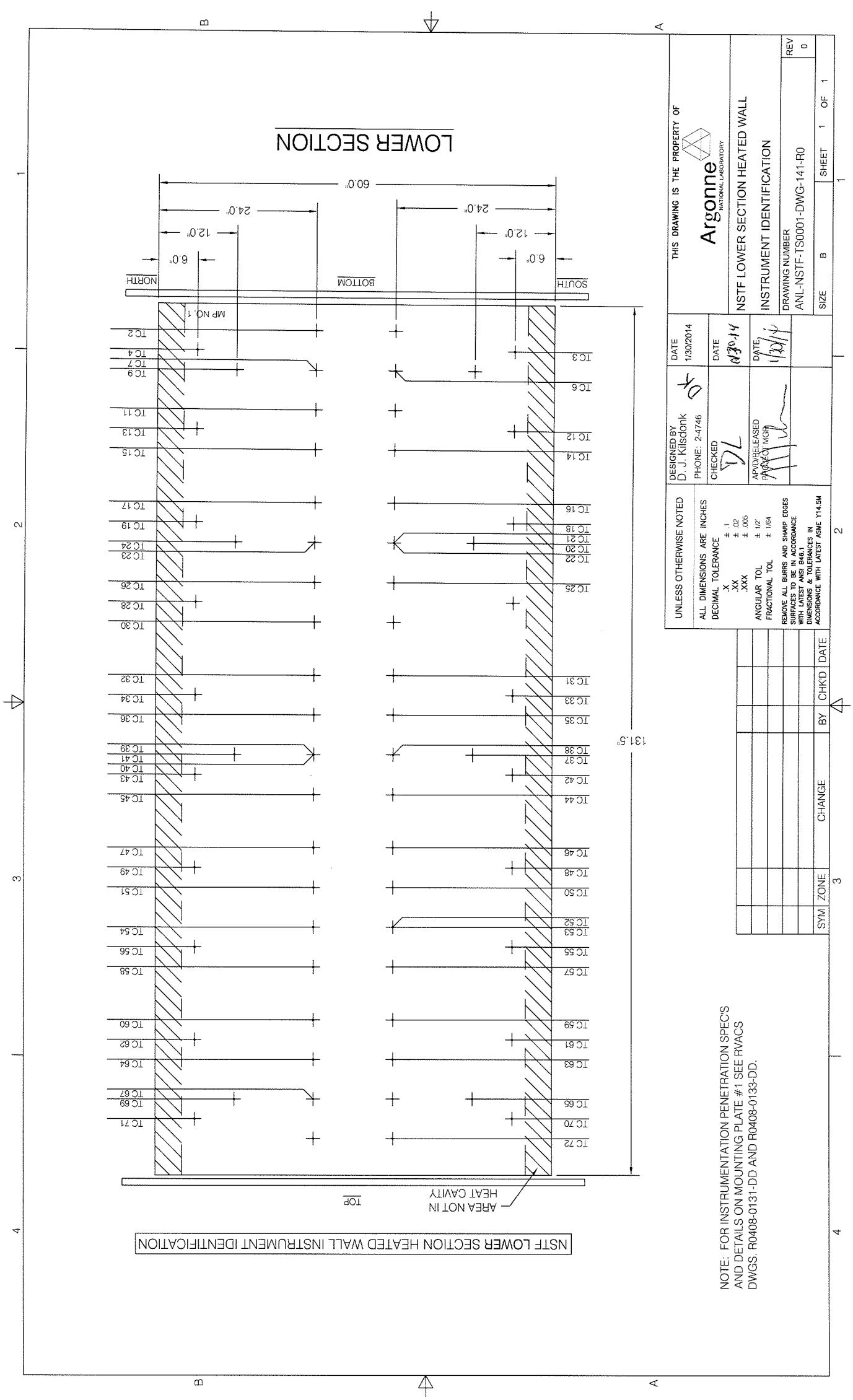




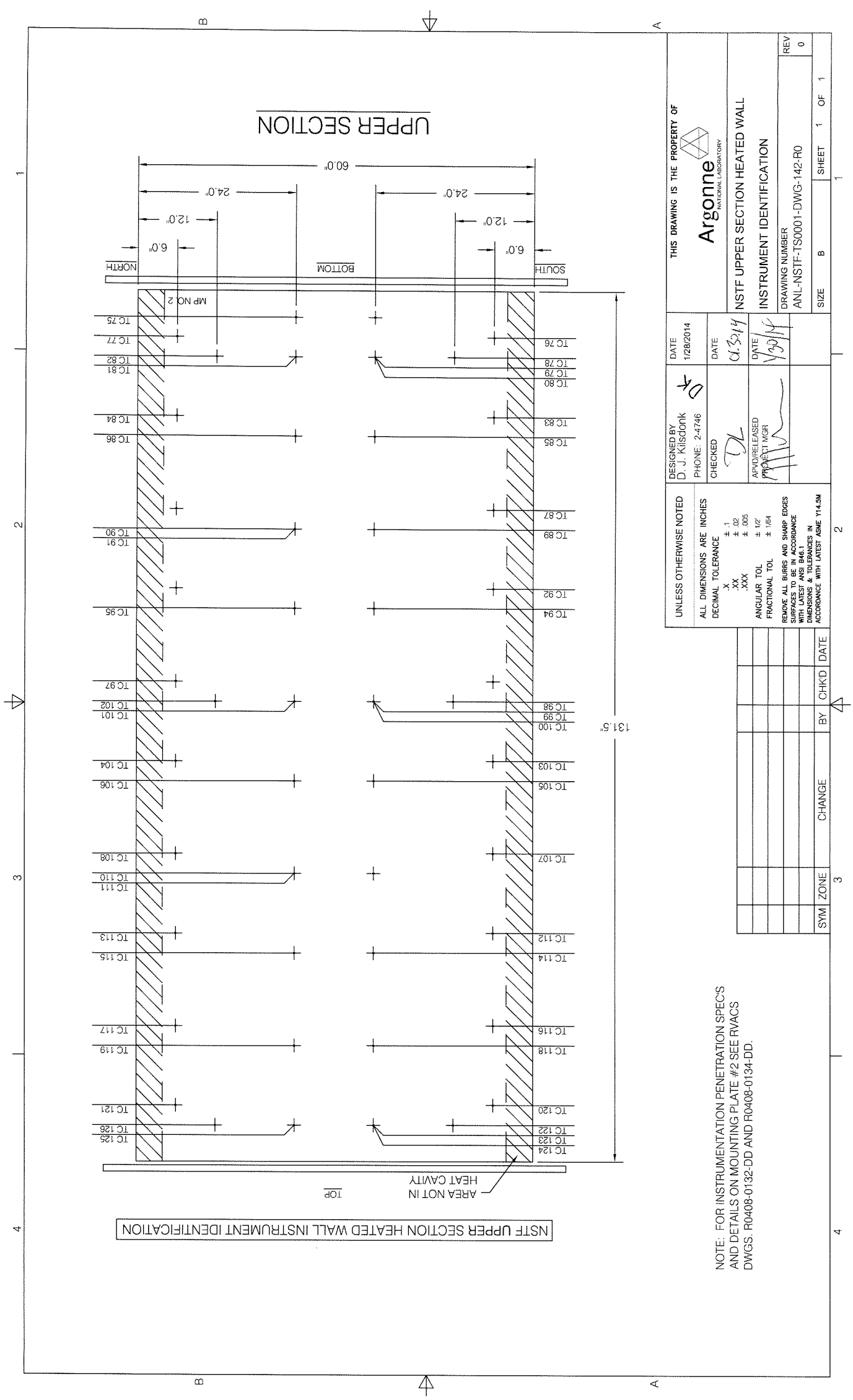


Design Report for the $1 / 2$ Scale Air-Cooled RCCS Tests in the NSTF

June 2014

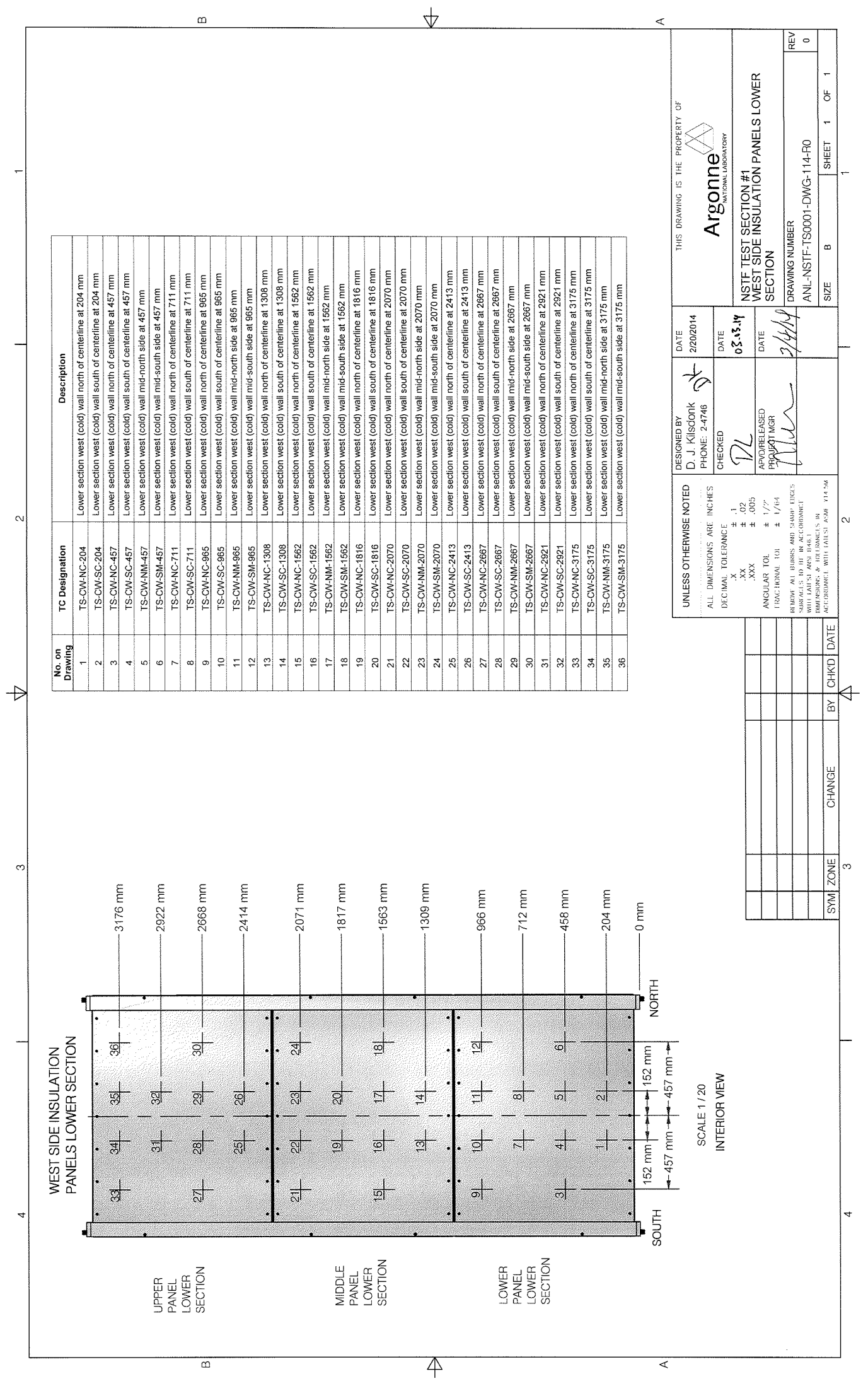




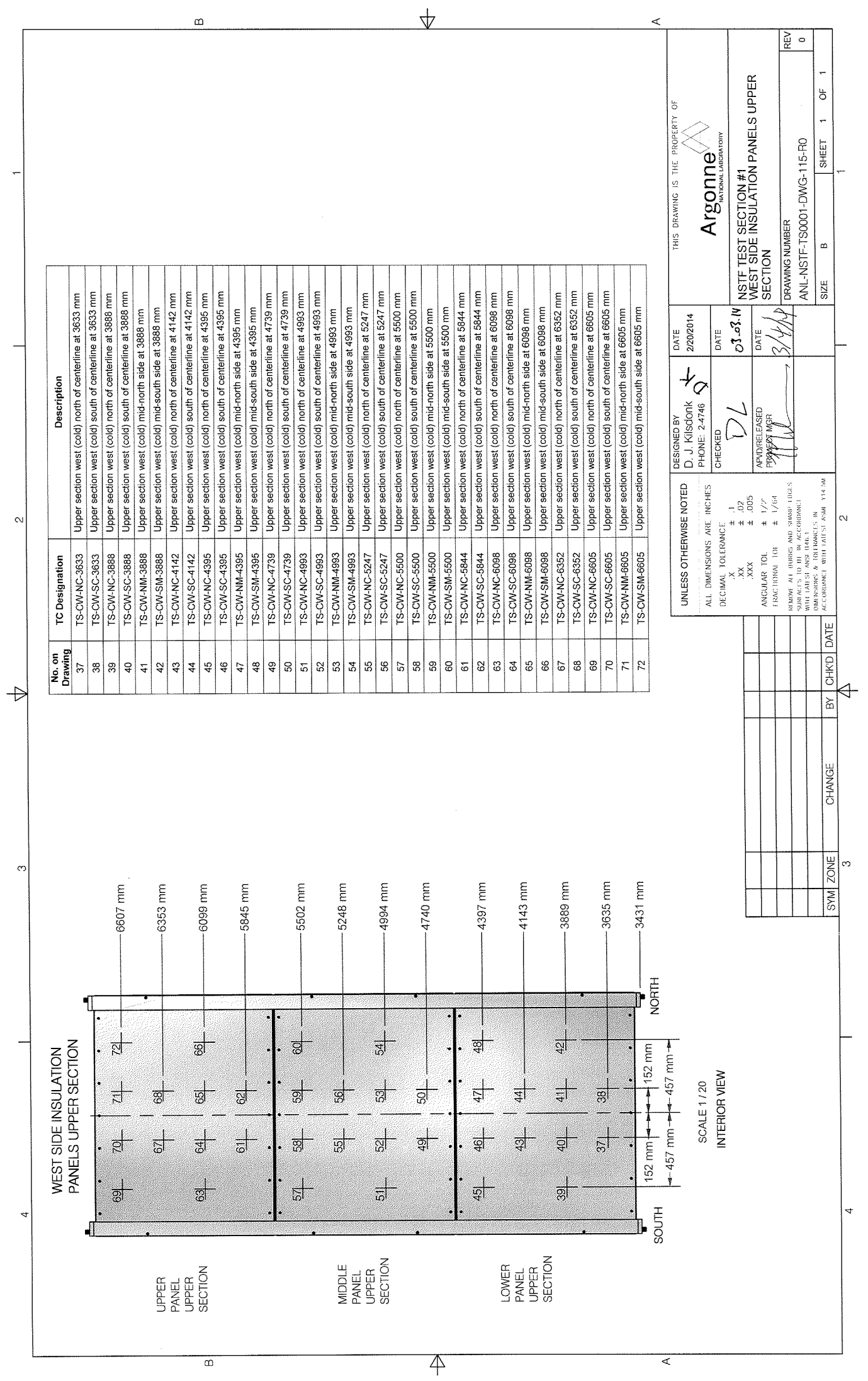


Design Report for the $1 / 2$ Scale Air-Cooled RCCS Tests in the NSTF

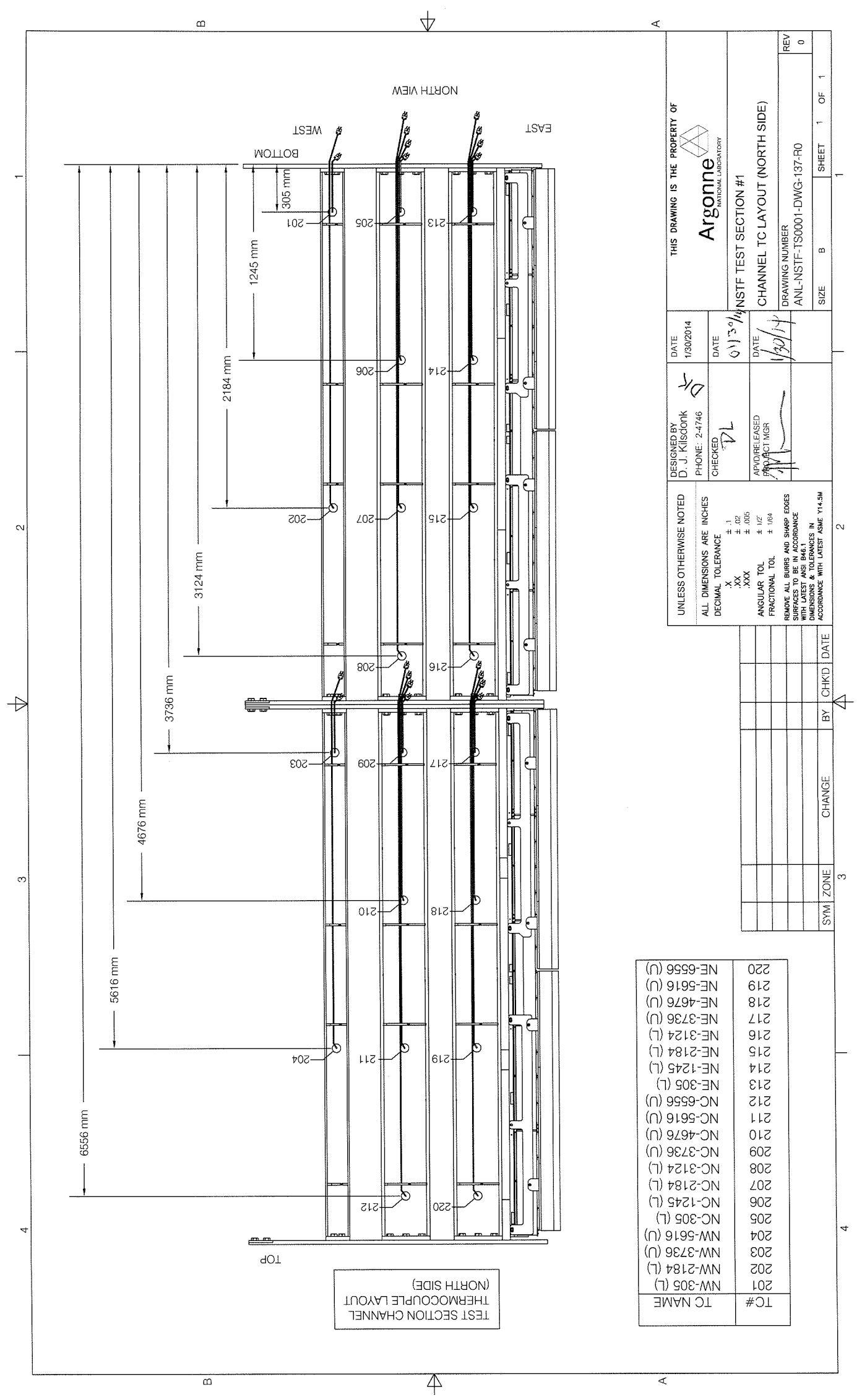


Design Report for the $1 / 2$ Scale Air-Cooled RCCS Tests in the NSTF

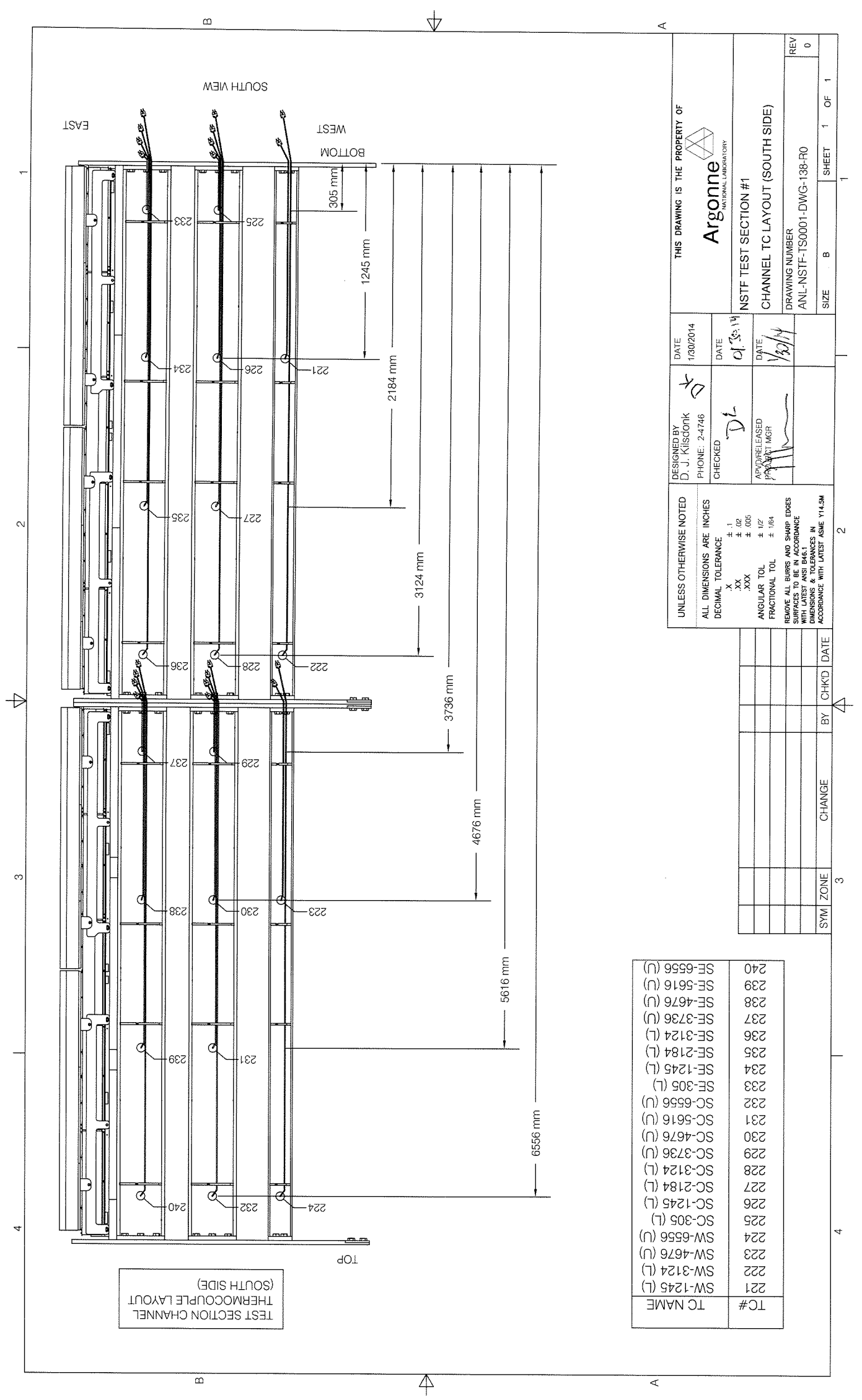


Design Report for the $1 / 2$ Scale Air-Cooled RCCS Tests in the NSTF

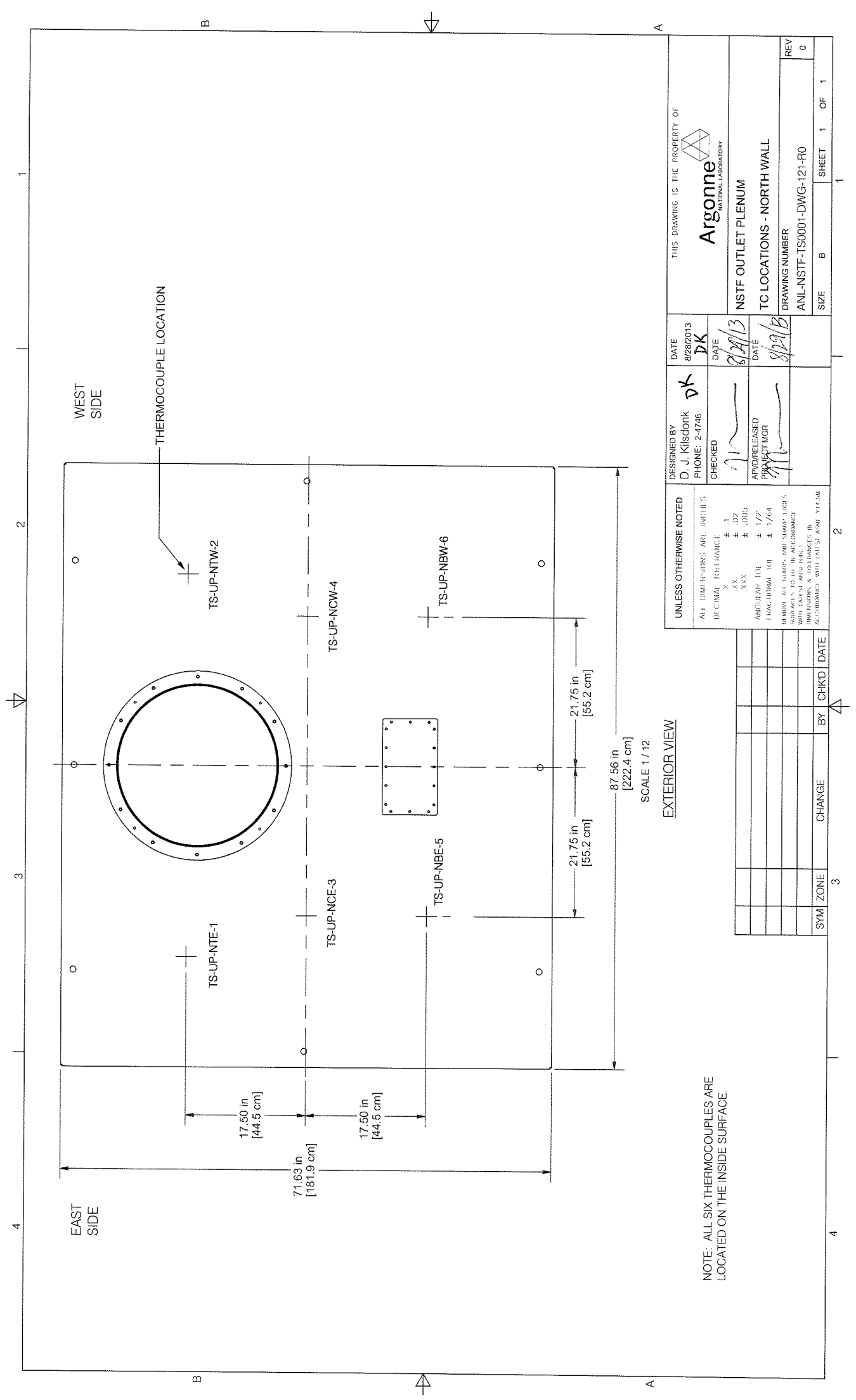


Design Report for the $1 / 2$ Scale Air-Cooled RCCS Tests in the NSTF June 2014

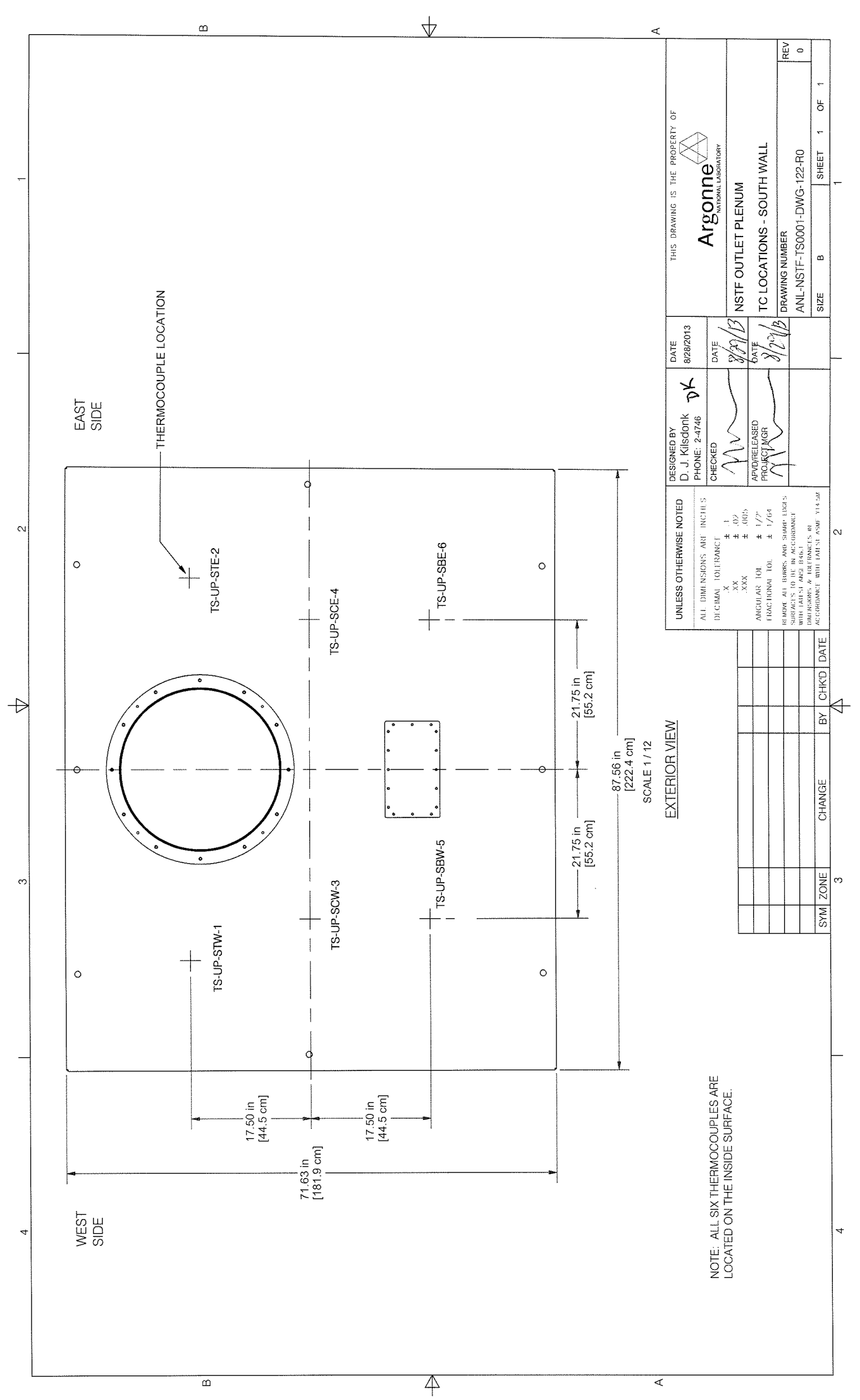


Design Report for the $1 / 2$ Scale Air-Cooled RCCS Tests in the NSTF

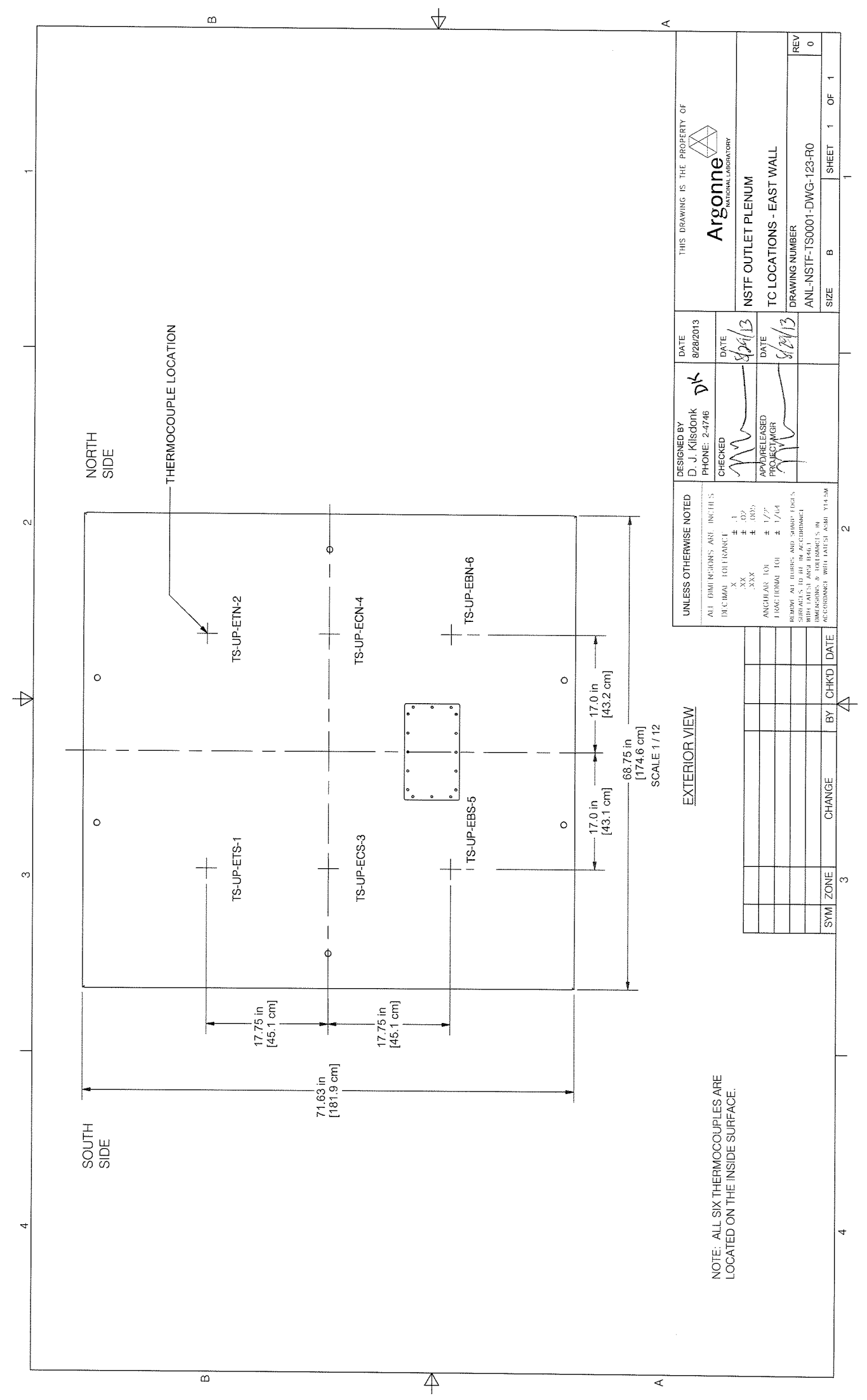


Design Report for the $1 / 2$ Scale Air-Cooled RCCS Tests in the NSTF

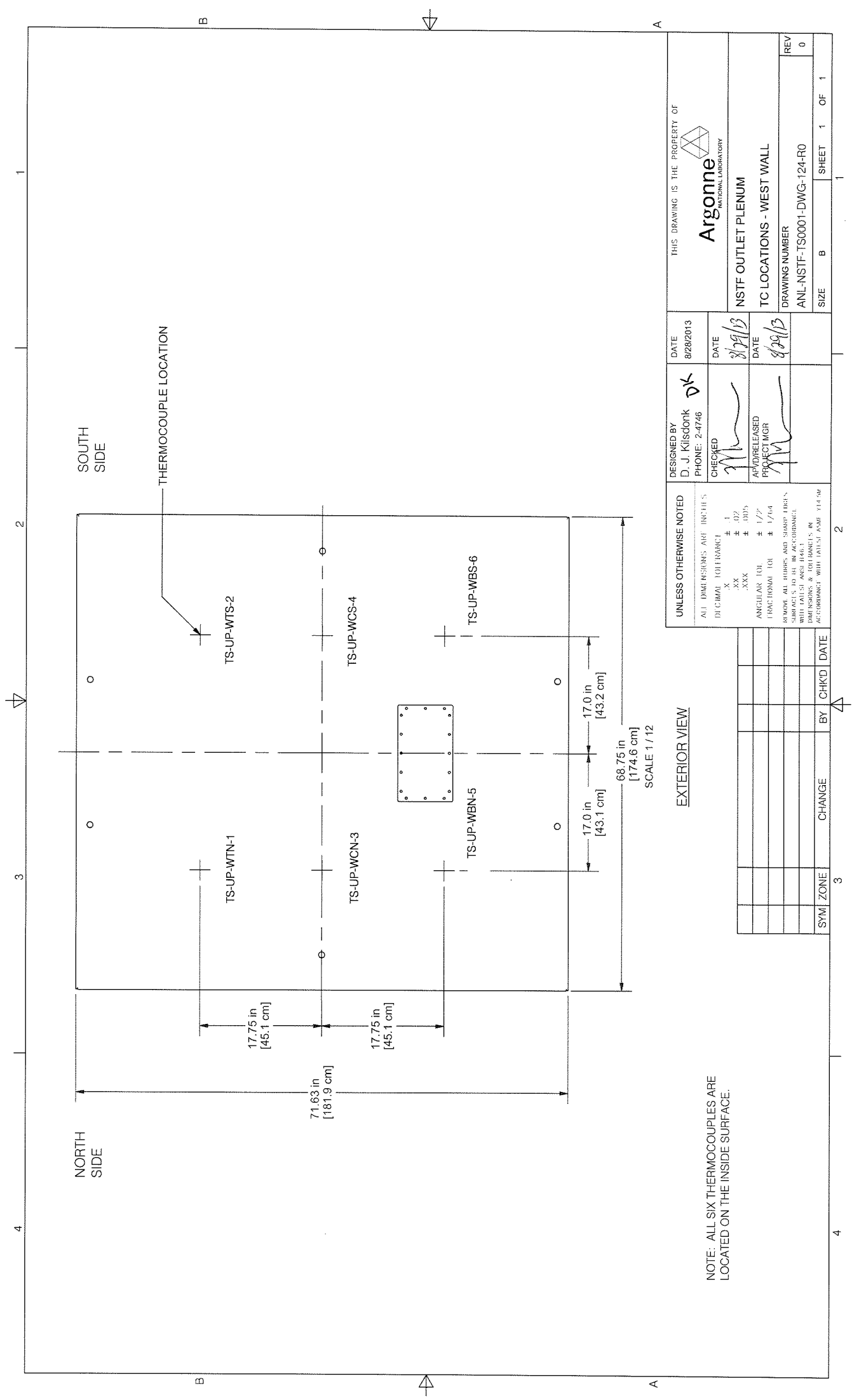


Design Report for the $1 / 2$ Scale Air-Cooled RCCS Tests in the NSTF

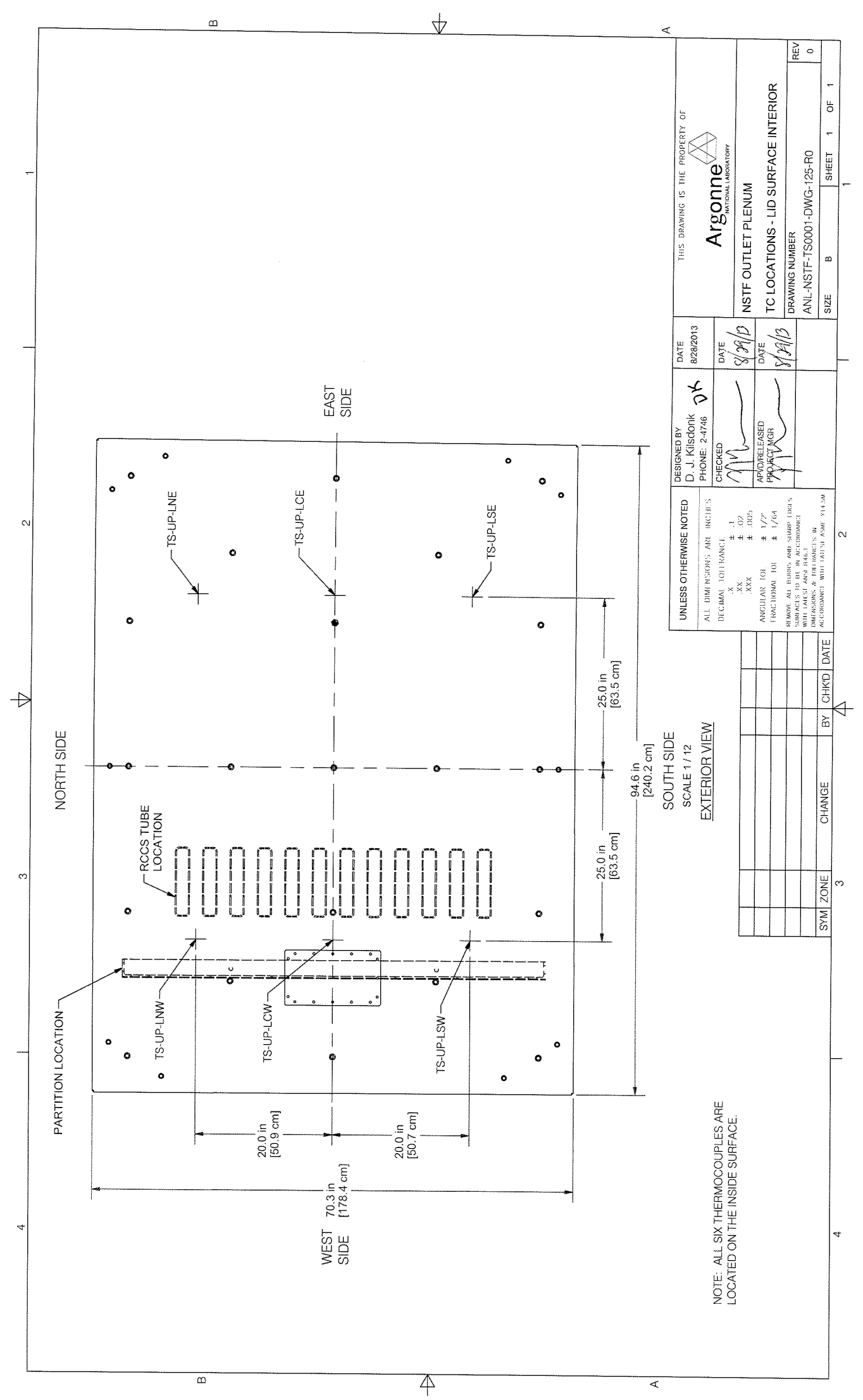




\subsubsection{Heat Flux Sensors}

Heat flux meters are used to measure the heat transfer from the heated plate to the riser ducts, and have been positioned along various riser tubes on both the cold and hot facing walls. The principle of the measurement is the same as that for a pair of thermocouples measuring the temperature difference across a conductor with a known thermal conductivity. Instead of thermocouples, the heat flux sensor uses a pair of thermopiles (TP), which greatly amplifies the signal generated by the temperature difference. The relationship between the signal and heat flux is obtained through NIST traceable calibration.

Sixteen sensors were purchased from iTi Inc, and are of Model BHT with additional polyimide HFT, NIST-calibrated for 5\% accuracy, rated for a maximum temperature of $300^{\circ} \mathrm{C}$, Figure 30 .

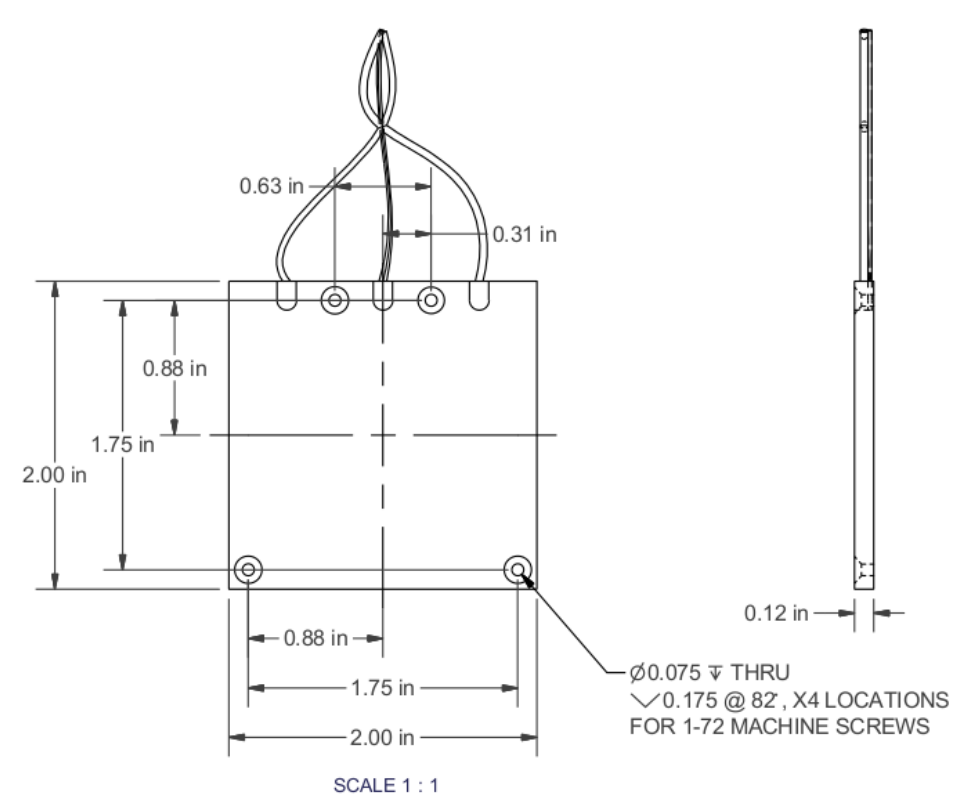

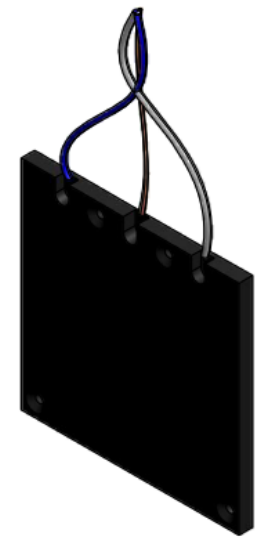

SCALE $1: 1$

Figure 30: iTi model BHT, $300{ }^{\circ} \mathrm{C}$ Polyimide HFT 
Two types of sensors were purchased: one featuring a matte black surface, and the other a high reflectivity golden surface by means of a polyimide HFT coating. The combination of separate matte black surfacing $(\varepsilon \approx 1.0)$ and silver reflective surfacing $(\varepsilon<<1.0)$ allows extraction of the split between convective and radiative heat transfer modes from the heated wall. Specific sensitivities and description of locations are provided below in Table 6, and reference drawings in on the following pages.

Table 6: Summary of heat flux sensors on risers. Procured from iTi Inc., model BHT

\begin{tabular}{ccccl}
\hline$\#$ & Sensor ID & $\mathrm{K}_{\text {radiative }}\left(\mathrm{W} / \mathrm{m}^{2}, \mathrm{mV}\right)$ & Surface finish & Location \\
\hline 1 & 950 & 20.2 & matte & Hot side of duct 1 at $100 \mathrm{~mm}$ \\
2 & 951 & 65.72 & reflective & Hot side of duct 1 at $100 \mathrm{~mm}$ \\
3 & 948 & 21.59 & matte & Hot side of duct 1 at $3500 \mathrm{~mm}$ \\
4 & 947 & 18.01 & matte & Hot side of duct 1 at $7000 \mathrm{~mm}$ \\
5 & 933 & 21.73 & matte & Cold side of duct 1 at $7000 \mathrm{~mm}$ \\
6 & 939 & 18.15 & matte & Cold side of duct 1 at $7000 \mathrm{~mm}$ \\
7 & 935 & 52.97 & reflective & Hot side of duct 7 at $3500 \mathrm{~mm}$ \\
8 & 949 & 73.42 & reflective & Hot side of duct 7 at $3500 \mathrm{~mm}$ \\
9 & 946 & 19.11 & matte & Hot side of duct 7 at $7000 \mathrm{~mm}$ \\
10 & 942 & 18.55 & matte & Cold side of duct 7 at $3500 \mathrm{~mm}$ \\
11 & 934 & 22.89 & matte & Cold side of duct 7 at $3500 \mathrm{~mm}$ \\
12 & 940 & 24.68 & matte & Hot side of duct 11 at $3500 \mathrm{~mm}$ \\
13 & 941 & 22.07 & matte & Hot side of duct 11 at $7000 \mathrm{~mm}$ \\
14 & 936 & 62.43 & reflective & Hot side of duct 11 at $7000 \mathrm{~mm}$ \\
15 & 932 & 19.77 & matte & Cold side of duct 11 at $350 \mathrm{~mm}$ \\
16 & 938 & 22.88 & matte & Cold side of duct 11 at $700 \mathrm{~mm}$ \\
\hline
\end{tabular}


Design Report for the $1 / 2$ Scale Air-Cooled RCCS Tests in the NSTF

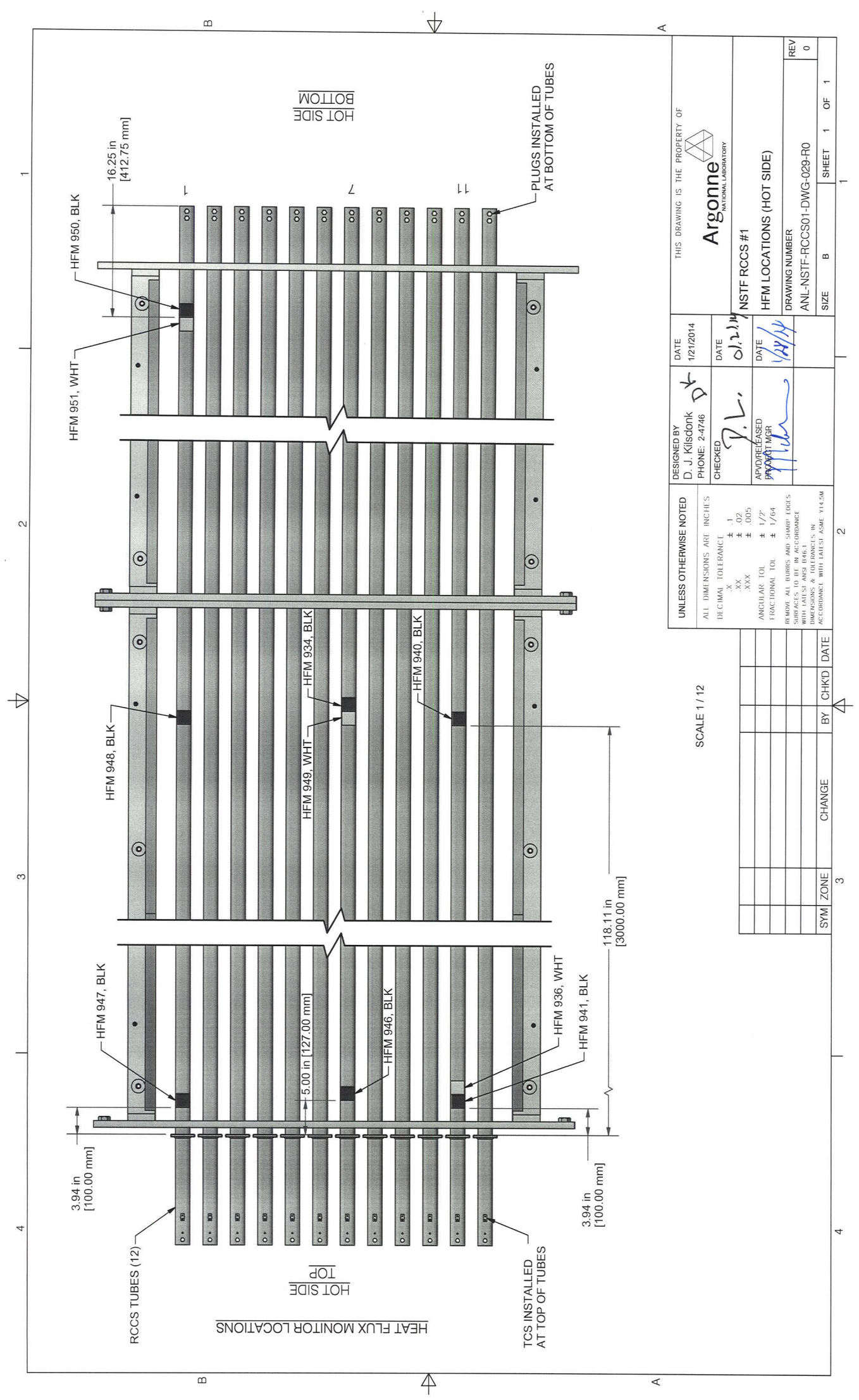


Design Report for the $1 / 2$ Scale Air-Cooled RCCS Tests in the NSTF

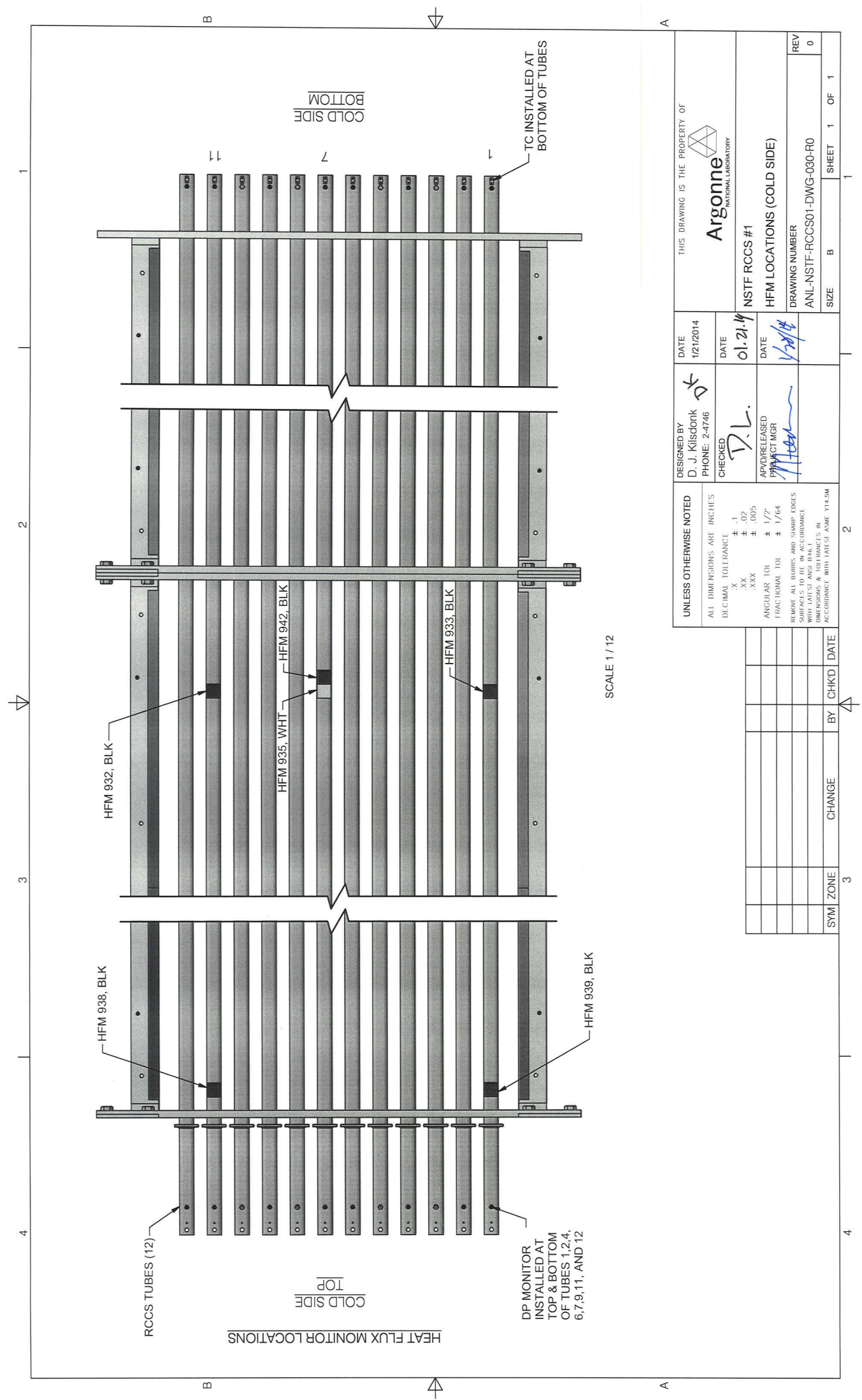




\subsubsection{Meteorological}

Ambient conditions can have a significant effect on RCCS performance and so it is necessary to monitor meteorological conditions near the stack outlet. A weather station, model Davis VantageVue, was selected for this purpose, providing barometric pressure, temperature, humidity, wind speed, and wind direction. All measurements except wind direction have been calibrated to NIST standards.

The weather station is mounted on the building roof and linked to a console station in the control room via wireless transmissions. The console is able to store up to 2,560 records on it's internal storage before it's begins overwriting the oldest data. The console has been configured to poll and store 1 data record every minute, which limits it's total capacity to 1.75 days or 42 hours. To work around this, given the 3 day or longer test operations, the software has been configured to automatically download and store all available records every 24 hours. Time synchronization across the devices is routinely performed to ensure accurate data. Details of the different meteorological measurements for the Davis VantageVue weather station are provided below in Table 7 , and a reference to its physical mounting location in Figure 31 and 32 .

Table 7: Device specifications for Davis VantageVue weather station

\begin{tabular}{llll}
\hline Function & Resolution & Range & Accuracy $( \pm)$ \\
\hline Barometric Pressure & $0.1 \mathrm{mmHg}$ & $410-820 \mathrm{mmHg}$ & $0.8 \mathrm{mmHg}$ \\
Humidity & 0.01 & $1-100 \%$ & 0.03 \\
Rainfall & $0.2 \mathrm{~mm}$ & $0-6553 \mathrm{~mm}$ & 0.04 \\
Temperature & $0.1^{\circ} \mathrm{C}$ & -40 to $60{ }^{\circ} \mathrm{C}$ & $0.5{ }^{\circ} \mathrm{C}$ \\
Wind direction & $1^{\circ}$ & $0-360^{\circ}$ & $3^{\circ}$ \\
Wind speed & $0.1 \mathrm{~m} / \mathrm{s}$ & $1-80 \mathrm{~m} / \mathrm{s}$ & 0.05 \\
Wind run & $0.01 \mathrm{~km}$ & unlimited & 0.05 \\
\hline
\end{tabular}


Bldg. 308 roof plan view

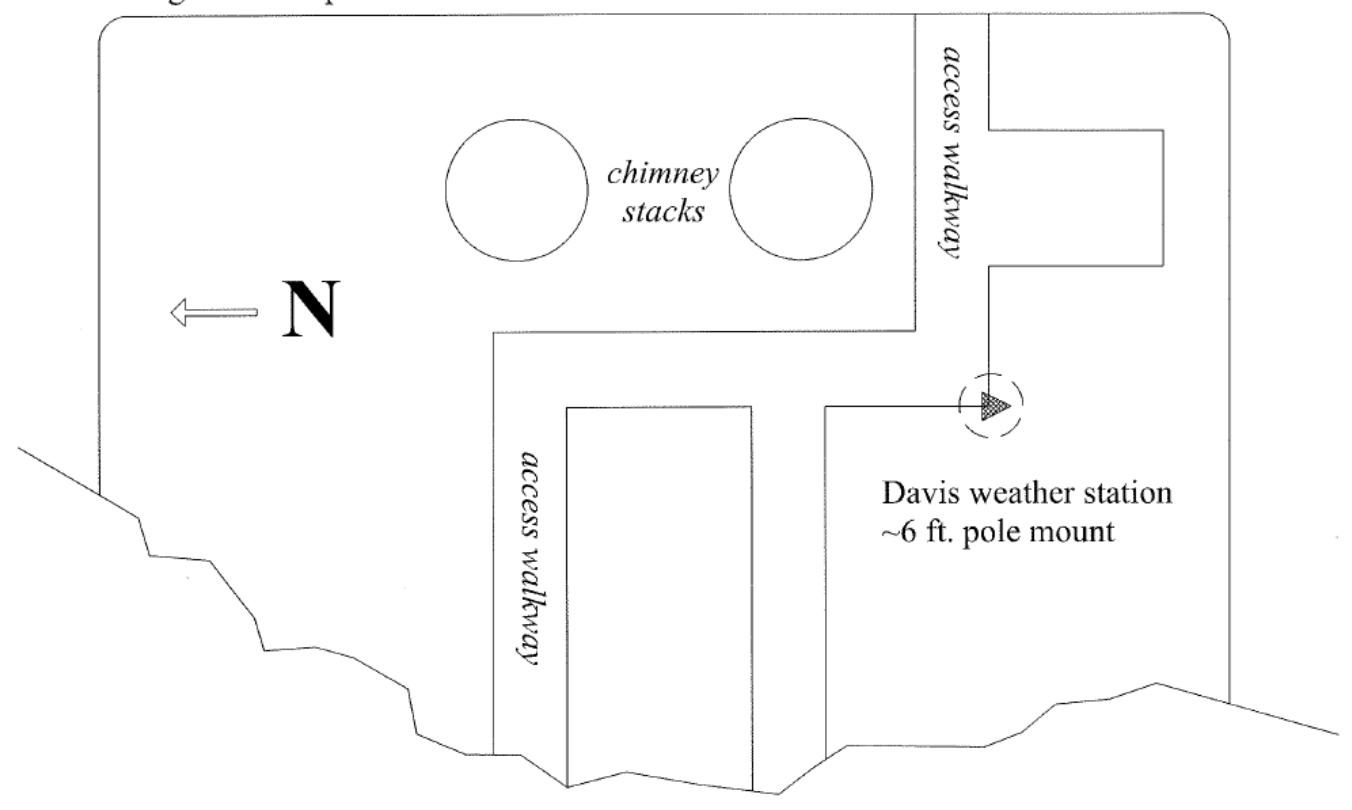

Figure 31: Position of weather station of Bldg. 308 roof top

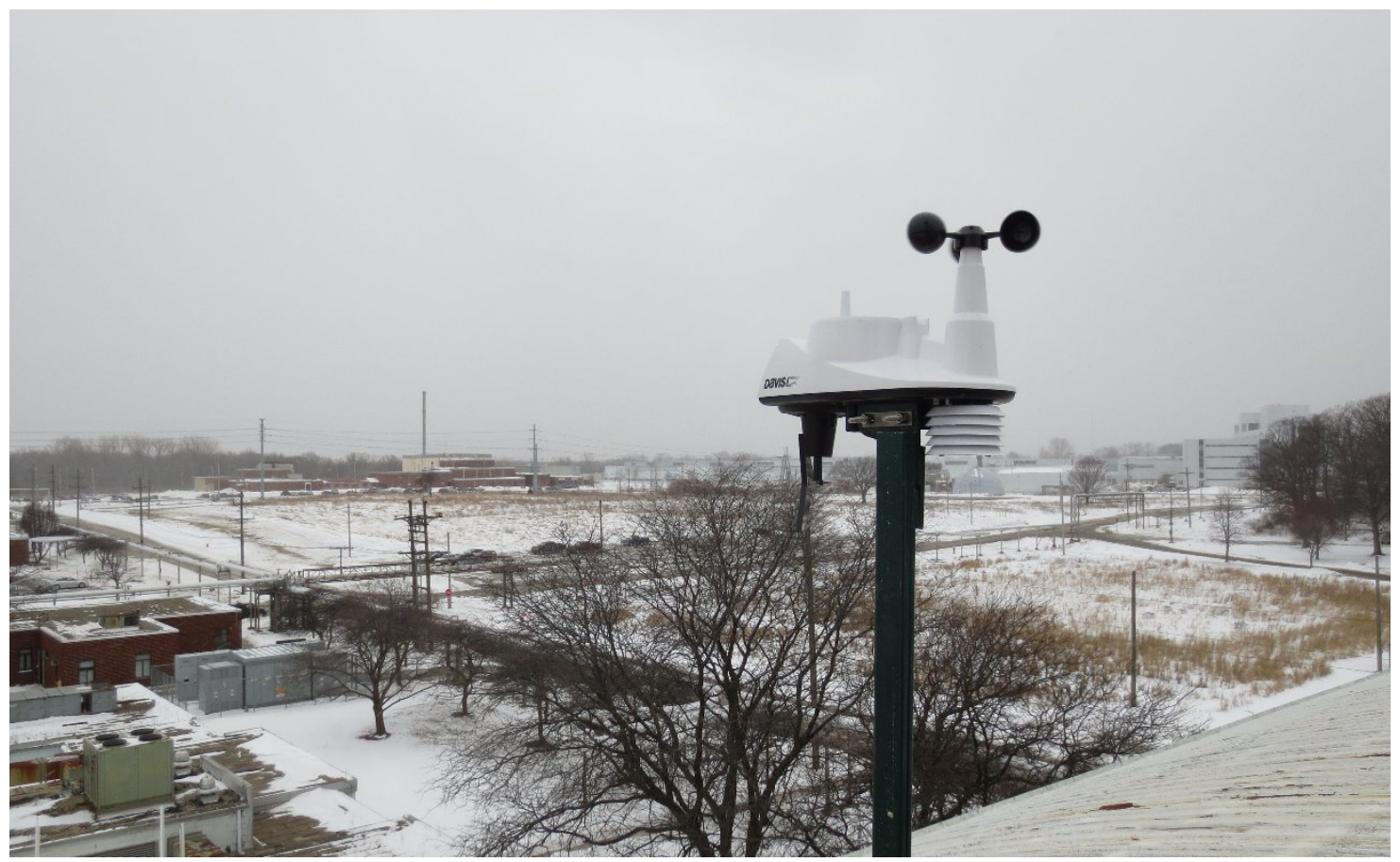

Figure 32: Picture of weather station of Bldg. 308 roof top 


\subsubsection{Differential Pressure}

Differential pressure transmitters are installed across eight of the riser ducts $(3,5,8$, and 10 omitted), and across both chimney networks. The total pressure drop can be defined by the sum of frictional, gravitational, and minor losses. To separate the gravitational (density) influences, thermocouples are positioned alongside each tap point and references to isothermal baseline measurements. Influences from ambient temperature gradients are minimized by tightly bundling impulse lines, selecting bundle runs that avoid surfaces at elevated temperatures, and shielding the transmitters from large temperature swings. Eight of the transmitters positioned across the riser ducts were purchased from Dwyer, model 668 which features bidirectional capabilities with a span of $+/-0.25$ " $\mathrm{H}_{2} \mathrm{O}(64 \mathrm{~Pa})$. Two additional transmitters across the chimney segments were also purchased from Dwyer, but high accuracy and resolution model 607 were selected, which features bidirectional capabilities with a span of $+/-0.1 " \mathrm{H}_{2} \mathrm{O}(24 \mathrm{~Pa})$

Table 8: Differential pressure device specifications

\begin{tabular}{|c|c|c|}
\hline & Dwyer 668-11 & Dwyer 607-0B \\
\hline NSTF location & Riser tubes & Chimney ducts \\
\hline Range & 0 to $\pm 0.25 "$ w.c. & 0 to $\pm 0.10 "$ w.c. \\
\hline Accuracy & Âś1\% of full scale (RSS) & $\pm 0.5 \%$ or $\pm 0.25 \%$ F.S. \\
\hline Long term stability & not rated & $\pm 0.5 \%$ F.S.O./yr. \\
\hline Temperature Limits & 0 to $150^{\circ} \mathrm{F}\left(-18\right.$ to $\left.65^{\circ} \mathrm{C}\right)$ & -20 to $160^{\circ} \mathrm{F}\left(-29\right.$ to $\left.71^{\circ} \mathrm{C}\right)$ \\
\hline Pressure Limits & 10 psig (0.69 bar). & 10 psig (0.69 bar). \\
\hline Operating Temp. & 0 to $150^{\circ} \mathrm{F}\left(-18\right.$ to $\left.65^{\circ} \mathrm{C}\right)$. & 35 to $135^{\circ} \mathrm{F}\left(2\right.$ to $\left.57^{\circ} \mathrm{C}\right)$. \\
\hline Thermal Effects & $0.033 \% \mathrm{FS} /{ }^{\circ} \mathrm{F}\left(0.18 \% \mathrm{FS} /{ }^{\circ} \mathrm{C}\right)$ & $\pm 0.015 \%$ F.S. $/{ }^{\circ} \mathrm{F}$ \\
\hline Supply Voltage & 12-30 VDC. & 12-36 VDC. \\
\hline Output & 4 to $20 \mathrm{~mA}, 2$-wire. & 4 to $20 \mathrm{~mA} \mathrm{DC}, 2$-wire. \\
\hline Response Time & $<60$ msec. & 250 msec max. \\
\hline Loop Resistance & 0-800 ohms. & 0 to 1045 ohms \\
\hline Housing & Fire retardant glass polyester & 300 Series stainless (NEMA 2) \\
\hline Weight & $3 \mathrm{oz}(85 \mathrm{~g})$ & $1.04 \mathrm{lb}(472 \mathrm{~g})$ \\
\hline Agency Approval & $\mathrm{CE}$ & $\mathrm{CE}$ \\
\hline
\end{tabular}



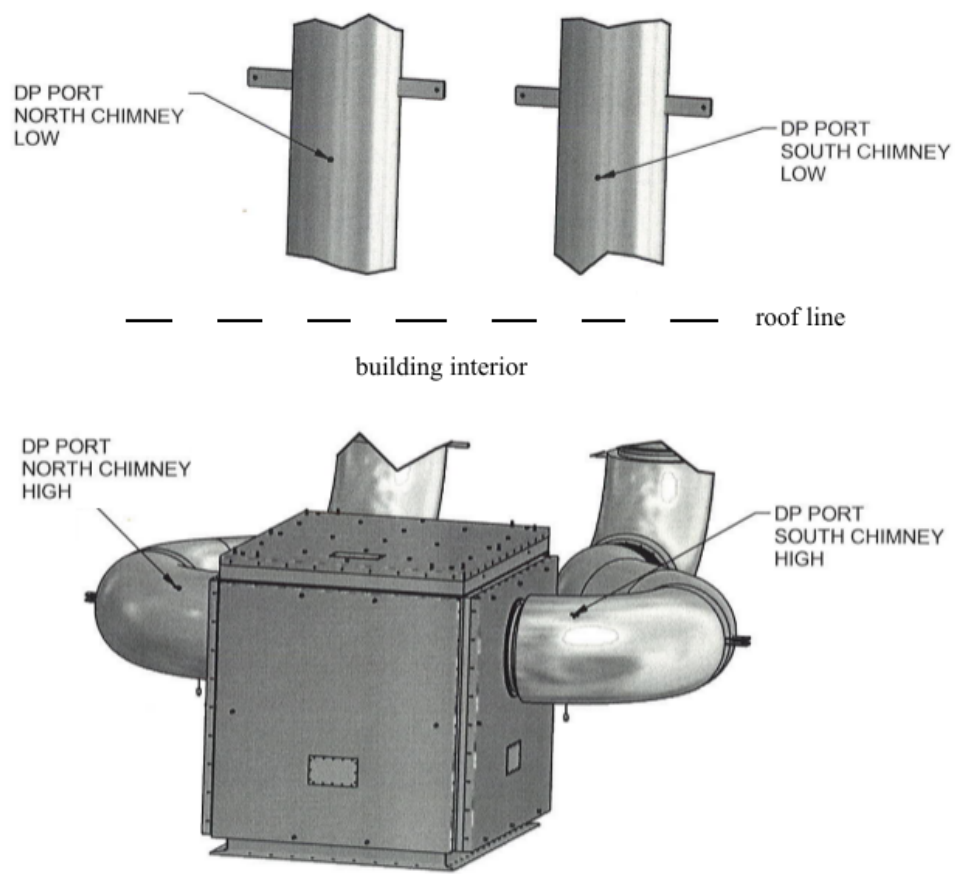

Figure 33: Chimney differential pressure tap location
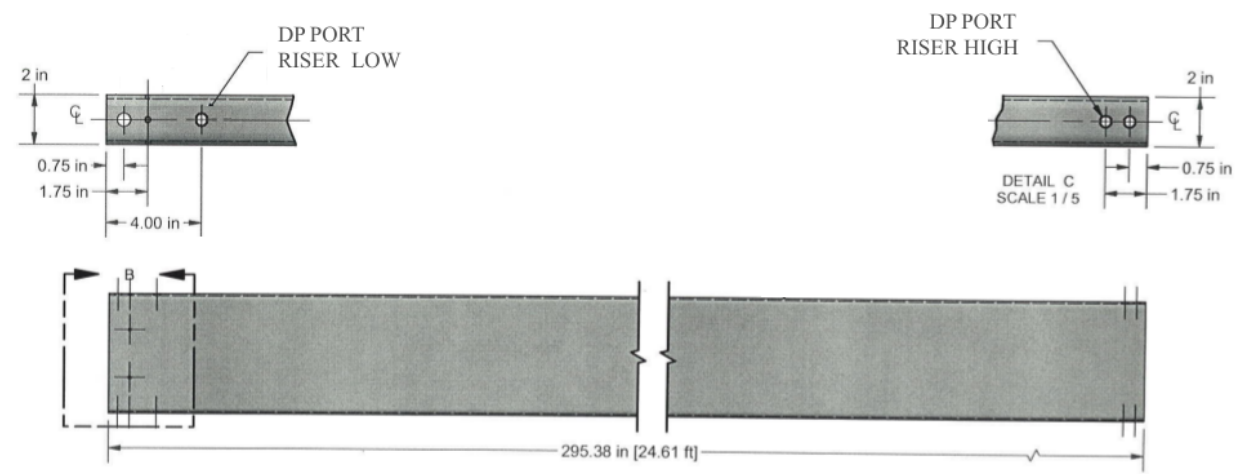

Figure 34: Riser differential pressure taps (all risers except 2, 4, 8, 10) 


\subsubsection{Inlet Flow and Humidity}

A Sierra 640S thermal mass flow meter is located 24" past the end of the flow conditioner and extends to the centerline of the duct. This instrument provides measurement of temperature compensated mass flow rates and is the first measurement parameter of the incoming air supply. Measurement of bulk humidity is made by a single humidity probe, Dwyer RHP2O11, which is positioned 24" above and at the centerline of the 24" diameter entrance area.

Table 9: Inlet plenum humidity probe specifications

\begin{tabular}{ll}
\hline & Dwyer RHP 2O-11 \\
\hline NSTF location & Inlet plenum \\
Relative Humidity Range & 0 to $100 \% \mathrm{RH}$. \\
Temperature Range & -40 to $140^{\circ} \mathrm{F}\left(-40\right.$ to $\left.60^{\circ} \mathrm{C}\right)$. \\
Accuracy & $\pm 2 \% 10-90 \% \mathrm{RH} @ 25^{\circ} \mathrm{C}$ \\
Hysteresis & $\pm 1 \%$. \\
Repeatability & $\pm 0.1 \%$ typical. \\
Temperature Limits & -40 to $140^{\circ} \mathrm{F}\left(-40\right.$ to $\left.60^{\circ} \mathrm{C}\right)$. \\
Response Time & 15 seconds. \\
Drift & $<1 \% \mathrm{RH} /$ year. \\
\hline
\end{tabular}

Table 10: Inlet mass flow meter specifications

\begin{tabular}{ll}
\hline & Sierra $640 \mathrm{~S}$ \\
\hline NSTF location & Inlet downcomer \\
Accuracy of Point Velocity & $\pm 1 \%$ of reading $+0.5 \%$ of full scale \\
Repeatability & $\pm 0.2 \%$ of full scale \\
Temperature Coef. & $\pm 0.06 \%$ per ${ }^{\circ} \mathrm{C}$ within $\pm 25^{\circ} \mathrm{C}$ to $50^{\circ} \mathrm{C}$ of calibration \\
Pressure Coef. & $0.02 \%$ per psi for air, consult factory for other gases \\
Response Time & One second to $63 \%$ of final velocity value \\
Pressure Drop & Negligible for pipes three inches in diameter or larger \\
\hline
\end{tabular}




\subsubsection{Gas Temperature}

Within each riser, high accuracy Type-K thermocouples are placed and extend to the length wise (10") duct centerline, Figure 35. These thermocouples were purchased from ARI industries, and are of model T-22N-12BK8A-96(MOD). The inlet thermocouple is placed 0.75" from the bottom lip on the cold side, and the outlet placed 4.0" below the top lip from the hot side.

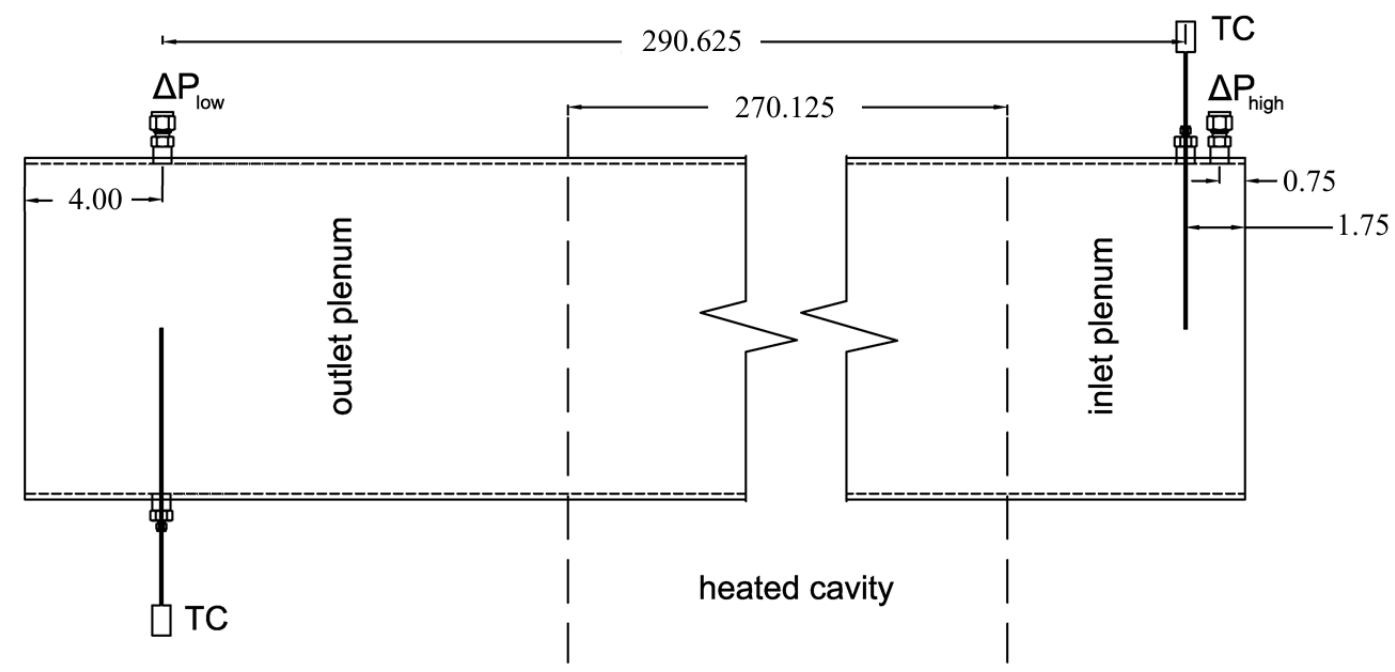

Figure 35: Placement of inlet and outlet instruments for riser

The outlet plenum features five instrumented insulation panels. The four adjacent vertical sides (north, south, east, and west) contain six embedded interior wall thermocouples, while the fifth top ceiling panel contains identical wall thermocouples in addition to seven thermocouple rakes for gas temperature measurements within the bulk volume of the plenum. Each rake measures six junctions along its length, extending a $170 \mathrm{~cm}$ along the total $188 \mathrm{~cm}$ height of the plenum. 
Design Report for the $1 / 2$ Scale Air-Cooled RCCS Tests in the NSTF June 2014

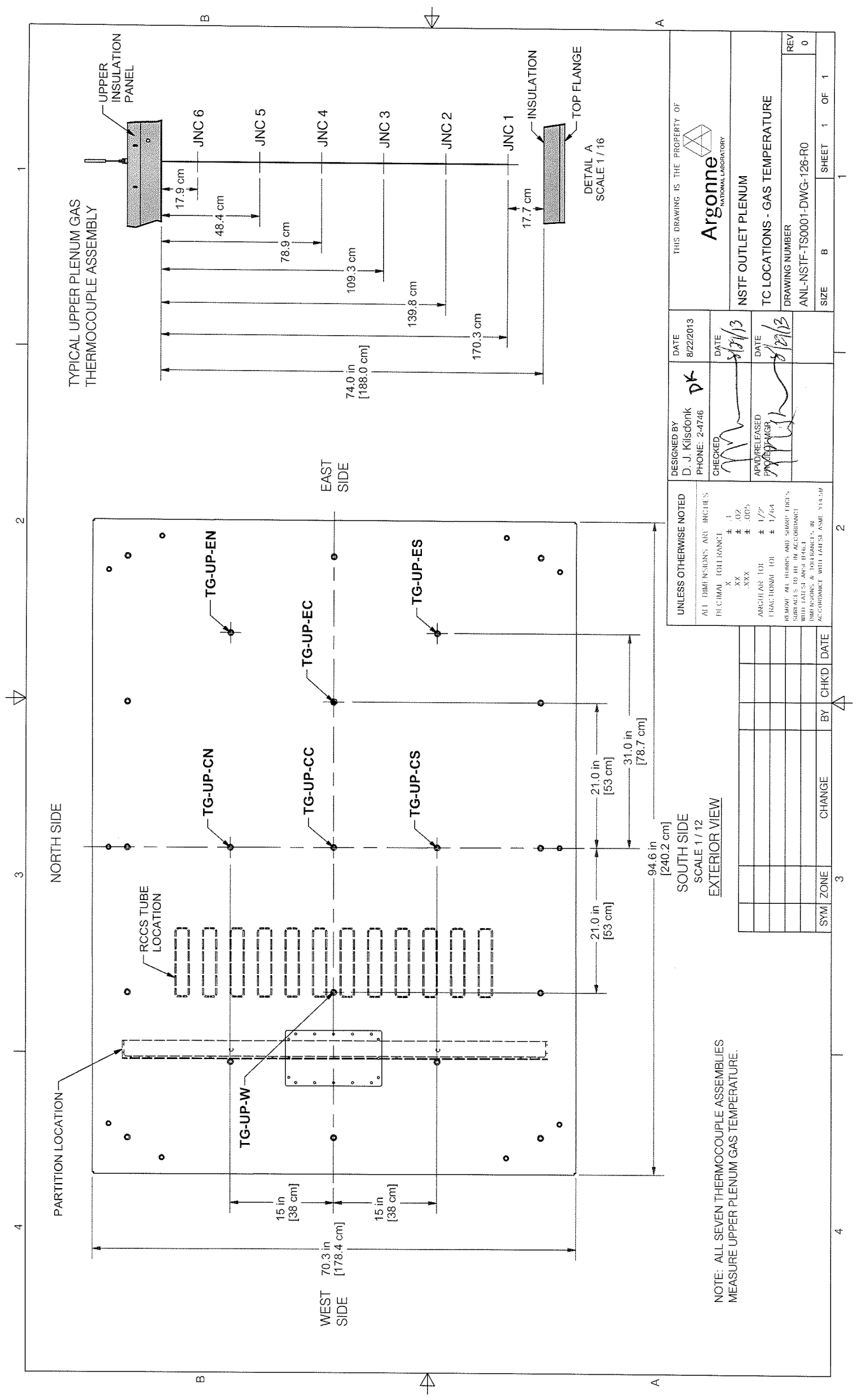




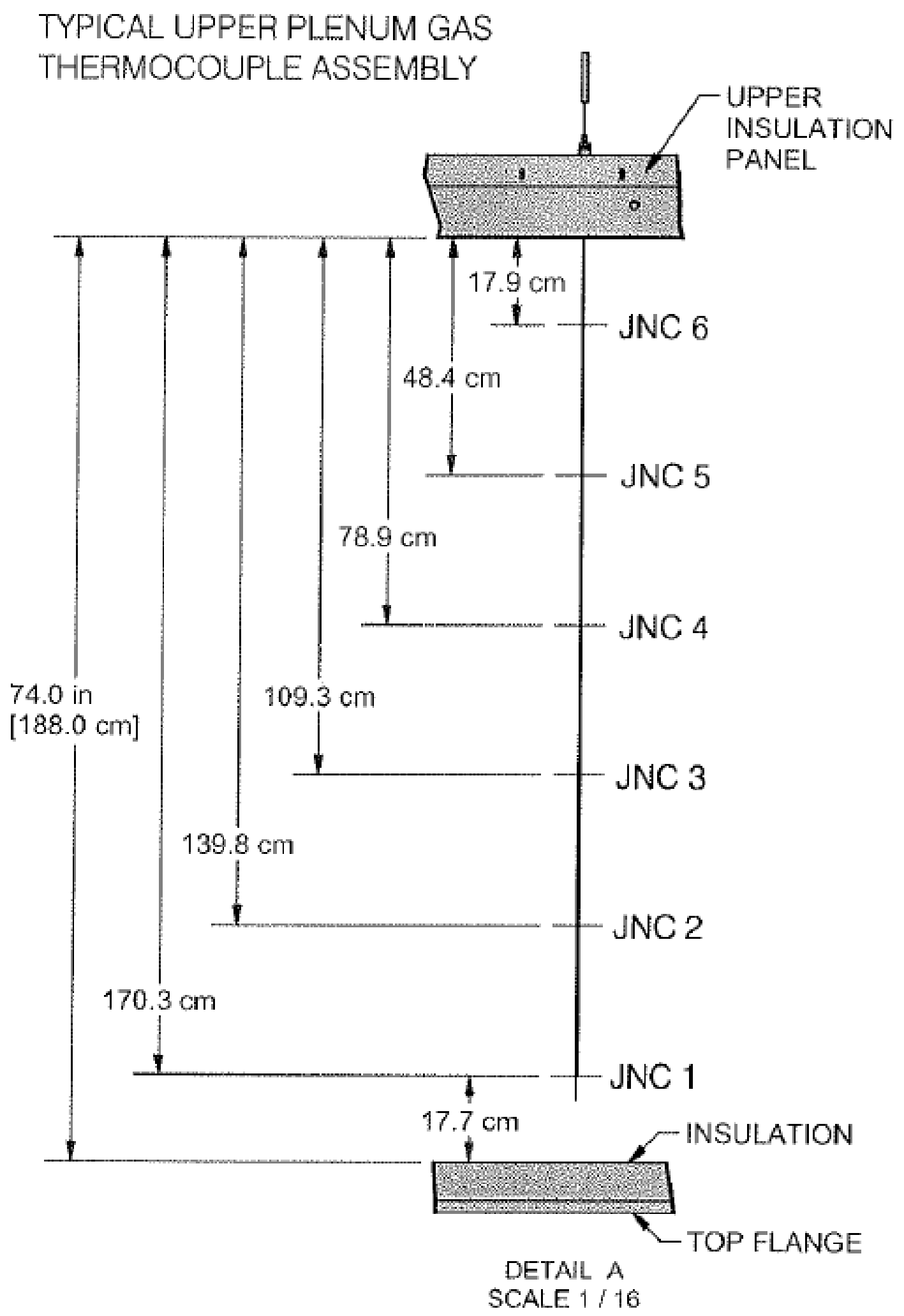

Figure 36: Typical rake junction locations, placed along upper plenum top panel and extending downward 


\subsubsection{Luna Fiber Optic Temperature}

The NSTF is outfitted for fiber optics, a distributed sensing system by Luna Technologies that can provide the necessary data density for validation of CFD tools. Distributed fiber optic temperature sensing is a relatively new technique based upon distributed strain sensing and enables the acquisition of thousands of temperature measurements from a single optical fiber. The fiber temperature sensors used here exploit Rayleigh scattering losses from structural inhomogeneities and impurities at the molecular level of ordinary telecom fibers. The ODiSi A-10 from Luna Technologies was used for these measurements.

Table 11: Specifications of Luna ODiSi A-10

\begin{tabular}{lc}
\hline \multicolumn{1}{c}{ Parameter } & Specification \\
\hline Model & $\mathrm{A} 10$ \\
Maximum Sensing Length & $10 \mathrm{~m}$ \\
Acquisition Rate $^{1}$ & $5 \mathrm{~Hz}$ \\
Minimum Sensor Spacing $^{\text {Minimum Gage Length }}{ }^{2}$ & $0.4 \mathrm{~mm}$ \\
Wavelength Accuracy $^{3}$ & $1 \mathrm{~mm}$ \\
Strain & $1.5 \mathrm{pm}$ \\
Range $_{\text {Single scan repeatability }}{ }^{4} 5$ & $\pm 13,000 \mu \mathrm{Strain}$ \\
Temperature $^{5}$ & $\pm 2 \mu \mathrm{Strain}$ \\
Range $^{6}$ & -50 to $300{ }^{\circ} \mathrm{C}$ \\
Single scan repeatability $^{14} 5$ & $\pm 0.2{ }^{\circ} \mathrm{C}$ \\
\hline
\end{tabular}

\footnotetext{
${ }^{1}$ For the default measurement range of $\pm 1,250 \mu$ Strain or $\pm 200{ }^{\circ} \mathrm{C}$

${ }^{2}$ Minimum gage length is achievable using the largest measurement range, having a single scan repeatability of $\pm 17.0 \mu$ Strain or $\pm 2.0{ }^{\circ} \mathrm{C}$

${ }^{3}$ Accuracy maintained by an internal NIST - traceable HCN gas cell

${ }^{4}$ Temperature and strain measurements are calculated from the spectral shift of scattered laser light. Using the default conversion coefficients of $1 \mathrm{GHz}=0.8{ }^{\circ} \mathrm{C}=6.58 \mu$ Strain , the accuracy of temperature and strain are $0.15^{\circ} \mathrm{C}$ and $1.25 \mu$ Strain

${ }^{5}$ For the default gage length of $1 \mathrm{~cm}$

${ }^{6}$ Based on material properties of the standard sensor: polyimide - coated, low - bend - loss optical fiber
} 
The fibers are made of $155 \mu \mathrm{m}$ polyimide-coated single-mode commercial telecom fiber (Specialty Photonics CL POLY 1310) that we have tested for accuracy and repeatability to $150^{\circ} \mathrm{C}[6]$. The system can generate temperature measurements every $10 \mathrm{~mm}$ at $1 \mathrm{~Hz}$ for a total of 9,750 data point/s along each $7.5 \mathrm{~m}$ fiber. We have limited this initial installation to a single duct because the measurement technique is new and this is the first time its use has been attempted in a large-scale test facility.

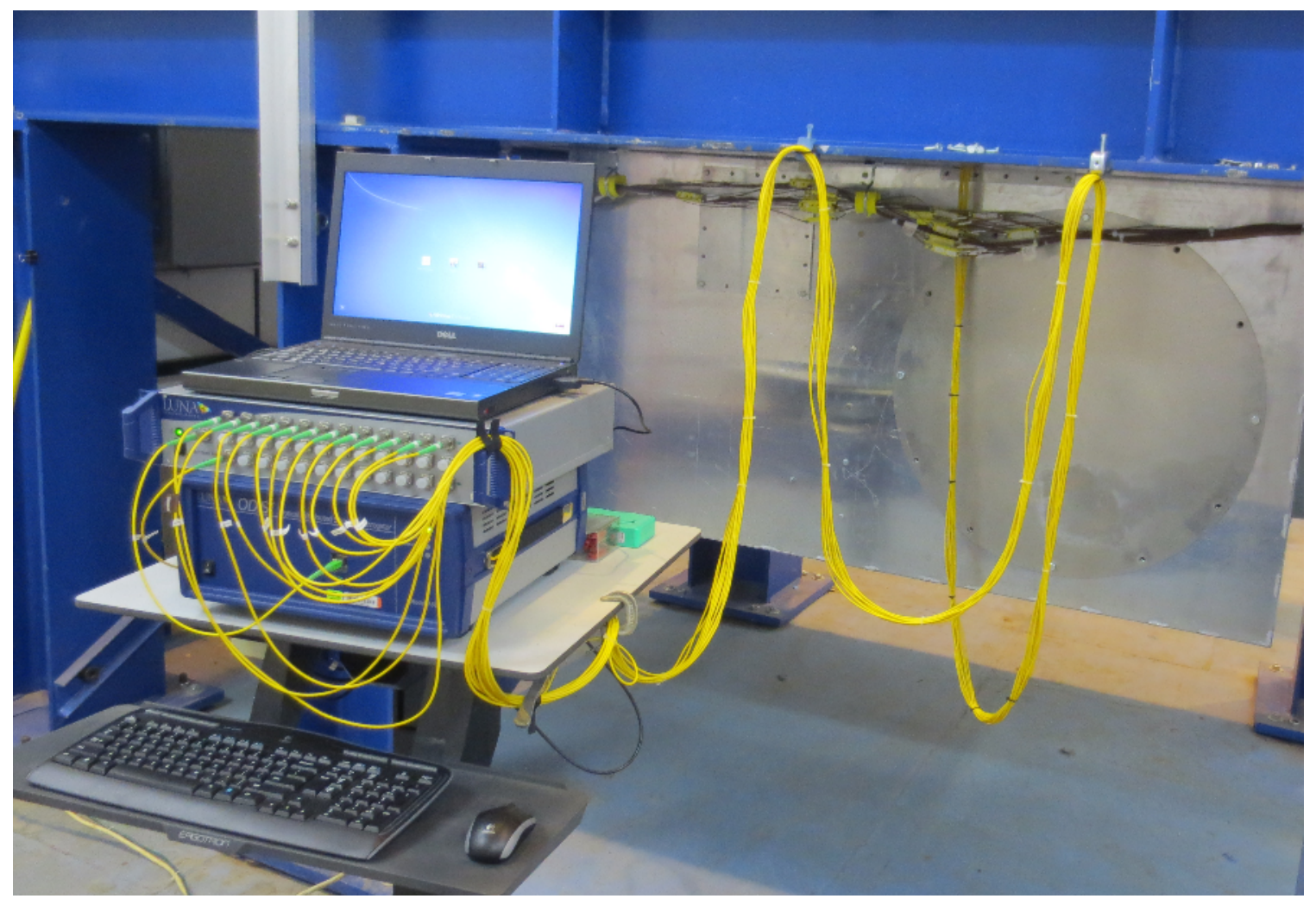

Figure 37: Luna fiber setup, setup near base mount and fed from inlet plenum 
Inherent in their design, these sensors are unable to distinguish between strain and temperature: either will influence the measured signal. To overcome this, we have installed the fibers within 1/16" OD x 0.030 ID stainless steel capillaries and heat shrunk the length nearest the connector to the tubing, Figure 38.

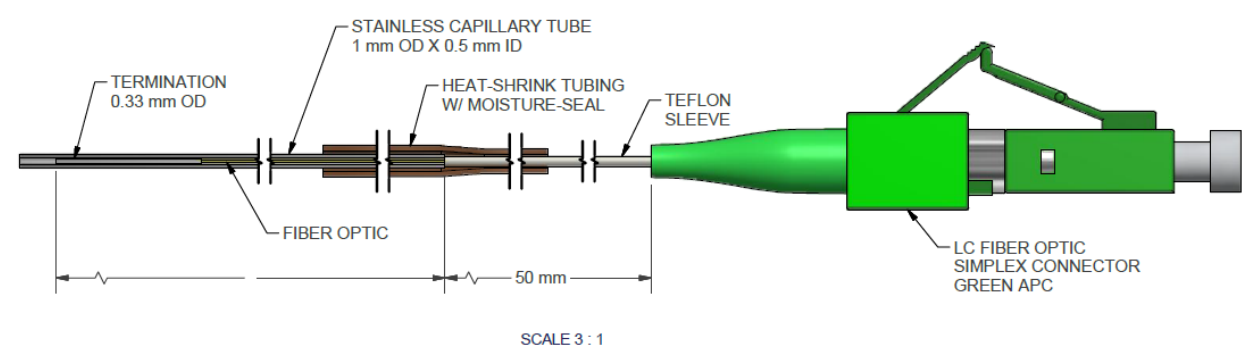

Figure 38: Method of Luna fiber optic cables securement to capillary support tubes

This configuration allows the fiber to freely expand up the capillary when heated, thus preventing any internal strain. A single riser duct, 6 , has been outfitted with eleven of these fibers: 6 on the outside wall and 5 within the gas space. These capillaries have been secured to the duct wall with spot welded bands, and within the gas space by routing through 8-32 brass fillister head screws.

The Luna fiber optic temperature measurement system requires a baseline calibration, as the actual measurements are in the form of a temperature difference from a known baseline, and not an absolute value themselves. Thus, we have positioned sixteen (x16) NISTcalibrated Type-K wall thermocouples along the duct walls for purposes of calibrating the LUNA fiber optic cables during baselines. These have been placed in a similar fashion to the wall capillaries - they extend along the length and are secured with spot welded bands to the riser tubes. 


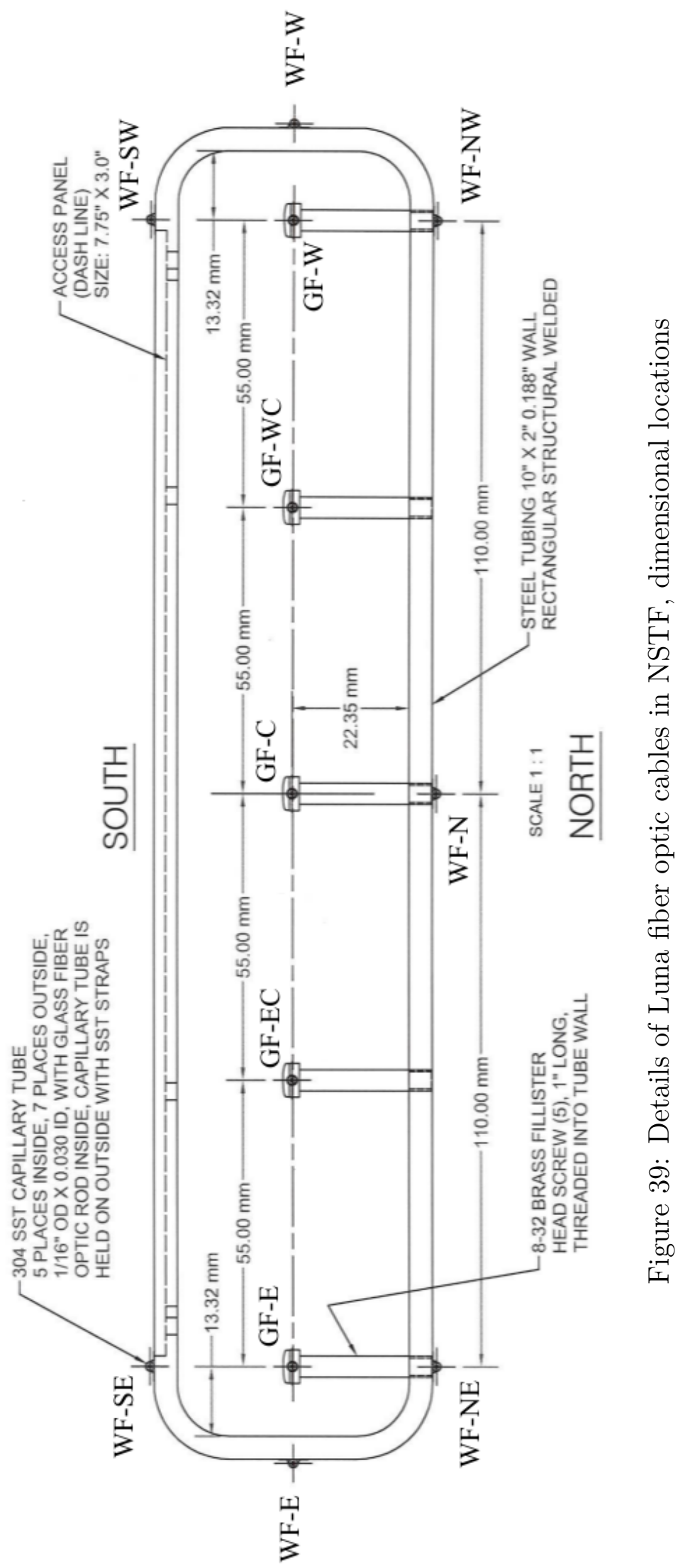




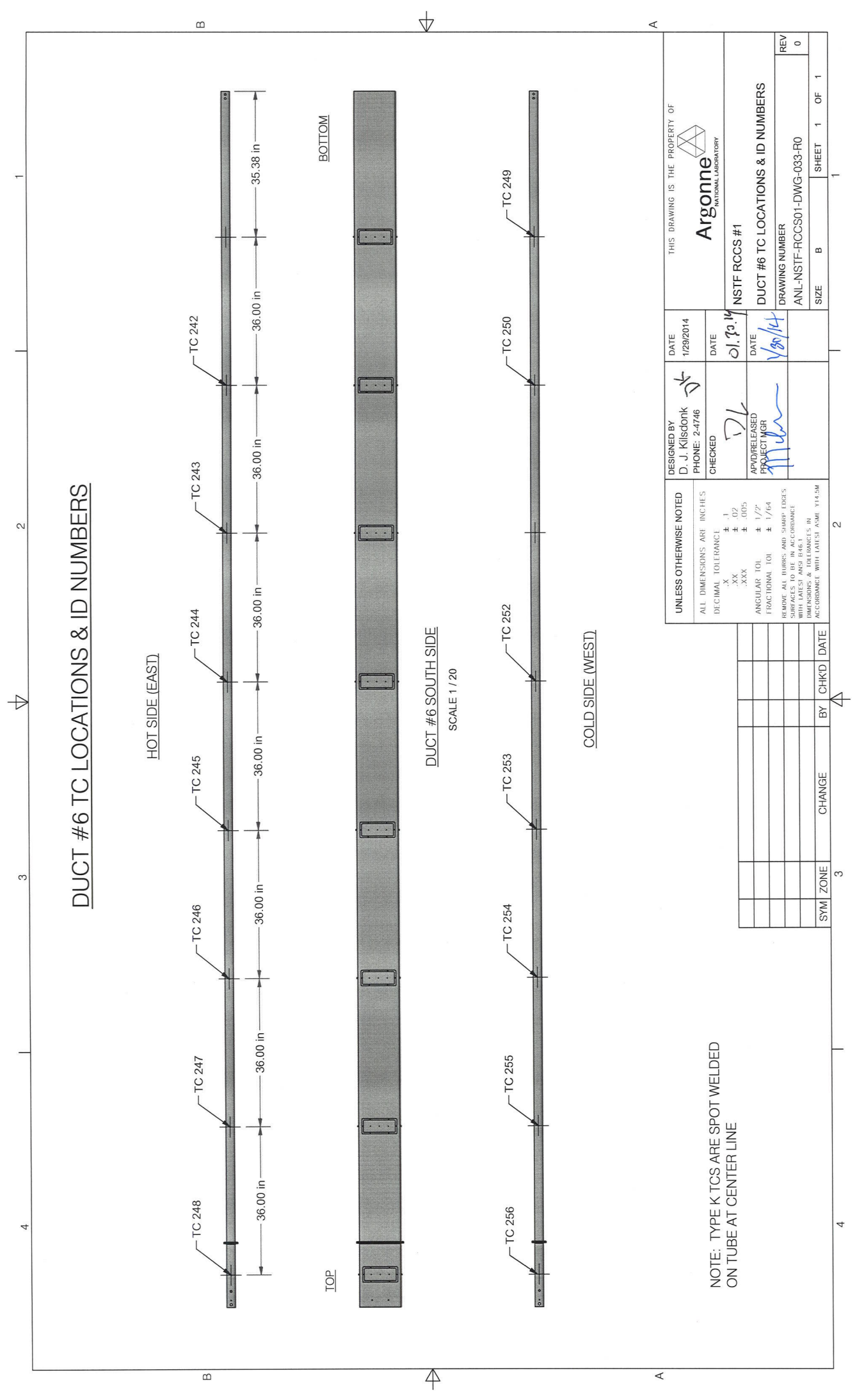




\section{Chapter 5}

\section{Test Operations}

Data quality testing, defined as tests conducted with full verification of procedures and calibrated instrumentation by NQA-1 standards, will be initiated in early 2014 and are anticipated to extend through early 2015. The following document outlines the parameters of primary interest and also provides a proposed test matrix. Any given test is expected to run 72 hours and span two weeks when one includes pre- and post-test work along with documentation requirements.

Of primary interest are areas of heat flux variation (integral levels and profiling), scaling verification, mimicking of a typical accident scenario, and investigations onto the chimney roles. Within the subset of chimney roles we are particularly interested in the startup procedure as initial scoping tests conducted in late 2013 suggested a strong sensitivity to ambient weather conditions during system start up. Thus certain tests will be repeated as weather conditions change and may precede other scheduled tests, altering the proposed testing order. Finally, as new behaviors are discovered additional tests may be introduced to further investigate these patterns.

Table 12: Test operations time frame

\begin{tabular}{|c|c|c|c|c|}
\hline \multirow[b]{2}{*}{ Steady-state heat load } & \multirow[t]{2}{*}{ Spring } & Summer & Fall & Winter \\
\hline & & & & \\
\hline Baseline accident scenario & & & & \\
\hline Variations in physical scale & & & & \\
\hline Prototypical power history profile & & & & \\
\hline Variations in heated profile & & & & \\
\hline Investigatory test conditions & & & & \\
\hline Start-up procedure variations & & & & \\
\hline
\end{tabular}


1. Shakedown/Calibration

(a) Conduct electrical, power, and instrumentation system shakedown tests

(b) Carry out insulation and ceramic heater bake-out procedure

(c) Verify gross system mass flow rate measurement methodology

(d) Evaluate system pressure drop under isothermal forced flow

(e) System energy balance verification tests and characterization of facility heat loss

2. Baseline testing at nominal conditions, and document the conduct of this test in a report.

- Full exit plenum elevation

- Full heater plate elevation with flat power profile at $1.5 \mathrm{MW}_{t}$ scaled power

- Full stack cross-section and elevation

- Nominal RCCS tube setback from heater plate.

3. Scaling Laws, Initial Iteration (carried out at steady-state conditions)

(a) Heat source variation

i. Steady state heat removal $\left(700 \mathrm{~kW}_{t}\right)$

ii. Constant temperature $\left(441^{\circ} \mathrm{C}, \mathrm{RPV}\right.$ during depressurized cool down)

(b) Variation of heated zone length

i. $1 / 4$ scale

(c) Variation of atmospheric discharge height

4. GA-MHTGR accident scenario

(a) Full time history of design basis power profile incorporated into test procedure

(b) Repeatability testing

5. Scaling Laws, Second Iteration

(a) Profile shaping

i. Cosine (axial)

ii. Azimuthal

(b) Pressure drop tests (introduce orifice downstream of tube bank)

6. Alternative / investigatory configuration testing

(a) Modifications to chimney roles (outlet/outlet, inlet/outlet, cross-flow, etc.)

(b) Single chimney

(c) Blocked riser channels

7. Startup procedure investigations (with unfavorable weather conditions) 


\section{References}

1. C. P. Tzanos and M. Farmer, "Feasibility Study for Use of the Natural Convection Shutdown Heat Removal Test Facility NSTF for Initial VHTR Water-Cooled RCCS Shutdown," ANL-GenIV-079, Nuclear Engineering Division, Argonne National Laboratory, (2006)

2. "Preliminary Safety Information Document for the Standard MHTGR," HTGR-86-024, Vol. 1, Amendment 13, U.S. Department of Energy, (1992)

3. M. M. Hecht, "MHTGR - nuclear engine or world development," EIR, Vol. 16, 49, pp. $22-28,(1989)$

4. S. Lomperski, W. D. Pointer, C. P. Tzanos, T. Y. C. Wei and A. R. Kraus, "Air-Cooled Option RCCS Studies and NSTF Preparation," ANL-GenIV-179, Nuclear Engineering Division, Argonne National Laboratory, (2011)

5. R. R. Steward, Argonne National Laboratory, unpublished information, (1987)

6. Lomperski S, Gerardi C, Pointer DW (2013) Distributed fiber optic temperature sensing for CFD code validation. In: Proceedings of 15th International Topical Meeting on Nuclear Reactor Thermal Hydraulics (NURETH-15) Pisa, Italy, (2013) 
This page was intentionally left blank. 


\section{Appendix A: Emissivity records}

The emissivity of the test section heater plates and insulated cavity sidewalls were mapped. The results indicate that the heater plate emissivity was nominally 0.8 , while the sidewall emissivity was nominally 0.2 . A summary of the statistic results is provided below in Table 13, specific locations and detailed results are provided on the following pages, and devices with their model numbers listed below.

Table 13: Measured emissivity values for NSTF north \& south walls

\begin{tabular}{rccc} 
& $\varepsilon_{\min }$ & $\varepsilon_{\max }$ & $\varepsilon_{\text {avg }}$ \\
\hline Upper primary plate & 0.75 & 0.85 & $\mathbf{0 . 7 9}$ \\
Lower primary plate & 0.73 & 0.84 & $\mathbf{0 . 7 8}$ \\
Lower U-channel & 0.17 & 0.21 & $\mathbf{0 . 1 9}$
\end{tabular}

\section{Devices used for measurement:}

- Devices Services-Emissometer, Model AE1, SN-2 367

- Devices Services-Scaling Digital Voltmeter, Model RD1, SN-1498

- Test Plate Standards, SN-2294 2260 
Table 14: Specific measurement locations and emissivity readings

\begin{tabular}{|c|c|c|c|c|c|c|c|}
\hline \multicolumn{3}{|c|}{ Upper primary plate ${ }^{1}$} & \multicolumn{3}{|c|}{ Lower primary plate ${ }^{2}$} & \multicolumn{2}{|c|}{ South U-chnl. ${ }^{3}$} \\
\hline $\begin{array}{c}\mathrm{TC} \\
\#\end{array}$ & $\begin{array}{c}\varepsilon_{I} \\
\mathbb{\Downarrow}\end{array}$ & $\begin{array}{c}\varepsilon_{I I} \\
\Leftrightarrow\end{array}$ & $\begin{array}{c}\text { TC } \\
\#\end{array}$ & $\begin{array}{c}\varepsilon_{I} \\
\mathbb{I}\end{array}$ & $\begin{array}{c}\varepsilon_{I I} \\
\Leftrightarrow\end{array}$ & $\begin{array}{c}\mathrm{TC} \\
\#\end{array}$ & $\begin{array}{l}\varepsilon_{I} \\
\mathbb{1}\end{array}$ \\
\hline 74 & 0.80 & 0.77 & 1 & 0.76 & 0.73 & 222 & 0.21 \\
\hline 75 & 0.78 & 0.75 & 2 & 0.76 & 0.74 & 221 & 0.20 \\
\hline 76 & 0.80 & 0.78 & 3 & 0.80 & 0.79 & 228 & 0.21 \\
\hline 77 & 0.80 & 0.76 & 4 & 0.83 & 0.81 & 227 & 0.19 \\
\hline 83 & 0.79 & 0.76 & 10 & 0.79 & 0.77 & 226 & 0.19 \\
\hline 84 & 0.78 & 0.77 & 11 & 0.77 & 0.75 & 225 & 0.17 \\
\hline 85 & 0.79 & 0.78 & 12 & 0.79 & 0.77 & 236 & 0.19 \\
\hline 86 & 0.83 & 0.80 & 13 & 0.84 & 0.80 & 235 & 0.19 \\
\hline 87 & 0.83 & 0.78 & 16 & 0.82 & 0.79 & 234 & 0.18 \\
\hline 88 & 0.81 & 0.78 & 17 & 0.83 & 0.80 & 233 & 0.19 \\
\hline 89 & 0.81 & 0.78 & 18 & 0.83 & 0.79 & & \\
\hline 90 & 0.81 & 0.77 & 19 & 0.83 & 0.78 & Nortl & U-chnl. ${ }^{4}$ \\
\hline 92 & 0.78 & 0.76 & 25 & 0.81 & 0.80 & $\mathrm{TC}$ & $\varepsilon_{I}$ \\
\hline 93 & 0.77 & 0.75 & 26 & 0.81 & 0.78 & $\#$ & $\Uparrow$ \\
\hline 94 & 0.79 & 0.77 & 27 & 0.81 & 0.80 & 202 & 0.21 \\
\hline 95 & 0.78 & 0.76 & 28 & 0.81 & 0.78 & 201 & 0.19 \\
\hline 96 & 0.80 & 0.77 & 31 & 0.78 & 0.75 & 208 & 0.21 \\
\hline 97 & 0.79 & 0.78 & 32 & 0.81 & 0.76 & 207 & 0.21 \\
\hline 100 & 0.79 & 0.78 & 33 & 0.78 & 0.74 & 206 & 0.20 \\
\hline 101 & 0.79 & 0.76 & 34 & 0.78 & 0.77 & 205 & 0.19 \\
\hline 103 & 0.80 & 0.77 & 42 & 0.79 & 0.76 & 216 & 0.20 \\
\hline 104 & 0.79 & 0.76 & 43 & 0.79 & 0.77 & 215 & 0.18 \\
\hline 105 & 0.82 & 0.80 & 44 & 0.75 & 0.73 & 214 & 0.19 \\
\hline 106 & 0.79 & 0.77 & 45 & 0.79 & 0.75 & 213 & 0.18 \\
\hline 107 & 0.83 & 0.80 & 48 & 0.78 & 0.75 & & \\
\hline 108 & 0.82 & 0.79 & 49 & 0.78 & 0.76 & & \\
\hline 109 & 0.82 & 0.79 & 50 & 0.78 & 0.77 & & \\
\hline 110 & 0.85 & 0.80 & 51 & 0.79 & 0.77 & & \\
\hline 112 & 0.81 & 0.76 & 55 & 0.78 & 0.76 & & \\
\hline 113 & 0.79 & 0.76 & 56 & 0.78 & 0.75 & & \\
\hline 114 & 0.84 & 0.79 & 57 & 0.79 & 0.77 & & \\
\hline 115 & 0.83 & 0.77 & 58 & 0.80 & 0.78 & & \\
\hline 116 & 0.82 & 0.77 & 61 & 0.82 & 0.77 & & \\
\hline 117 & 0.82 & 0.80 & 62 & 0.78 & 0.76 & & \\
\hline 118 & 0.80 & 0.79 & 63 & 0.79 & 0.76 & & \\
\hline 119 & 0.82 & 0.80 & 64 & 0.78 & 0.75 & & \\
\hline 120 & 0.82 & 0.77 & 70 & 0.80 & 0.76 & & \\
\hline 121 & 0.81 & 0.81 & 71 & 0.80 & 0.79 & & \\
\hline 123 & 0.82 & 0.80 & 72 & 0.79 & 0.75 & & \\
\hline 125 & 0.83 & 0.79 & 73 & 0.78 & 0.77 & & \\
\hline
\end{tabular}

\footnotetext{
${ }^{1}$ per drawing ANL-NSTF-TS0001-DWG-142-R0, pg. 45

${ }^{2}$ per drawing ANL-NSTF-TS0001-DWG-141-R0, pg. 44

${ }^{2}$ per drawing ANL-NSTF-TS0001-DWG-138-R0, pg. 49

${ }^{2}$ per drawing ANL-NSTF-TS0001-DWG-137-R0, pg. 48
} 
* $\begin{aligned} & \mathscr{0} 0 \\ & 0 \\ & 0\end{aligned}$

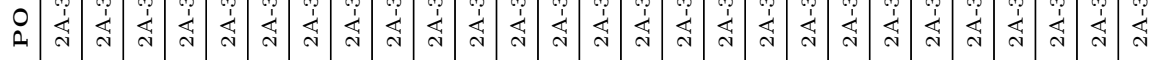

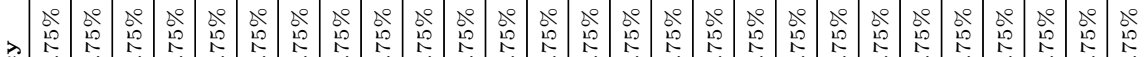

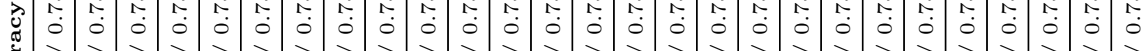

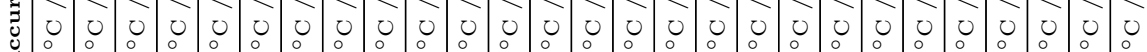

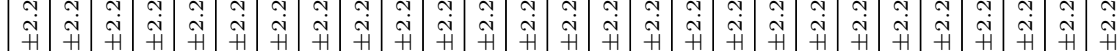

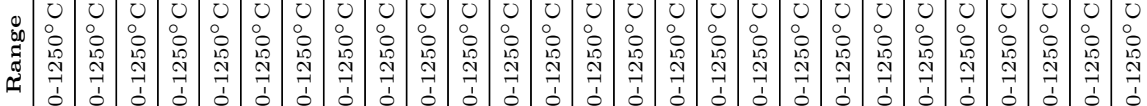

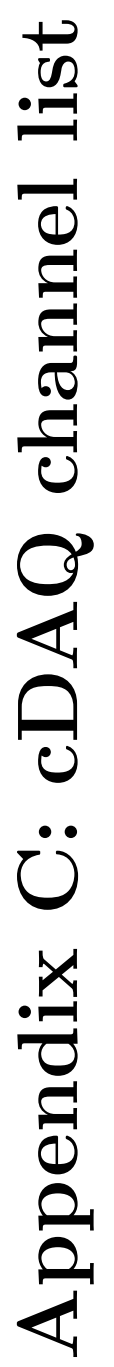

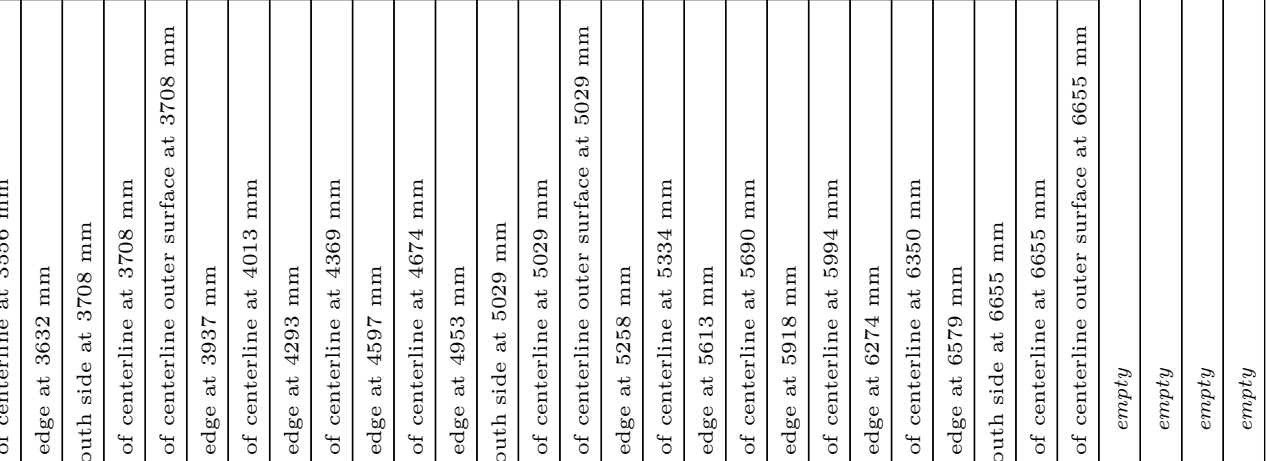

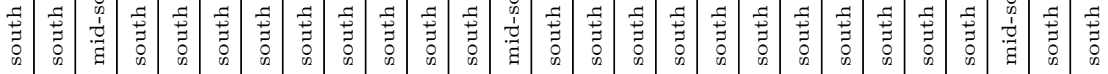

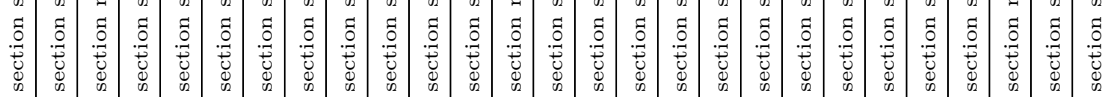

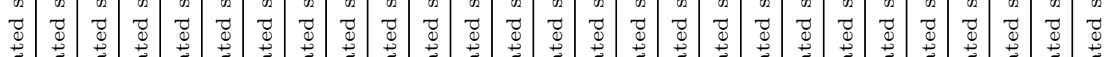

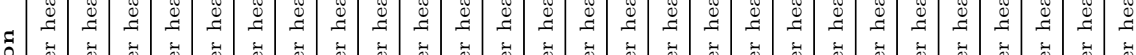

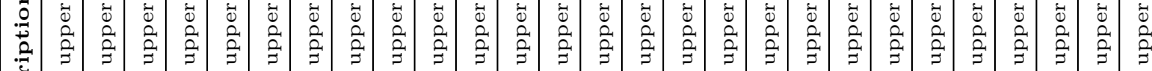

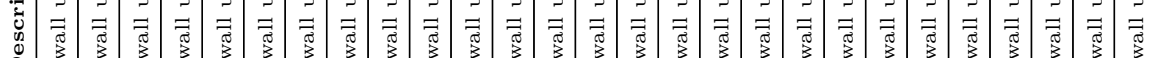

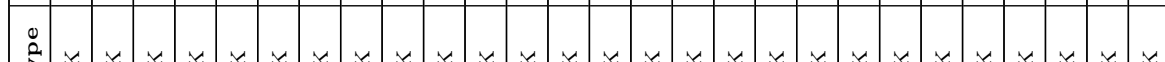

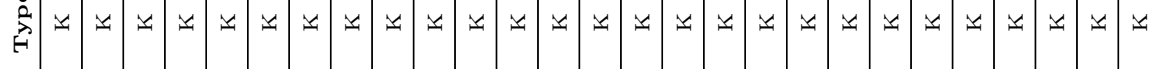

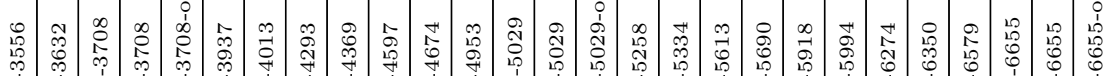

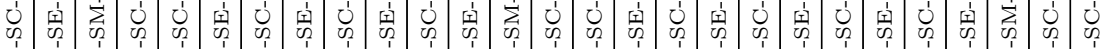

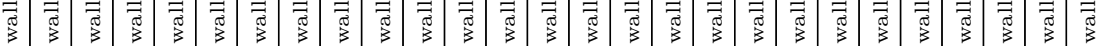

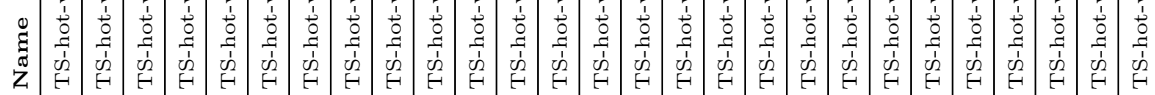

乙

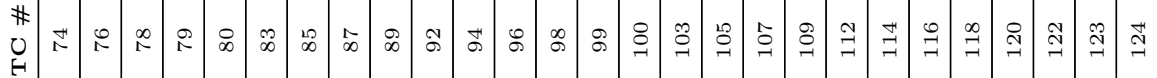

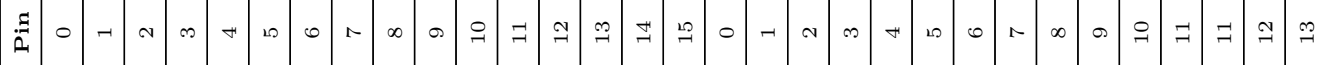

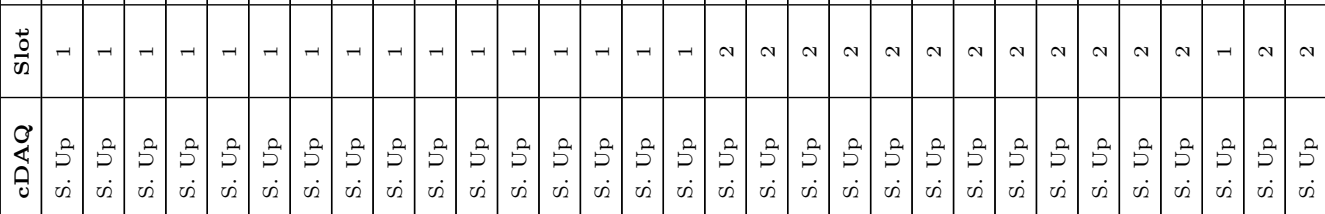




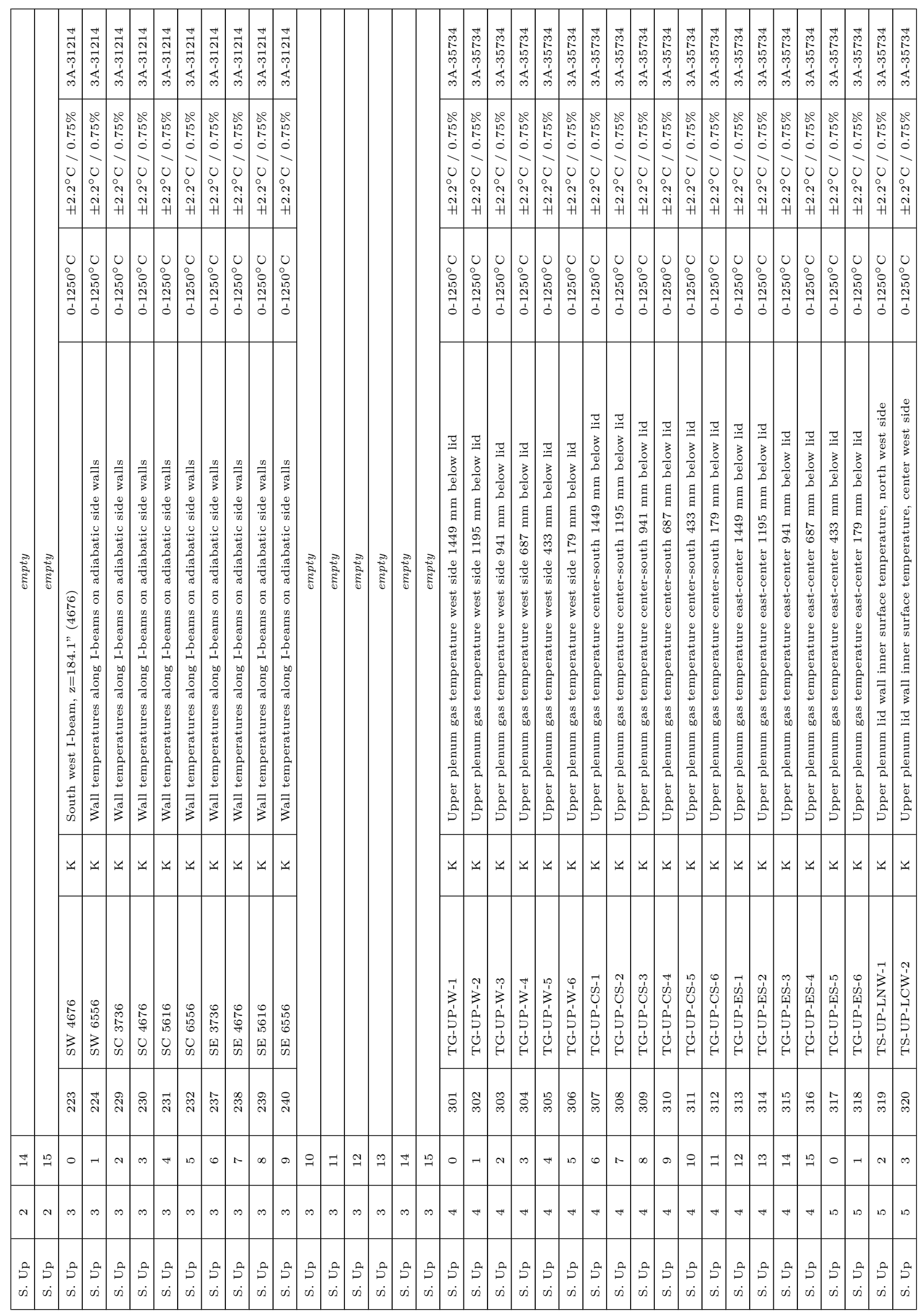


Design Report for the $1 / 2$ Scale Air-Cooled RCCS Tests in the NSTF

June 2014

\begin{tabular}{|c|c|c|c|c|c|c|c|c|c|c|c|c|c|c|c|c|c|c|c|c|c|c|c|c|c|c|c|c|c|c|c|c|}
\hline & $\mid \begin{array}{c}\overrightarrow{1} \\
0 \\
0 \\
0 \\
0 \\
\dot{1} \\
\infty \\
0\end{array}$ & 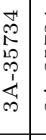 & 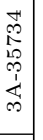 & & & & & & & & & 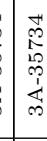 & 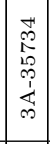 & 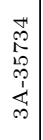 & 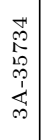 & 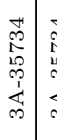 & 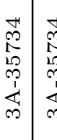 & 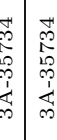 & 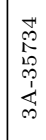 & & & & & & 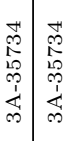 & 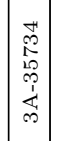 & $\begin{array}{c}\overrightarrow{0} \\
0 \\
0 \\
p \\
p \\
\dot{p} \\
m\end{array}$ & 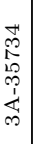 & 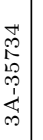 & & & 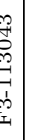 \\
\hline & $\begin{array}{c}0 \\
0 \\
0 \\
0 \\
0 \\
0 \\
0 \\
0 \\
0 \\
0 \\
i \\
H \\
H\end{array}$ & 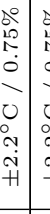 & 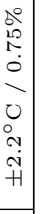 & & & & & & & & & 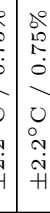 & $\begin{array}{c}0 \\
0 \\
1 \\
1 \\
0 \\
0 \\
0 \\
0 \\
0 \\
0 \\
N \\
i \\
+1 \\
H\end{array}$ & $\begin{array}{c}0 \\
i \\
1 \\
0 \\
0 \\
0 \\
0 \\
0 \\
0 \\
i \\
i \\
+1\end{array}$ & 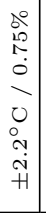 & 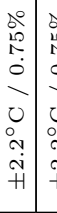 & 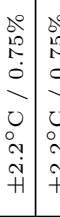 & \begin{tabular}{c|c}
0 & \\
0 \\
0
\end{tabular} & $\begin{array}{l}0 \\
0 \\
10 \\
0 \\
0 \\
0 \\
0 \\
0 \\
0 \\
i \\
+1\end{array}$ & & & & & & 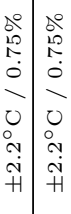 & 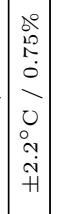 & 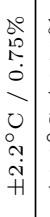 & 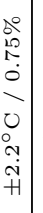 & 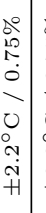 & & & 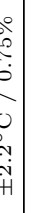 \\
\hline 0 & \begin{tabular}{l|l}
0 \\
0 \\
0 \\
$d$ \\
$\vdots$ \\
0 \\
0
\end{tabular} & 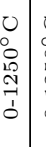 & $\begin{array}{c}0 \\
0 \\
0 \\
d \\
\\
0 \\
0\end{array}$ & & & & & & & & & 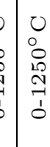 & $\begin{array}{l}0 \\
0 \\
0 \\
0 \\
d \\
0 \\
0 \\
0\end{array}$ & $\begin{array}{l}0 \\
0 \\
0 \\
0 \\
\vdots \\
0\end{array}$ & $\begin{array}{c}0 \\
0 \\
0 \\
0 \\
\vdots \\
0 \\
0\end{array}$ & 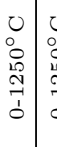 & 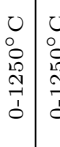 & 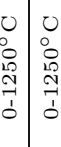 & 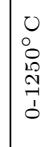 & & & & & & 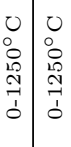 & $\begin{array}{l}0 \\
0 \\
0 \\
0 \\
\stackrel{0}{N} \\
0 \\
0\end{array}$ & 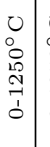 & \begin{tabular}{l|}
0 \\
0 \\
0 \\
\\
\\
0
\end{tabular} & 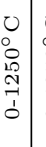 & & & है \\
\hline & 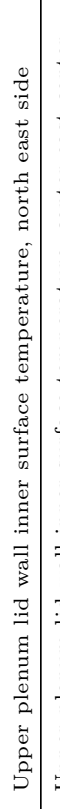 & 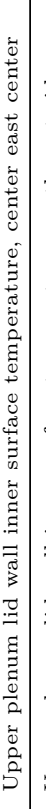 & 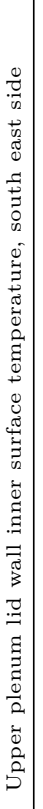 & & & & & & & & 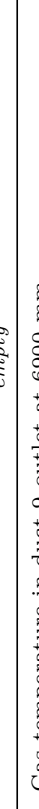 & 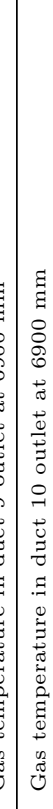 & 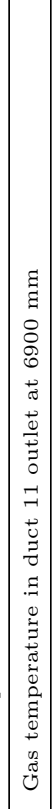 & 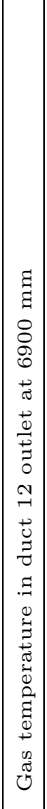 & 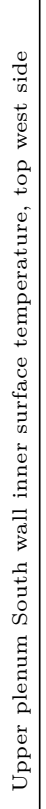 & 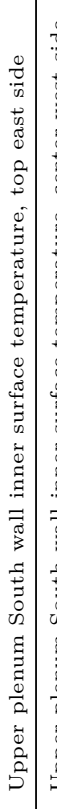 & 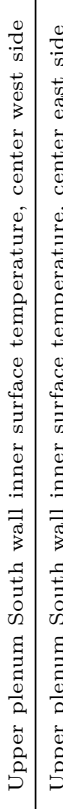 & 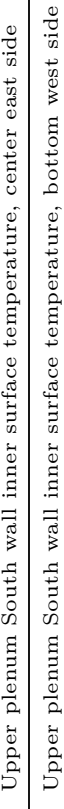 & 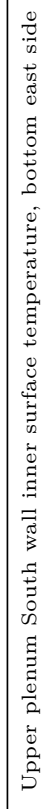 & 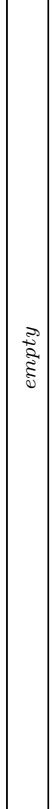 & & & है & & 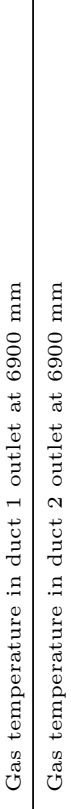 & 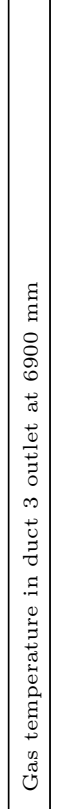 & 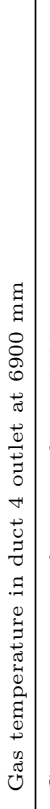 & 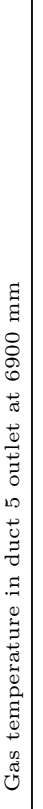 & 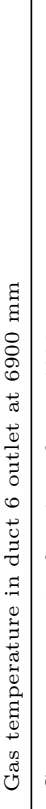 & 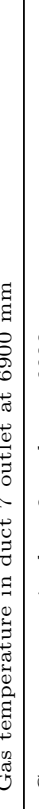 & 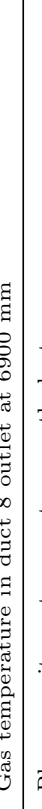 & $\begin{array}{l}\vec{Z} \\
\vec{z} \\
\vec{z} \\
\underline{E}\end{array}$ \\
\hline$\approx$ & $\approx$ & $\approx$ & $\approx$ & & & & & & & & 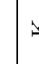 & $4=$ & $\approx$ & $\approx$ & $\approx$ & $\approx$ & $\approx=$ & $\because \approx$ & $\approx$ & & & & & & 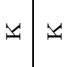 & $\approx$ & $x$ & 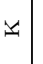 & $\approx$ & 4 & & 4 \\
\hline & 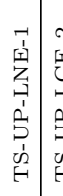 & 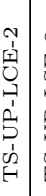 & & & & & & & & & & 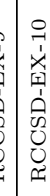 & 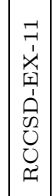 & 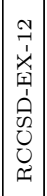 & 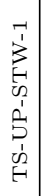 & 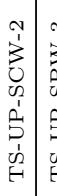 & 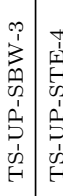 & 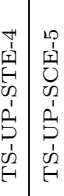 & 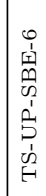 & & & & & & 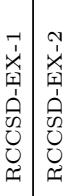 & 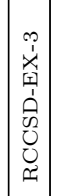 & 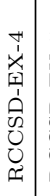 & 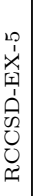 & 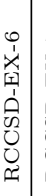 & 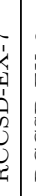 & & \\
\hline $\overrightarrow{\tilde{\nu}}$ & 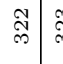 & ळ్ & 芯 & & & & & & & & & 㤐 & $\begin{array}{c}\infty \\
\infty \\
\infty \\
\infty\end{array}$ & 总 & $\begin{array}{l}\infty \\
\infty \\
\infty\end{array}$ & \begin{tabular}{l|l}
$\vec{\infty}$ & \multirow{\infty}{\infty}{}
\end{tabular} & \begin{tabular}{l|l}
$\infty$ & $\infty$ \\
$\infty$ & $\infty$ \\
$\infty$
\end{tabular} & $\begin{array}{l}\infty \\
\infty \\
\infty \\
\infty\end{array}$ & $\begin{array}{l}\infty \\
\infty \\
\infty\end{array}$ & & & & & & \begin{tabular}{l|l}
$\infty$ \\
$\stackrel{\infty}{\infty}$
\end{tabular} & 品 & $\vec{D}$ & 졿 & 﨎 & C. & 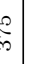 & F \\
\hline 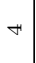 & $\infty 0$ & $\circ$ & $\wedge$ & $\infty$ & $\sigma$ & 욤 & 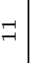 & $\mathcal{I}$ & $\stackrel{\Rightarrow}{\rightarrow}$ & 4 & & - & N & $\infty$ & 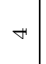 & 10 & $\begin{array}{lll}0 & 1\end{array}$ & $\begin{array}{l}\wedge \\
\wedge\end{array}$ & $\theta$ & $\stackrel{9}{\circ}$ & $\exists$ & 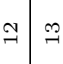 & \pm & . & \begin{tabular}{l|ll}
0 & -1
\end{tabular} & $\sim$ & $\infty$ & + & 10 & & & $\infty$ \\
\hline סג & 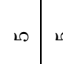 & 10 & 10 & 10 & 10 & 10 & 10 & 20 & 102 & ? & 0 & 00 & 0 & 0 & 0 & 0 & 00 & $\begin{array}{llll}0 & 0\end{array}$ & 0 & 0 & $\begin{array}{lll}0 & 0\end{array}$ & $\begin{array}{lll}0 & 0\end{array}$ & 0 & 0. & $\wedge$ & $r$ & $\wedge$ & $\therefore$ & $\wedge$ & & & A \\
\hline & 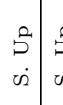 & \begin{tabular}{c|l}
$\vec{b}$ & \multicolumn{2}{c}{} \\
$\dot{\omega}$ & 0
\end{tabular} & $\begin{array}{l}5 \\
\dot{\omega}\end{array}$ & $\begin{array}{l}\overrightarrow{0} \\
\dot{c}\end{array}$ & $\begin{array}{l}D^{2} \\
\dot{s}\end{array}$ & & & & & & & 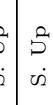 & $\begin{array}{l}0 \\
\dot{D} \\
\dot{s}\end{array}$ & $\mid \begin{array}{l}a \\
\vdots \\
\dot{s}\end{array}$ & $\begin{array}{c}0 \\
D \\
\dot{s}\end{array}$ & \begin{tabular}{c|c}
$a$ & \\
$\dot{s}$ & \\
$\dot{v}$ & $=$
\end{tabular} & 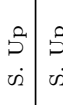 & 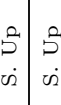 & $\mid \begin{array}{l}s^{2} \\
\dot{s}\end{array}$ & & & 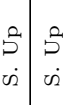 & $\mid \begin{array}{c}0 \\
D \\
\dot{s}\end{array}$ & & \begin{tabular}{c|c}
$s^{2}$ & \multicolumn{1}{c}{} \\
is & is
\end{tabular} & $\mid \begin{array}{c}0 \\
\dot{s} \\
\dot{s}\end{array}$ & $\begin{array}{l}\vec{s} \\
\dot{s}\end{array}$ & $\begin{array}{l}\overrightarrow{2} \\
\dot{s} \\
\dot{2}\end{array}$ & $\begin{array}{l}\dot{s} \\
\dot{s}\end{array}$ & & & sid \\
\hline
\end{tabular}


Design Report for the 1/2 Scale Air-Cooled RCCS Tests in the NSTF

June 2014

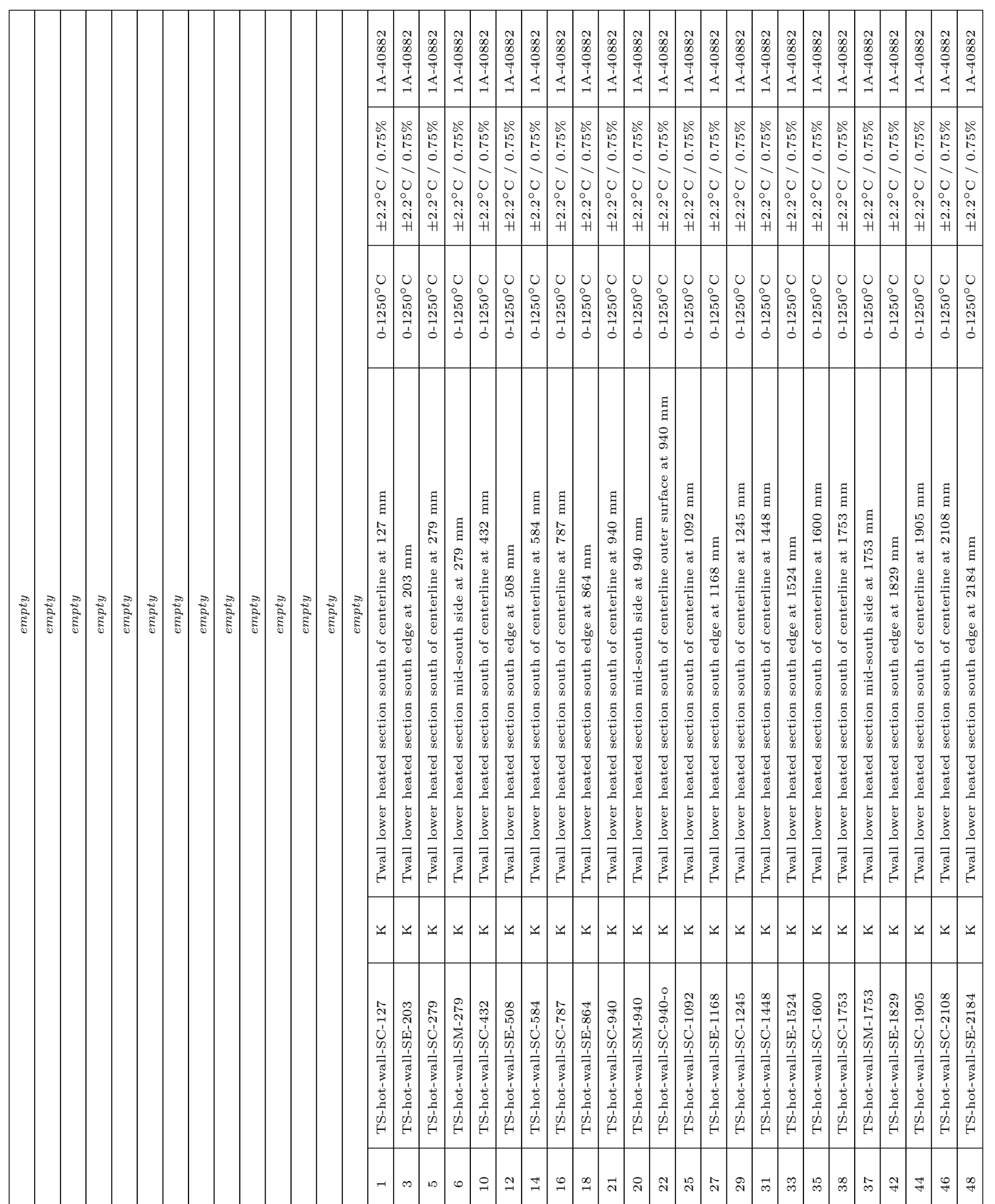

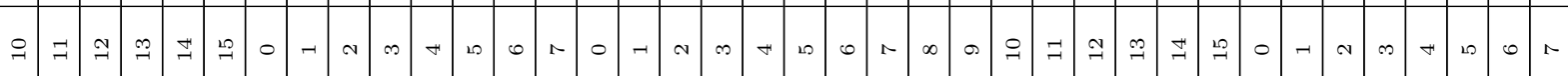

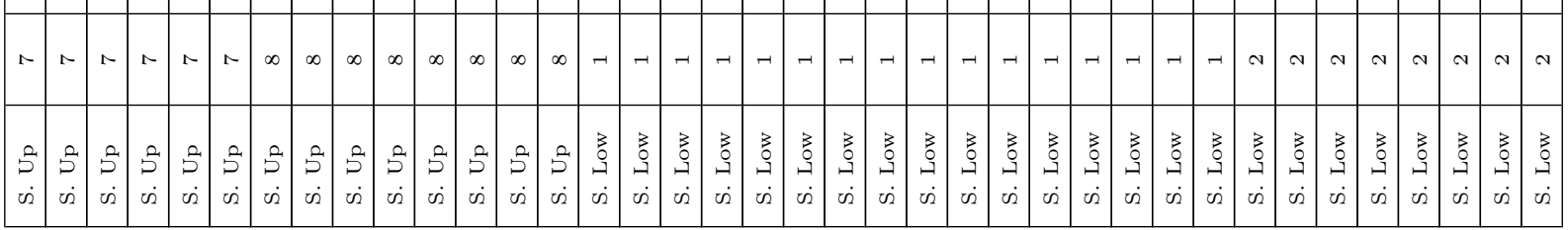




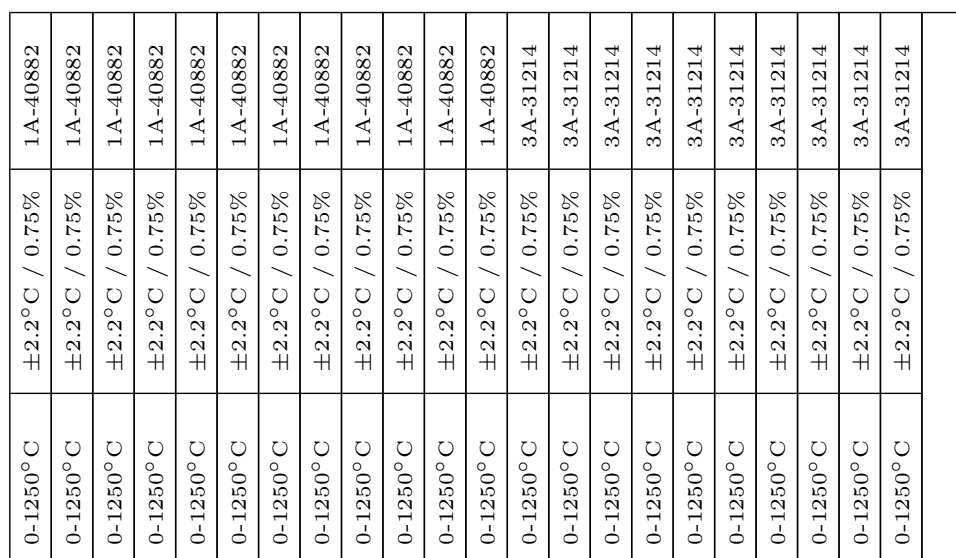

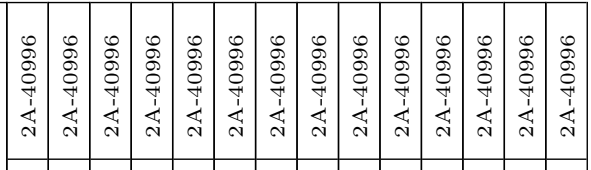

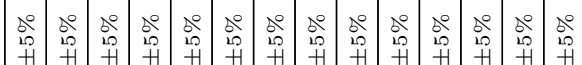

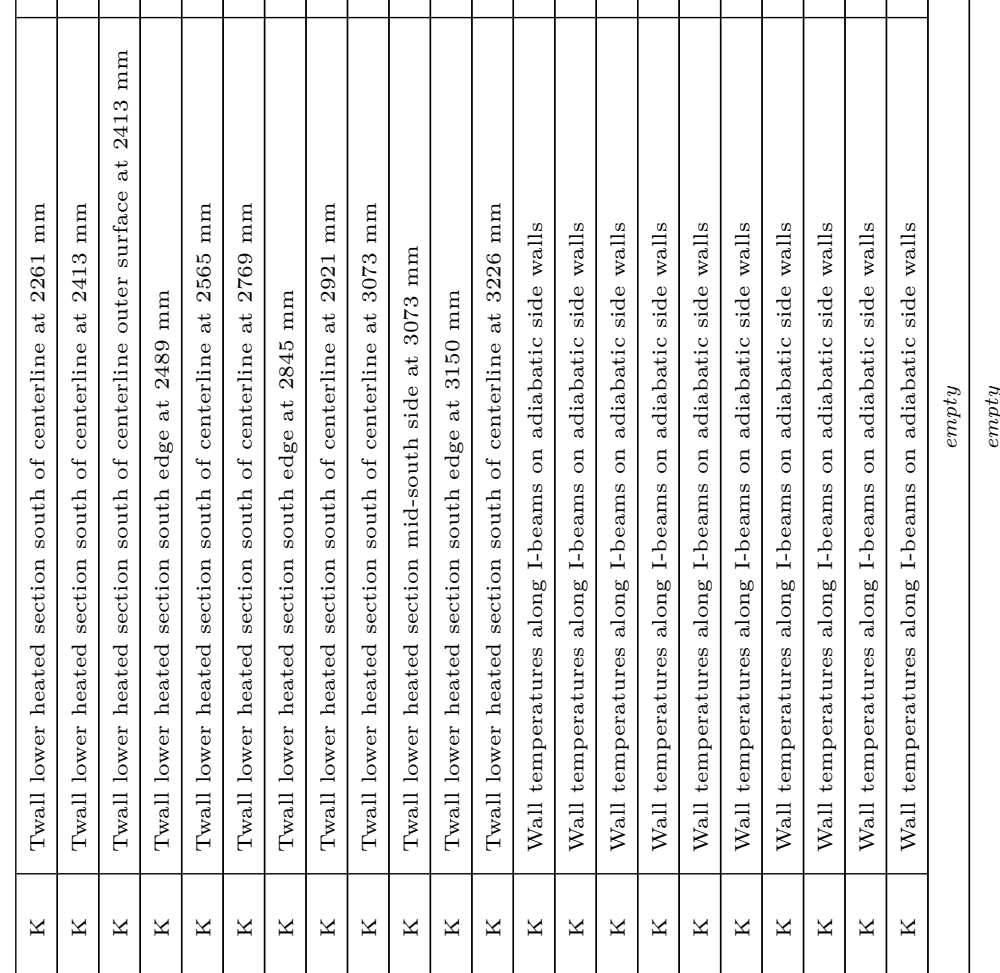

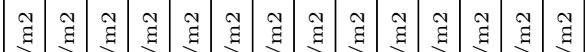

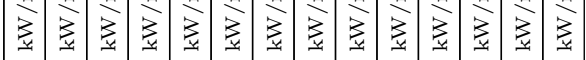
品然

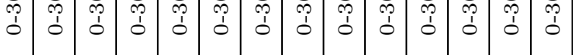

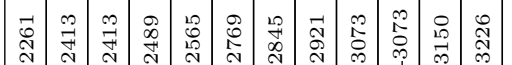

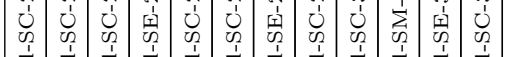

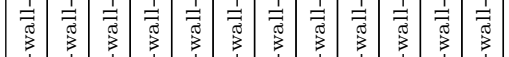

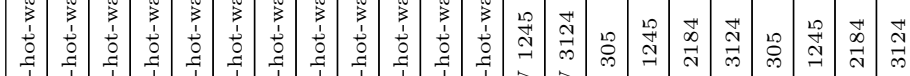

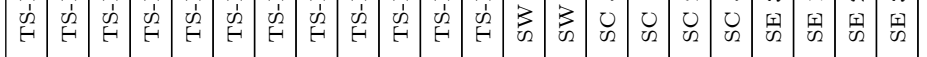

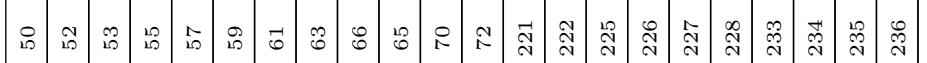

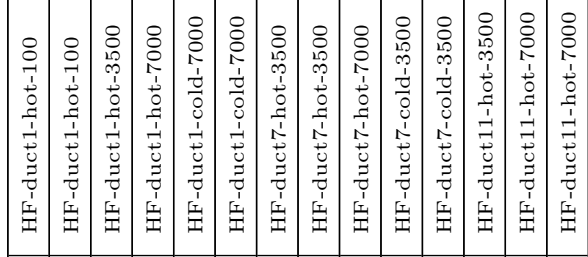

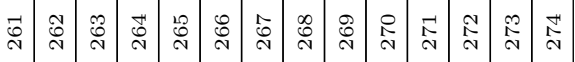
m の

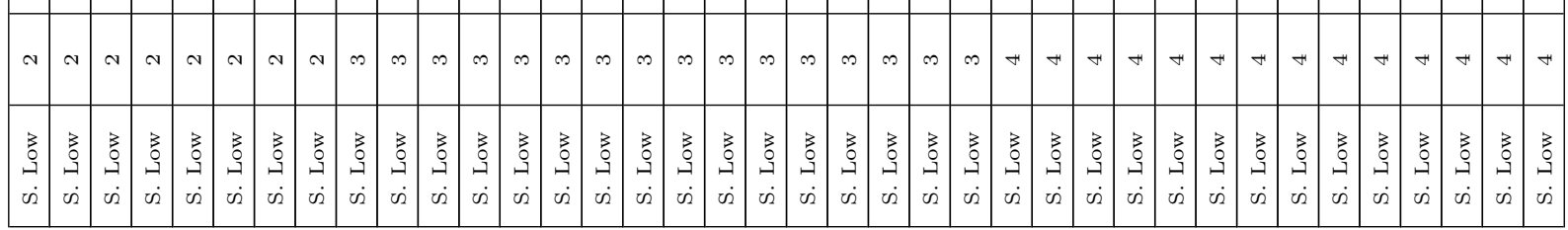


员

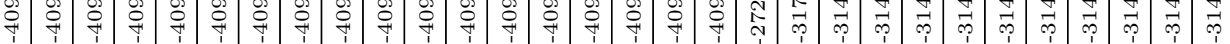

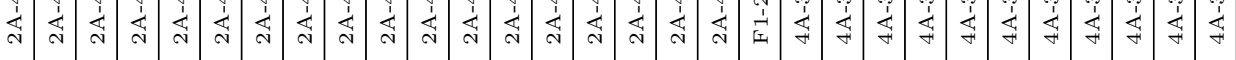

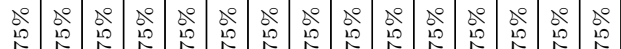

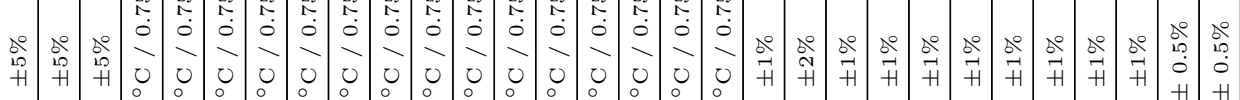

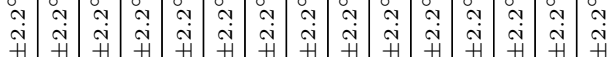

:

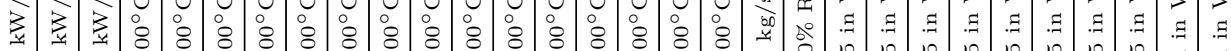

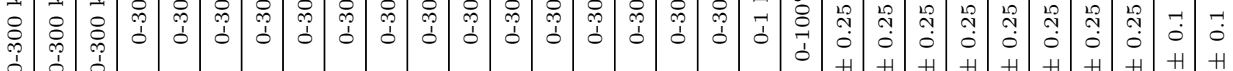

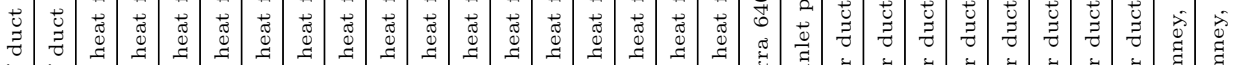

t)

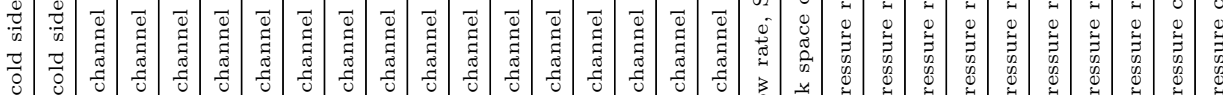

亏

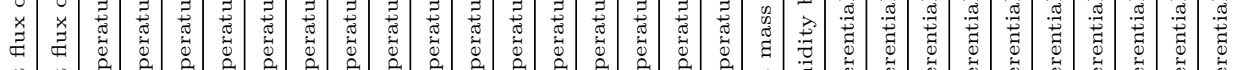

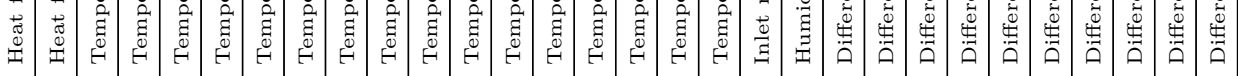

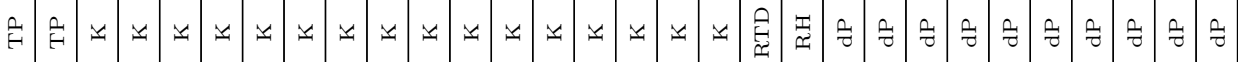

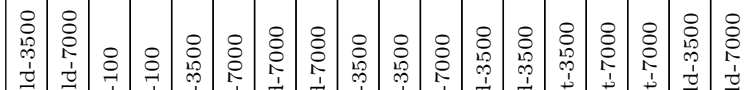

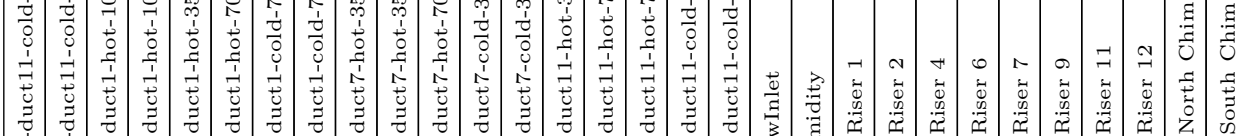

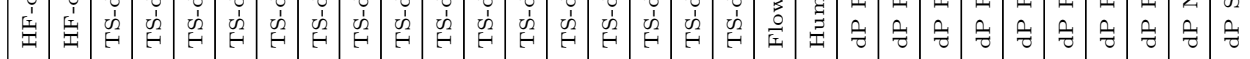

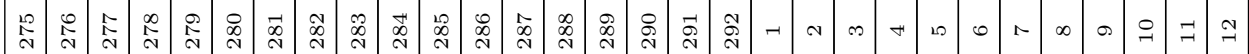

d

\begin{tabular}{|c|c|c|c|c|c|c|c|c|c|c|c|c|c|c|c|c|c|c|c|c|c|c|c|c|c|c|c|c|c|c|c|c|}
\hline & & & & & & & & & & & & & & & & & & & & & & & & & & & & & & & & \\
\hline 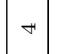 & 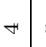 & & of & מo & 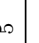 & מo & 20. & 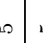 & r 2 & 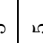 & $\infty$ & 10 & $\infty$ & 10 & \begin{tabular}{c|c|c}
6 & 10. \\
\end{tabular} & 0 & 0 & 0 & 0 & 0 & 0.0 & 0 & 0 & 0 & $\begin{array}{lll}0 & 0\end{array}$ & $\begin{array}{lll}0 & 0\end{array}$ & 0 & 0 & $\begin{array}{lll}0 & 1\end{array}$ & 11 & 1 & r \\
\hline & u & & & & & $\stackrel{8}{9}$ & ${ }^{\prime}$ & كَ & 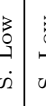 & 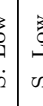 & $\begin{array}{c}3 \\
\vdots \\
\vdots \\
\dot{v}\end{array}$ & $\begin{array}{l}3 \\
0 \\
\vdots \\
\text { is }\end{array}$ & $\begin{array}{c}3 \\
\vdots \\
\dot{3} \\
\dot{v}\end{array}$ & $\begin{array}{l}3 \\
\vdots \\
\dot{y} \\
\dot{v}\end{array}$ & 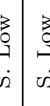 & $\begin{array}{l}0 \\
\vdots \\
\dot{b} \\
\dot{2}\end{array}$ & $\begin{array}{l}3 \\
\vdots \\
\\
\text { vi }\end{array}$ & \begin{tabular}{|l|}
3 \\
0 \\
9 \\
$\dot{\omega}$
\end{tabular} & & $\begin{array}{c}z \\
\vdots \\
\dot{y} \\
\dot{v}\end{array}$ & 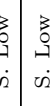 & 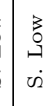 & $\mid \begin{array}{c}3 \\
0 \\
\vdots \\
v 2\end{array}$ & 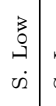 & & $\begin{array}{l}0 \\
\vdots \\
\vdots \\
\dot{2} \\
\dot{2}\end{array}$ & & $\begin{array}{c}3 \\
\vdots \\
0 \\
v i\end{array}$ & & & & 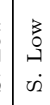 \\
\hline
\end{tabular}




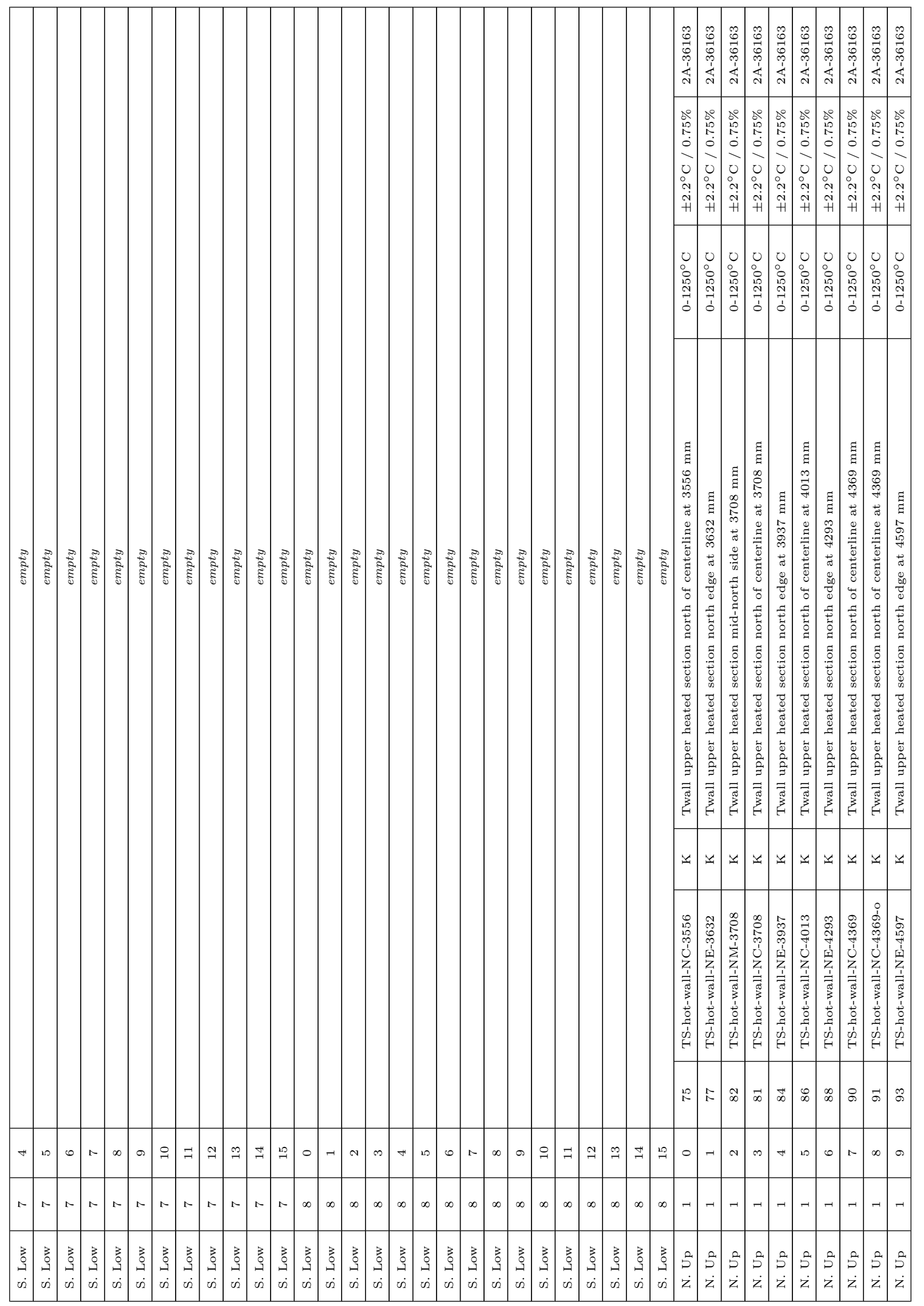




\begin{tabular}{|c|c|c|c|c|c|c|c|c|c|c|c|c|c|c|c|c|c|c|c|c|c|c|}
\hline & 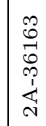 & 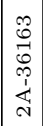 & $\begin{array}{l}0 \\
0 \\
0 \\
0 \\
0 \\
\frac{1}{4}\end{array}$ & 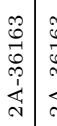 & 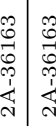 & 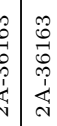 & 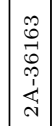 & $\begin{array}{l}0 \\
0 \\
0 \\
0 \\
0 \\
4 \\
4\end{array}$ & 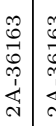 & 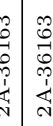 & 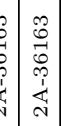 & 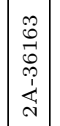 & 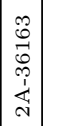 & $\begin{array}{l}\vec{d} \\
\vec{n} \\
\vec{p} \\
\frac{d}{m}\end{array}$ & 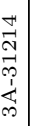 & & & $\frac{\pi}{\infty}$ & $\begin{array}{l}\vec{N} \\
\vec{N} \\
\vec{p} \\
\frac{d}{m}\end{array}$ & 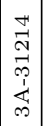 & & 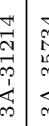 \\
\hline & $\begin{array}{l}0 \\
\text { O } \\
\text { in } \\
\text { H }\end{array}$ & $\begin{array}{l}0 \\
0 \\
0 \\
0 \\
0 \\
0 \\
0 \\
0 \\
0 \\
i \\
i \\
+1\end{array}$ & $\begin{array}{l}0 \\
0 \\
0 \\
0 \\
0 \\
0 \\
0 \\
0 \\
0 \\
i \\
+1\end{array}$ & 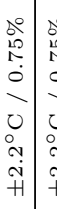 & 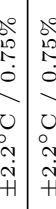 & 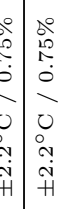 & $\mid \begin{array}{l}0 \\
0 \\
1 \\
0 \\
0 \\
0 \\
0 \\
0 \\
0 \\
ن \\
i \\
H\end{array}$ & $\begin{array}{l}0 \\
0 \\
1 \\
0 \\
0 \\
0 \\
0 \\
0 \\
\text { in } \\
H\end{array}$ & 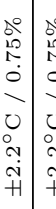 & 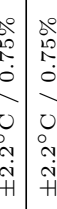 & 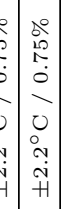 & $\mid \begin{array}{l}0 \\
0 \\
1 \\
0 \\
0 \\
0 \\
0 \\
0 \\
0 \\
\text { H } \\
+1\end{array}$ & $\begin{array}{c}0 \\
0 \\
1 \\
R \\
0 \\
0 \\
0 \\
0 \\
0 \\
i \\
i \\
H \\
H\end{array}$ & 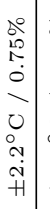 & 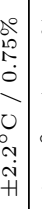 & v & 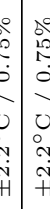 & $\begin{array}{l}0 \\
0 \\
1 \\
1 \\
0 \\
0 \\
0 \\
0 \\
0 \\
0\end{array}$ & $\begin{array}{l}0 \\
0 \\
1 \\
1 \\
0 \\
0 \\
\sim \\
0 \\
0 \\
0 \\
\sim \\
i \\
i \\
H\end{array}$ & \begin{tabular}{|c|}
0 \\
0 \\
1 \\
1 \\
0 \\
0 \\
0 \\
0 \\
0 \\
$i$ \\
$i$ \\
$H$
\end{tabular} & 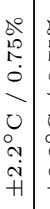 & 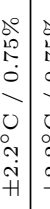 \\
\hline & & $\begin{array}{l}0 \\
0 \\
0 \\
0 \\
0 \\
0 \\
0 \\
0\end{array}$ & 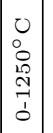 & 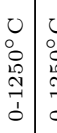 & 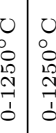 & 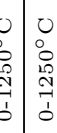 & 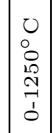 & j & 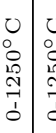 & 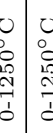 & 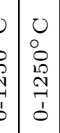 & $\begin{array}{l}0 \\
0 \\
0 \\
d \\
\vdots \\
0 \\
0\end{array}$ & \begin{tabular}{|l|}
0 \\
0 \\
0 \\
0 \\
0 \\
0 \\
0
\end{tabular} & \begin{tabular}{l}
0 \\
0 \\
0 \\
0 \\
\multirow{d}{0}{} \\
0
\end{tabular} & 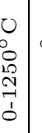 & & 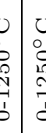 & , & $\begin{array}{l}0 \\
0 \\
0 \\
0 \\
\vdots \\
0 \\
0\end{array}$ & $\begin{array}{l}0 \\
0 \\
0 \\
a \\
0 \\
0 \\
0\end{array}$ & $\vec{c}$ & 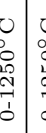 \\
\hline
\end{tabular}

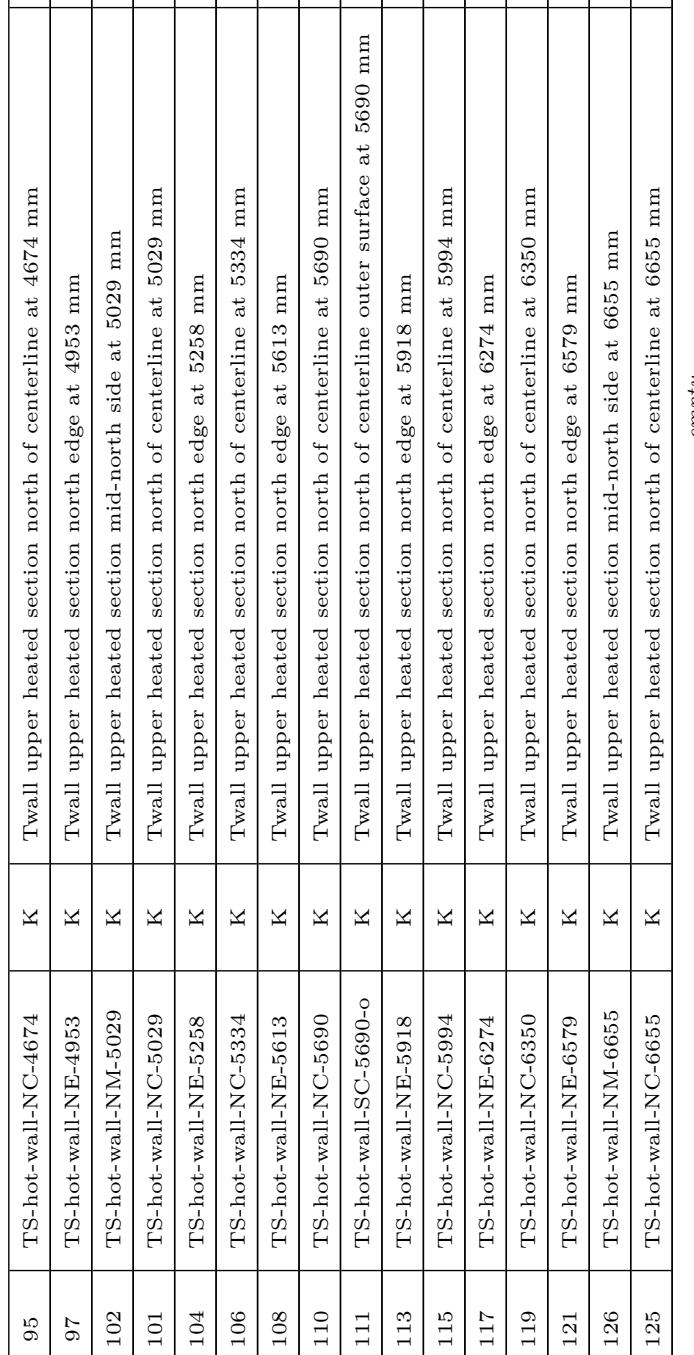

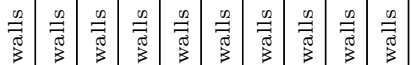

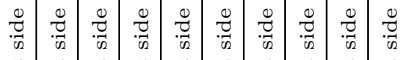

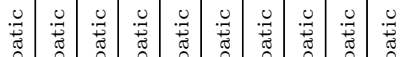

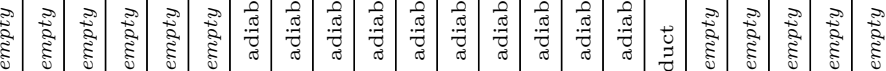

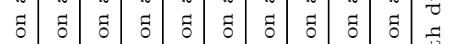

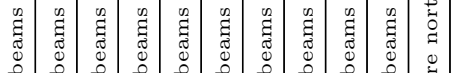

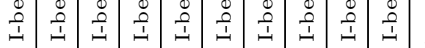

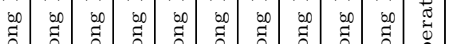

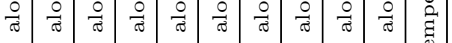

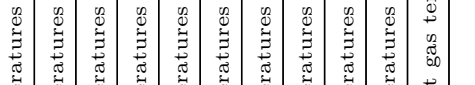

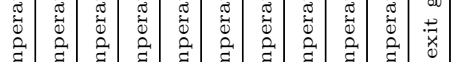

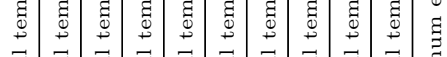

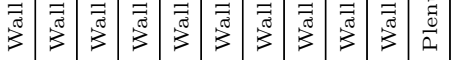

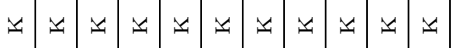

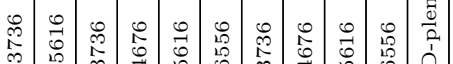

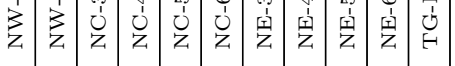

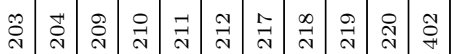

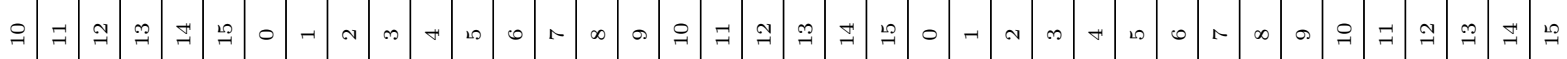

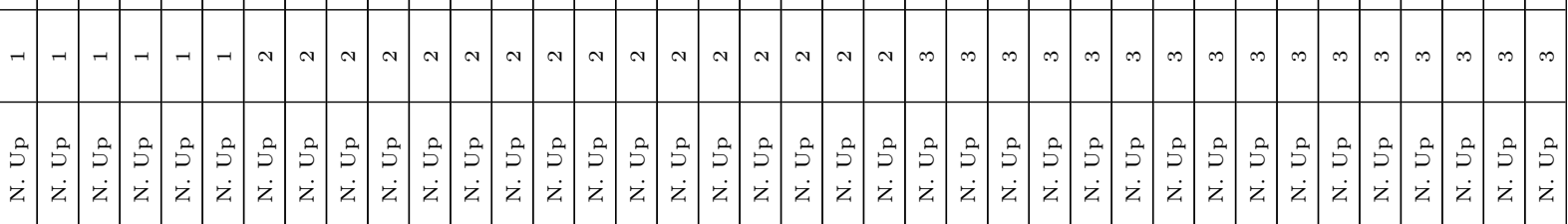




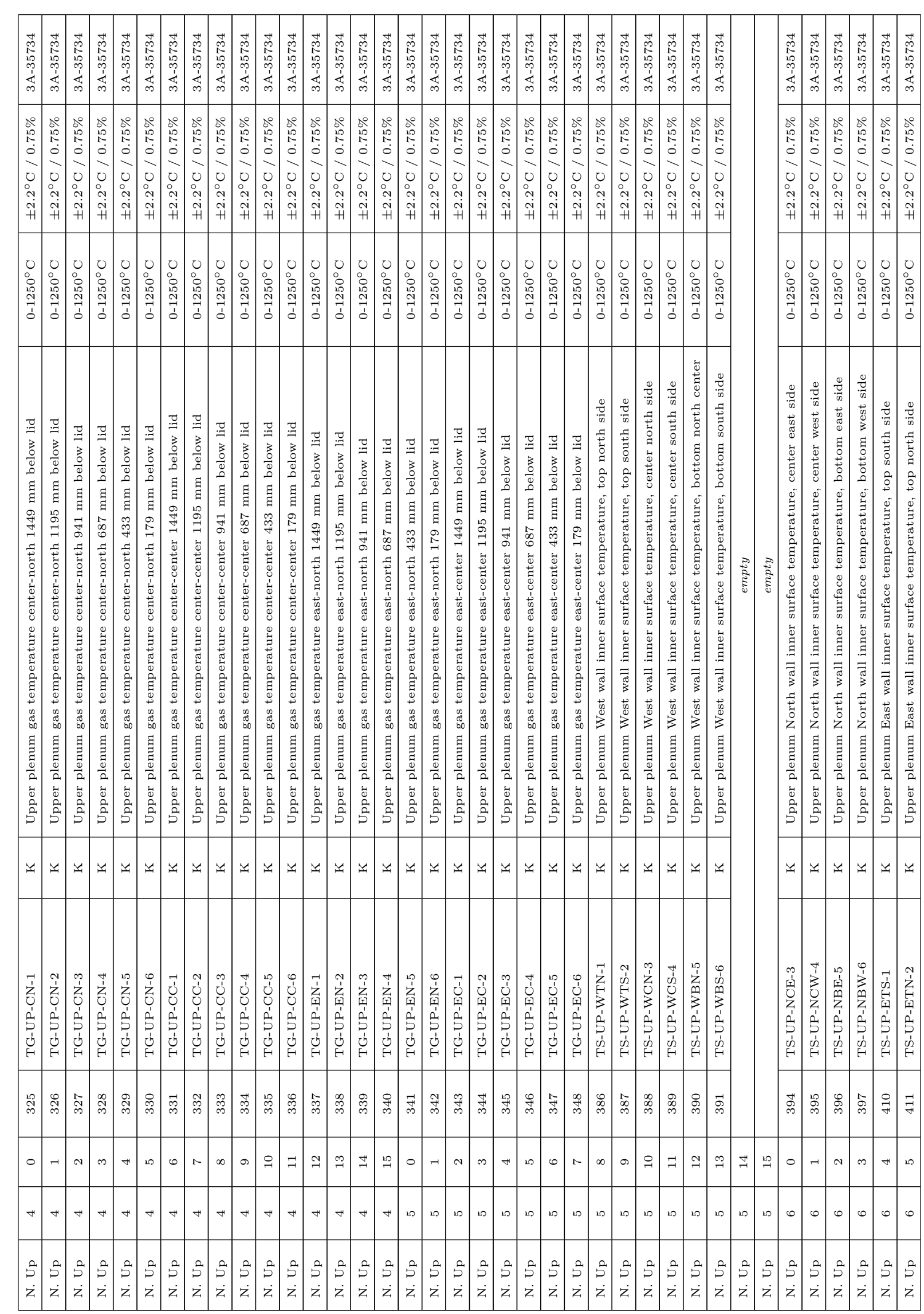




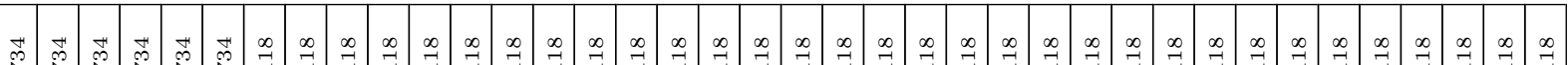

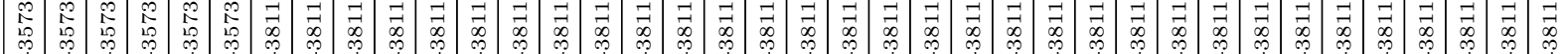
गं की

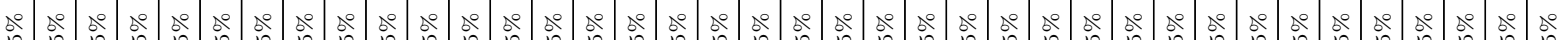

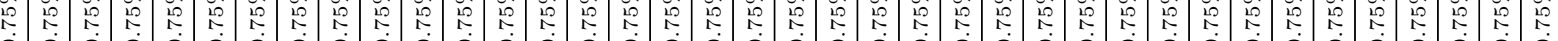

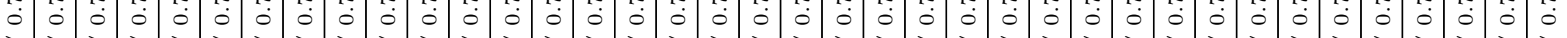

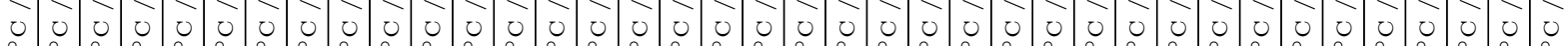

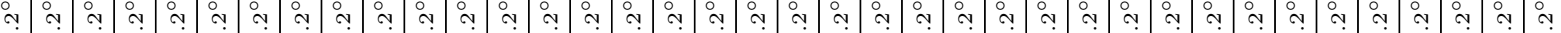

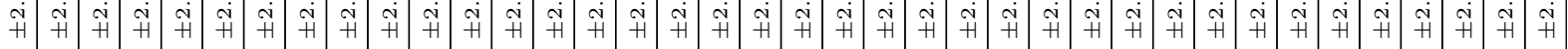

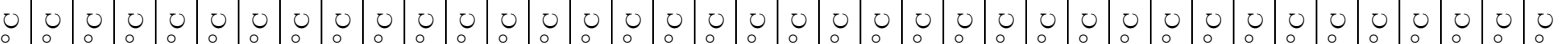

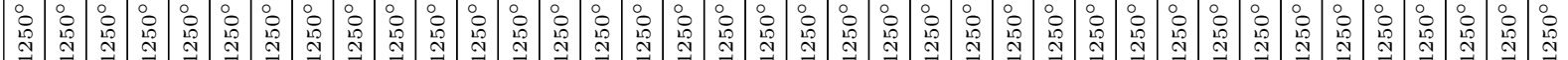

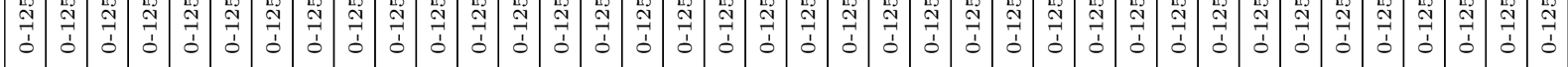

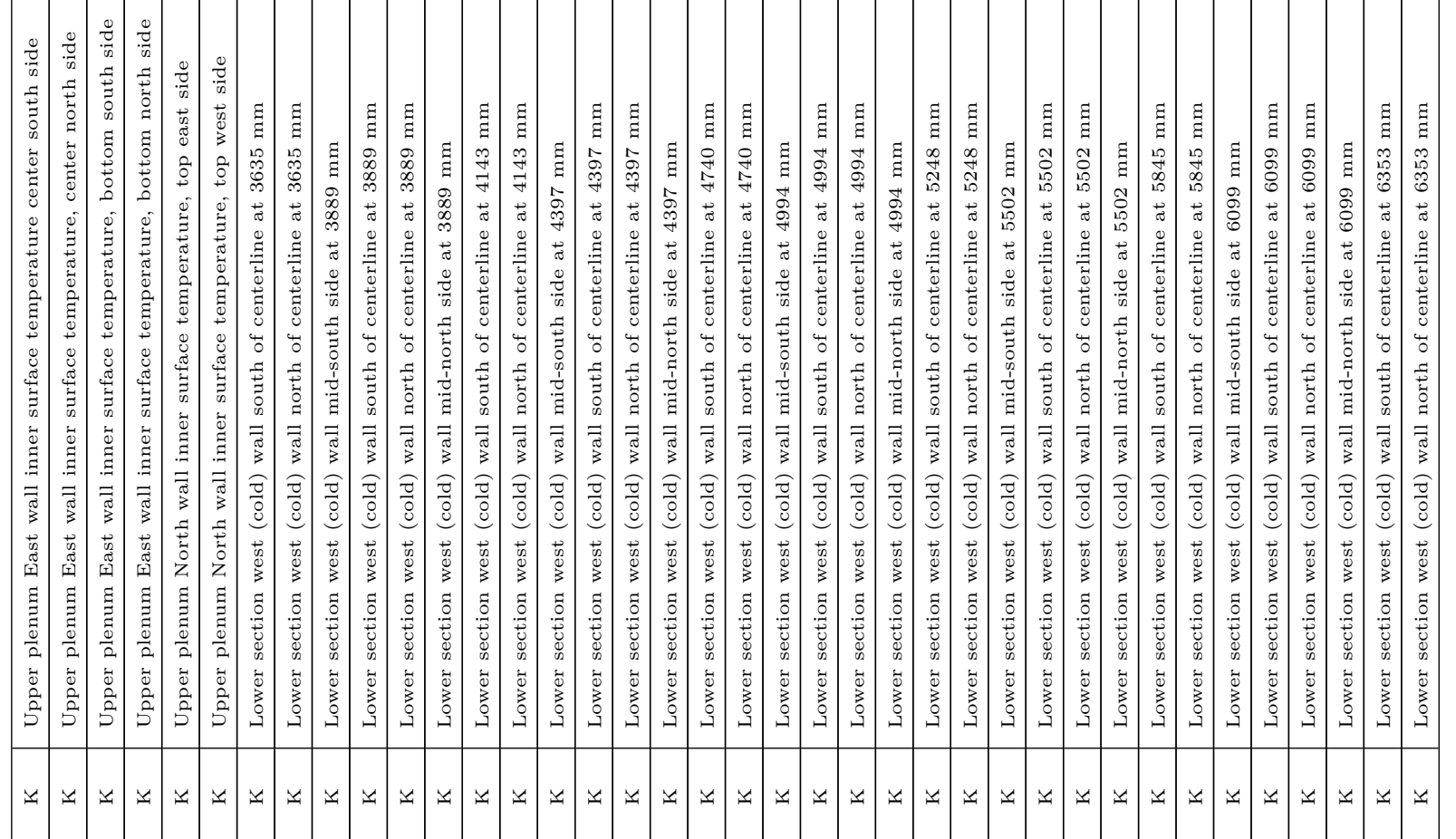

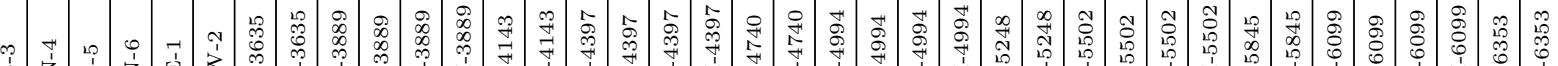

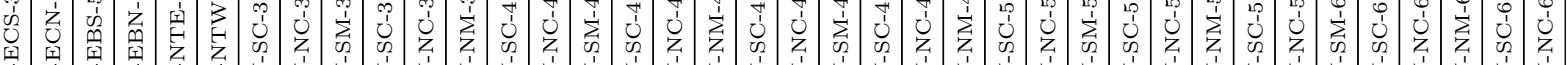

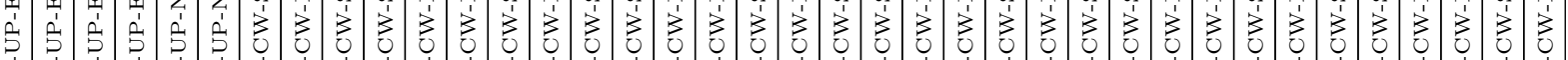
它

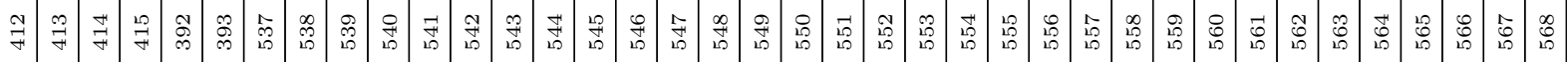

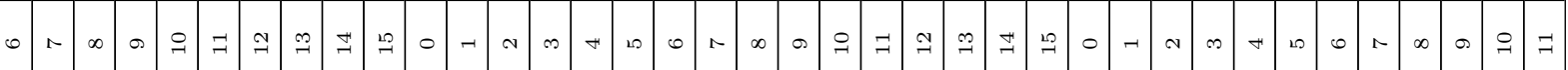

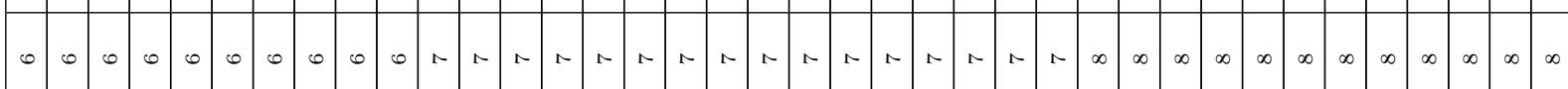

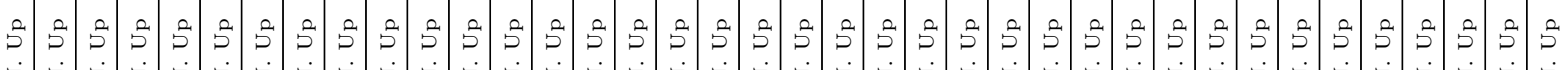

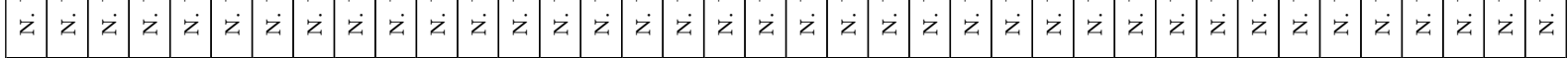




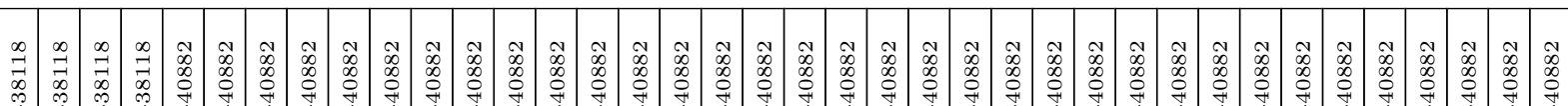

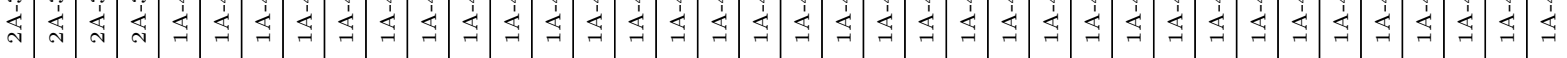

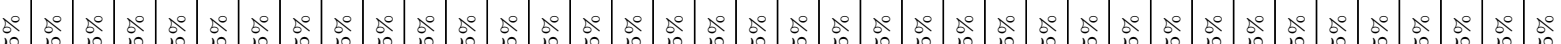

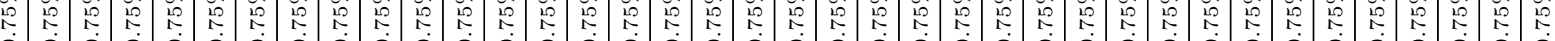

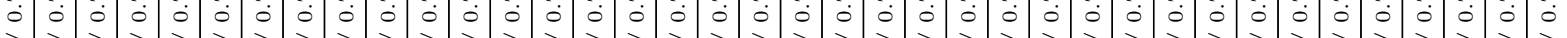

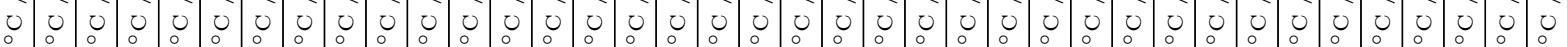

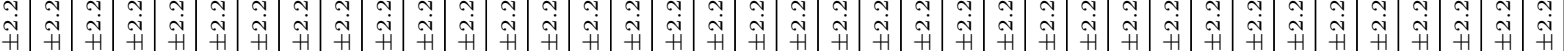

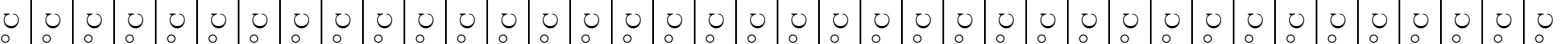

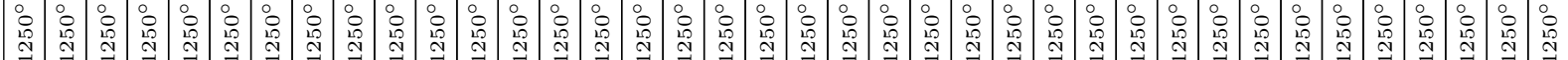

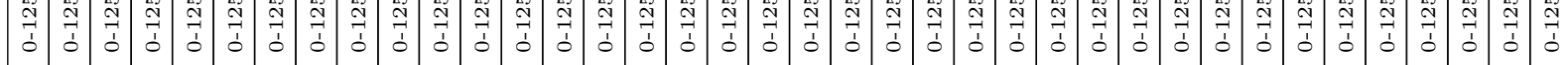

घ

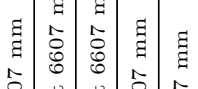

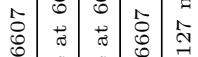

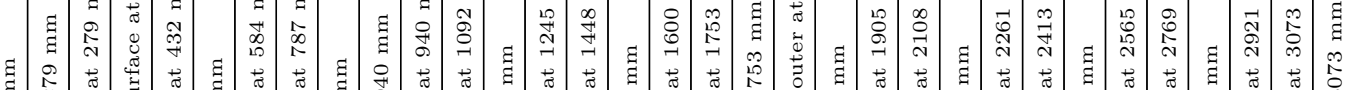

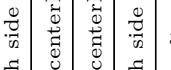

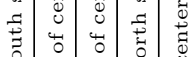

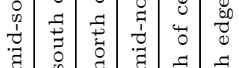

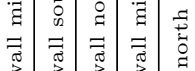

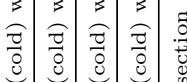

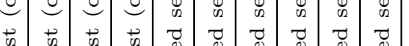

寻

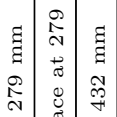

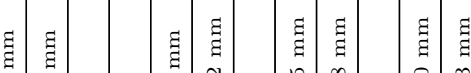

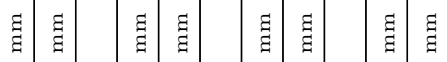

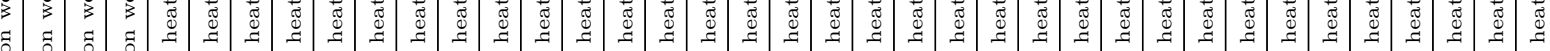

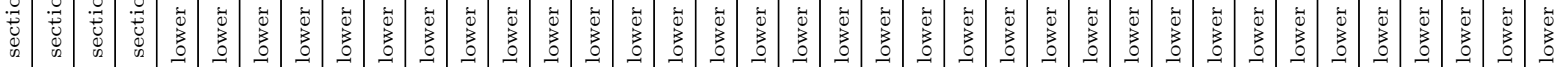

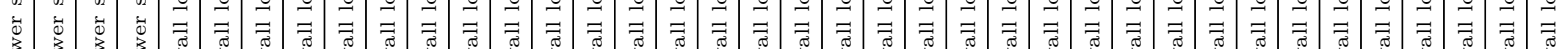

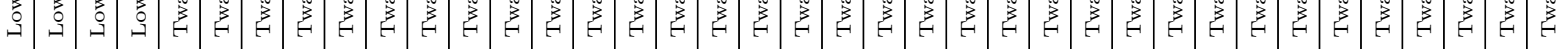

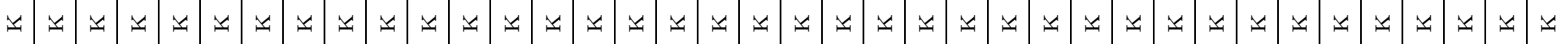

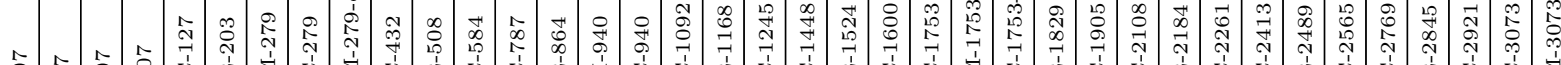

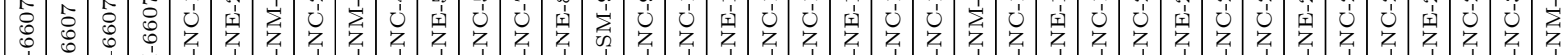

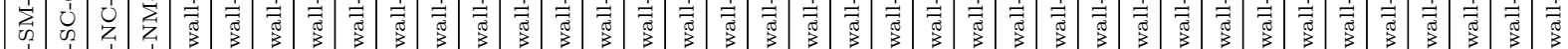

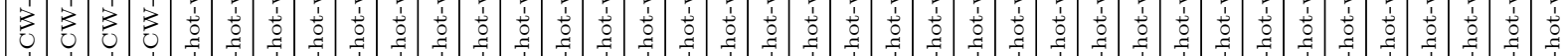

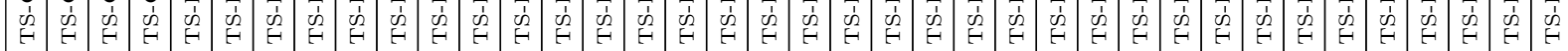

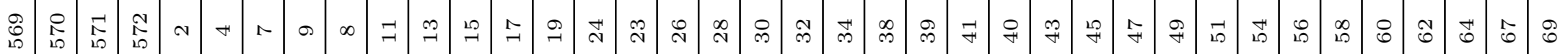

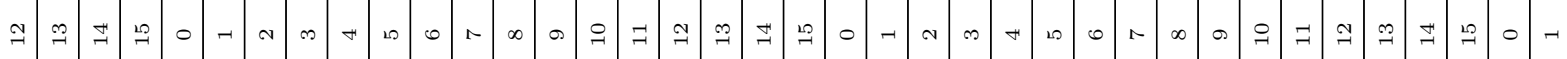

\begin{tabular}{|c|c|c|c|c|c|c|c|c|c|c|c|c|c|c|c|c|c|c|c|c|c|c|c|c|c|c|c|c|c|c|c|c|}
\hline & & & & & & & & & & & & & & & & & & & & & & & & & & & & & & & & \\
\hline$\infty$ & 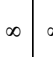 & \begin{tabular}{l|l}
$\infty$ & $\infty$
\end{tabular} & $\infty \quad-$ & $\rightarrow-$ & $\rightarrow$ & - & -7 & $\rightarrow$ & $\rightarrow-$ & -1 & $\neg$ & -7 & -7 & -1 & $\rightarrow$ & - & -1 & $\begin{array}{c}* \\
\text { a }\end{array}$ & $\sim$ & $\begin{array}{c}* \\
\text { a }\end{array}$ & ^ & a & ऽ & $\sim$ & \begin{tabular}{l|l}
$\curvearrowright$ & 0
\end{tabular} & $\sim$ & N & $\sim$ & $\sim$ & $\sim$ & & $\infty$ \\
\hline & $\begin{array}{l}a \\
\dot{z} \\
\dot{z}\end{array}$ & & $\begin{array}{l}8 \\
z\end{array}$ & & & $\begin{array}{l}0 \\
3 \\
3 \\
2\end{array}$ & & & & & $\begin{array}{l}3 \\
\vdots \\
\vdots \\
z \\
z\end{array}$ & $\begin{array}{l}5 \\
\text { 点 } \\
\dot{z}\end{array}$ & & & & $\begin{array}{l}3 \\
\vdots \\
\vdots \\
\vdots\end{array}$ & 童 & 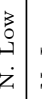 & s. & ב. & & & $\mid \begin{array}{l}3 \\
\vdots \\
\vdots \\
z\end{array}$ & $\left|\begin{array}{l}3 \\
0 \\
\vdots \\
\dot{z}\end{array}\right|$ & & & 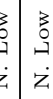 & & 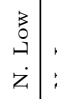 & & & \\
\hline
\end{tabular}


Design Report for the $1 / 2$ Scale Air-Cooled RCCS Tests in the NSTF

June 2014

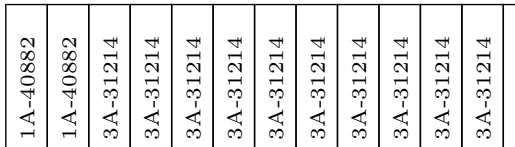

s0

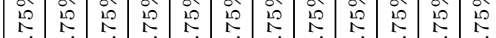

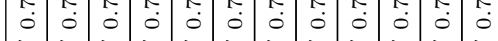

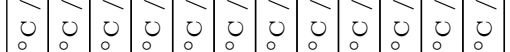

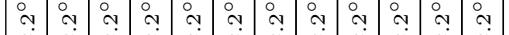

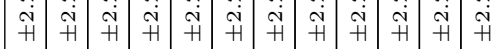

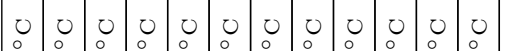

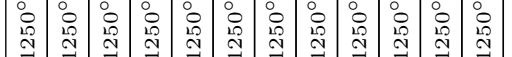

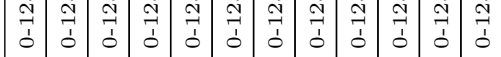

ت्ञ

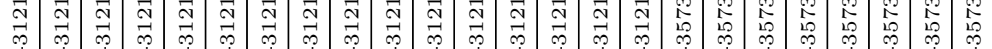

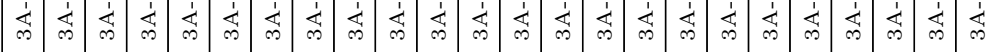

各 s0

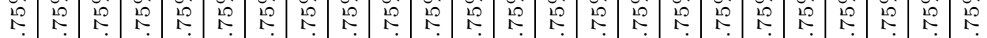

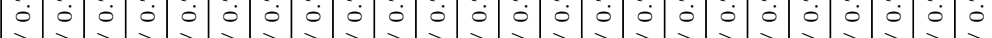

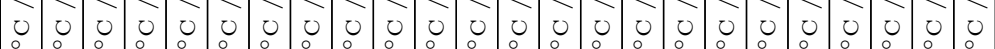

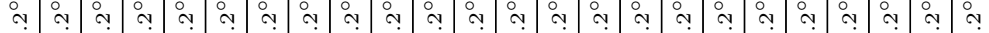

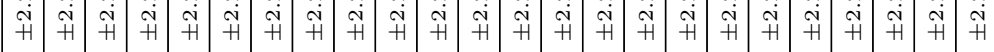

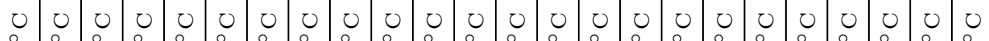

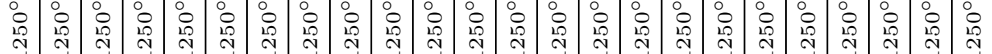

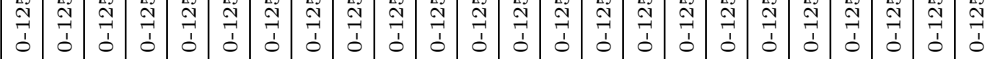

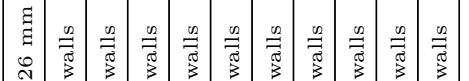

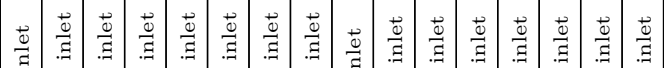

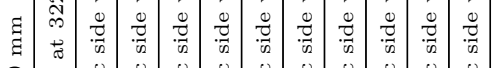

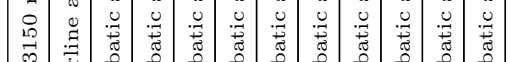

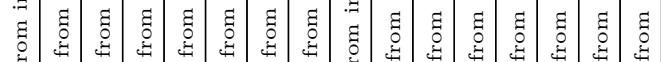

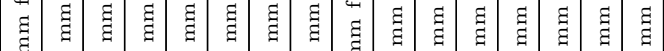

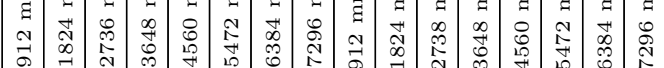

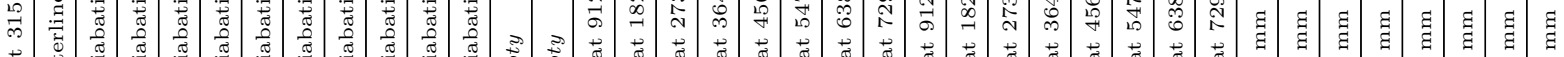

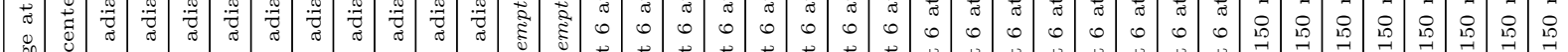

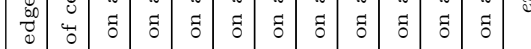

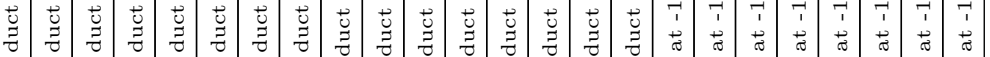

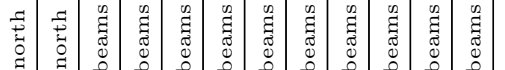

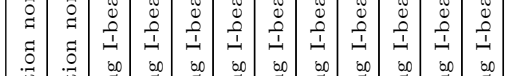

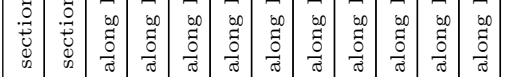

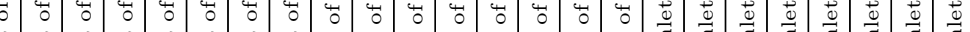

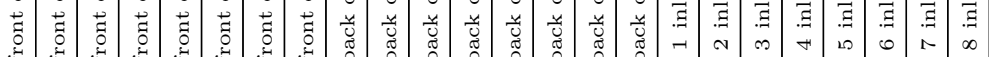

व

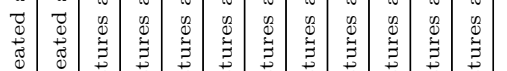

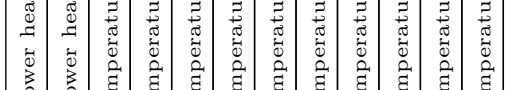

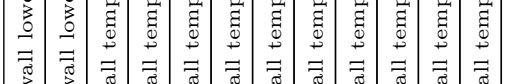

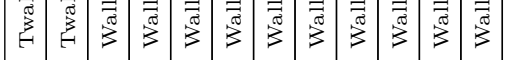

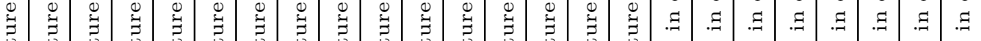

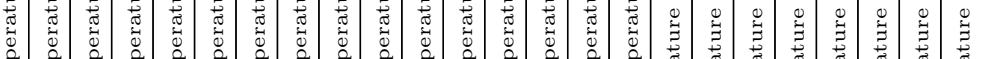

苟

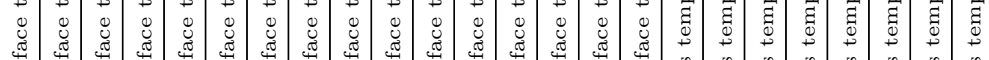

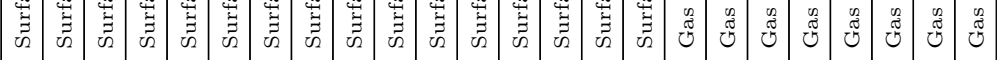

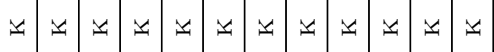

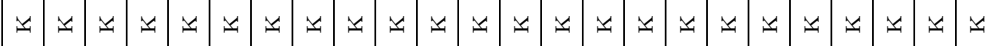

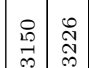

窐等

第需

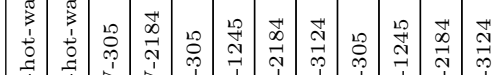

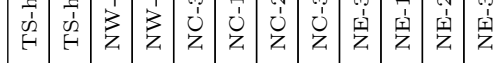

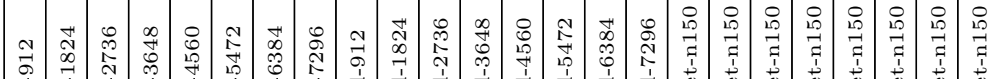

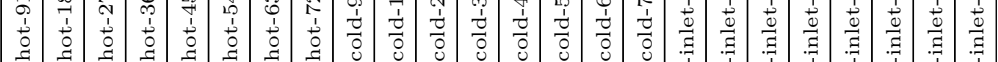

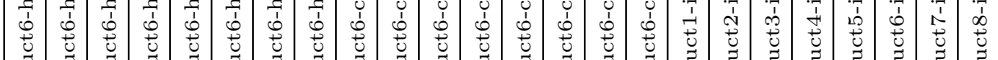

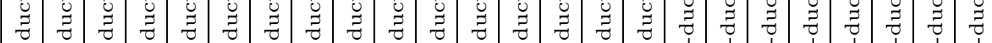

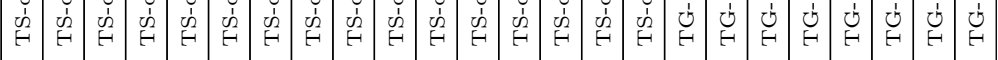
F

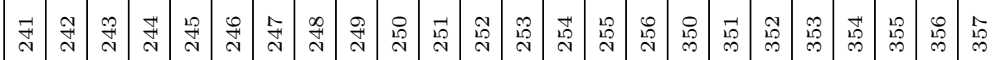
๙

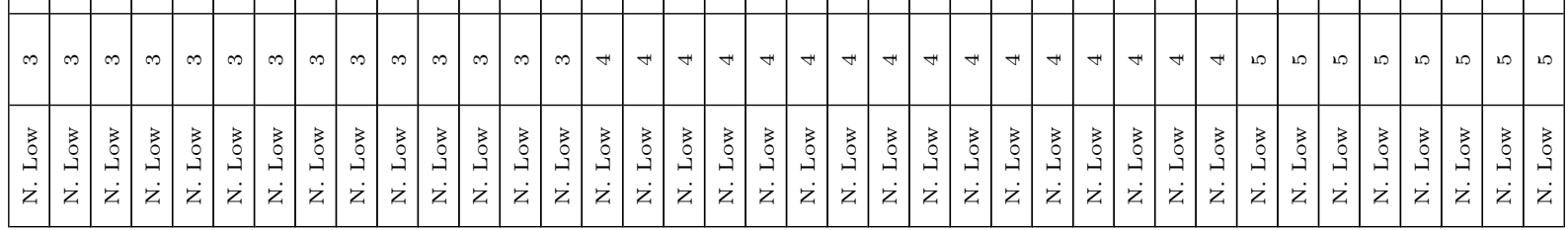




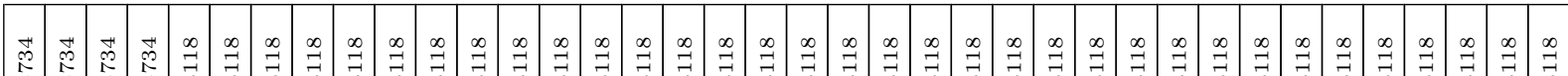

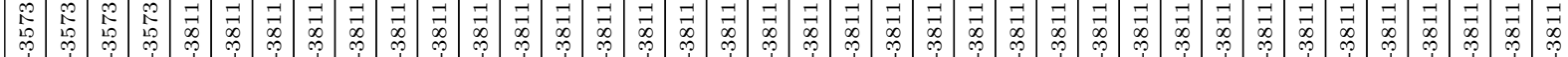

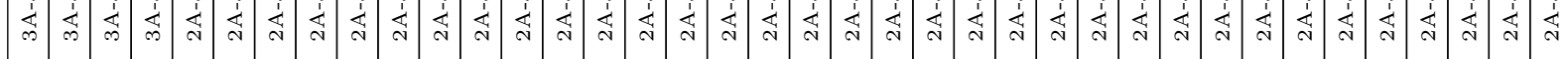

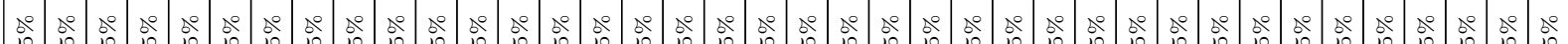

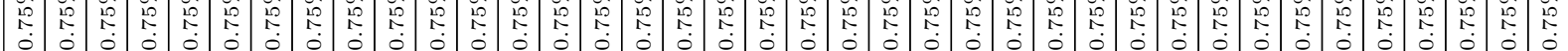

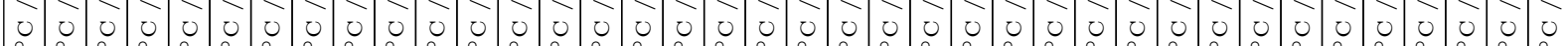

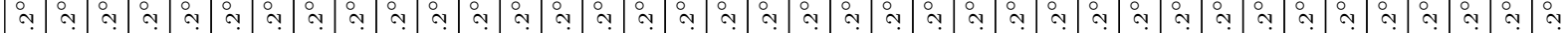

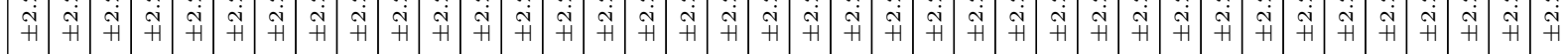

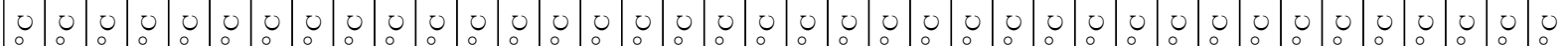

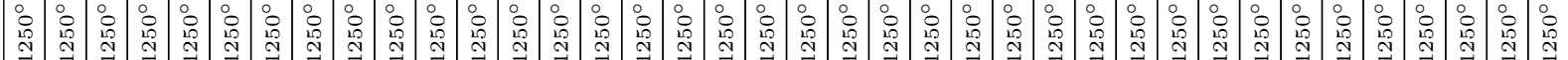

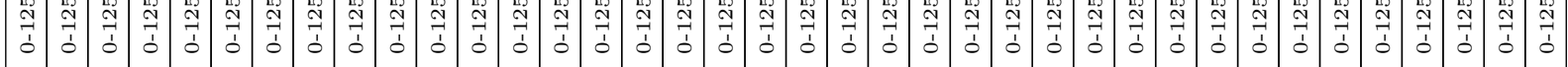

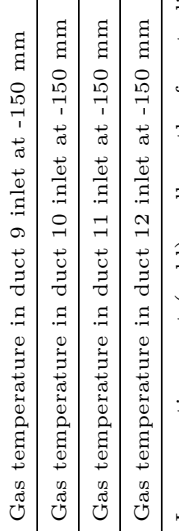

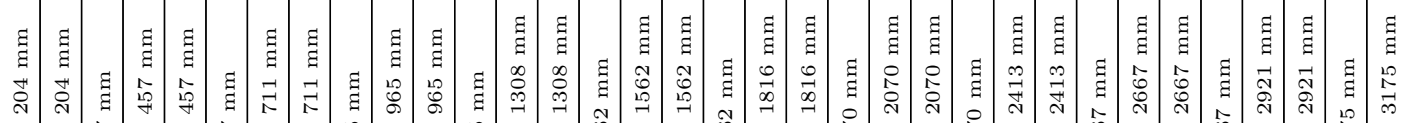

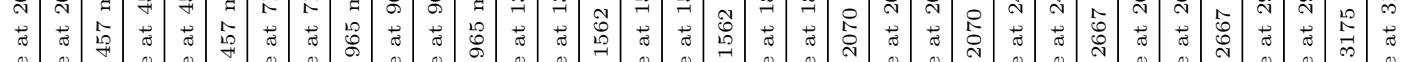

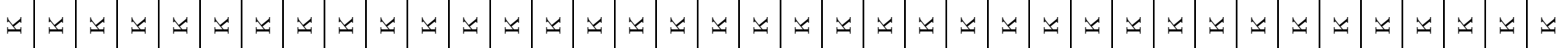

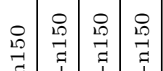

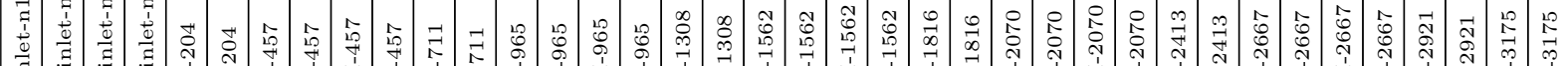

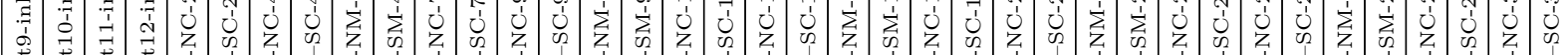

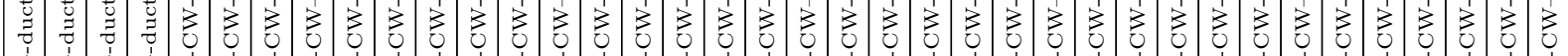

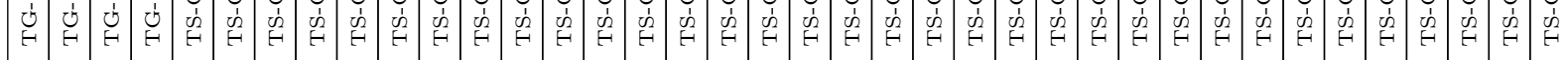

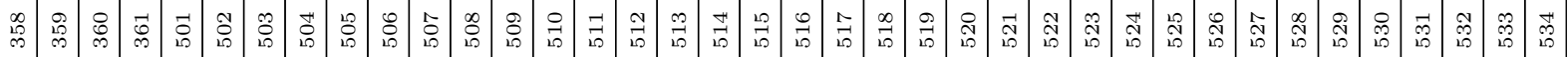

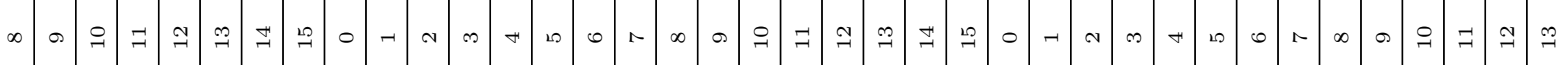

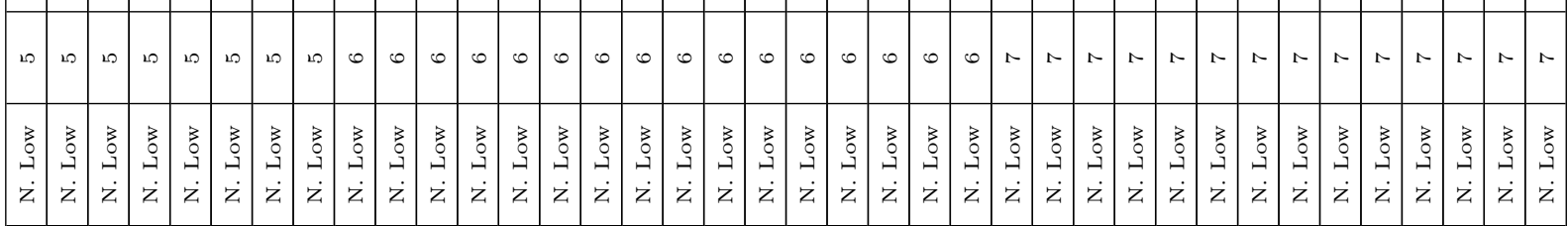


Design Report for the $1 / 2$ Scale Air-Cooled RCCS Tests in the NSTF June 2014

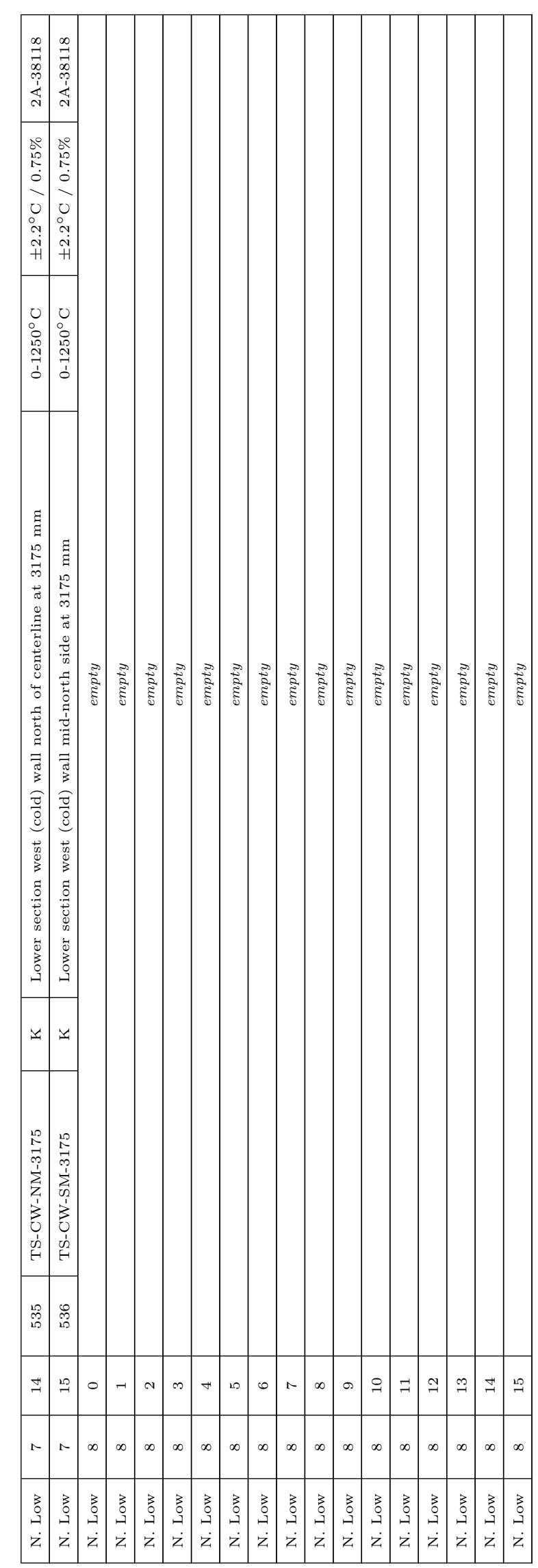




\section{Argonne}

Nuclear Engineering Division

Argonne National Laboratory

9700 South Cass Avenue, Bldg. 206

Argonne, IL 60439-4840

www.anl.gov 